\title{
Analyses of improved long term memory in SHARP1 and SHARP2 double knockout mice
}

\author{
Dissertation \\ for the award of the degree \\ "Doctor rerum naturalium (Dr. rer. nat.)" \\ of the Georg-August University Göttingen
}

submitted by

Ali Shahmoradi

from

Clausthal-Zellerfeld

Göttingen 2014 
Thesis committee:

Prof. Dr. Moritz Rossner, Reviewer

"Molecular Neurobiology", Department of Psychiatry,

Ludwig-Maximilian-University, Munich

Prof. Dr. Martin Göpfert, Reviewer

Department of Cellular Neurobiology,

Georg-August-University, Göttingen

Prof. Dr. Klaus-Armin Nave

Department of Neurogenetics,

Max Planck Institute of Experimental Medicine, Göttingen

Extended thesis committee

Prof. Dr. Michael Sereda

"Molecular and Translational Neurology", Department of Neurogenetics,

Max Planck Institute of Experimental Medicine, Göttingen

Dr. Judith Stegmüller

Department of Cellular \& Molecular Neurobiology,

Max Planck Institute of Experimental Medicine, Göttingen

Prof. Dr. Ernst Wimmer

Department of Developmental Biology,

Göttingen Center for Molecular Biosciences, Göttingen

Date of Disputation: 22nd of September 2014 


\section{Affidavit}

Here I declare that my doctoral thesis entitled "Analyses of improved long term memory in SHARP1 and SHARP2 double knockout mice" has been written independently with no other sources and aids than quoted.

Ali Shahmoradi

21st of August, 2014

Göttingen, Germany 


\section{Contents}

Contents $\quad$ v

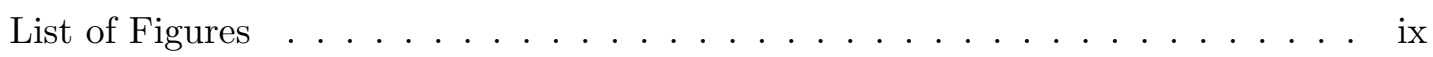

List of Tables . . . . . . . . . . . . . . . . . . . xi

Abbreviations xiii

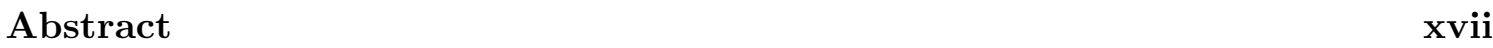

1 Introduction 1

1.1 Cognitive decline in psychiatric diseases . . . . . . . . . . . . 1

1.2 Prefrontal cortex dependent memory formation . . . . . . . . . . . . . 2

1.3 Circadian rhythms and cognitive processes . . . . . . . . . . . . . 4

1.3.1 SHARP1 and SHARP2 transcription factors . . . . . . . . . . . 5

1.4 Metabolism in the context of cognitive performance . . . . . . . . . 7

1.5 Aims of the study . . . . . . . . . . . . . . . . . 9

2 Materials and Methods $\quad 11$

2.1 Materials . . . . . . . . . . . . . . . . . . . . . 11

2.1.1 Chemicals and consumables . . . . . . . . . . . . 11

2.1 .2 Commercial kits . . . . . . . . . . . . . . . . . 11

2.1 .3 Enzymes. . . . . . . . . . . . . . . . . . 12

2.1.4 Buffers and stock solutions _. . . . . . . . . . . . . . 12

2.1.5 Antibodies and labeling components . . . . . . . . . . . . 17

2.1 .6 Animals . . . . . . . . . . . . . . . . . . . . 18

2.1 .7 Plasmids . . . . . . . . . . . . . . . . . . . 18

2.1 .8 Media and sera . . . . . . . . . . . . . . . . . . . . 19

2.1.8.1 Commercial media, sera and solutions . . . . . . . . 19

2.1.8.2 Media preparation . . . . . . . . . . . . . . . 19 
2.1 .9 Softwares . . . . . . . . . . . . . . . . . . . 19

2.2 Methods . . . . . . . . . . . . . . . . . . . . . . . . 19

2.2.1 Animal experiments . . . . . . . . . . . . . . . . . . . 19

2.2 .2 Genotyping PCR . . . . . . . . . . . . . . . . . . 20

2.2 .3 Behavioral analyses . . . . . . . . . . . . . . . 21

2.2.3.1 Memory tests . . . . . . . . . . . . . . 21

2.2.3.2 Standard behavior tests . . . . . . . . . . . . . . 21

2.2.3.3 Stereotactic injections . . . . . . . . . . . . . . 22

2.2.4 Molecular biology . . . . . . . . . . . . . . . . . . . . . 23

2.2.4.1 E.coli DNA transformation . . . . . . . . . . . 23

2.2.4.2 Purification of plasmid DNA . . . . . . . . . . 24

2.2 .5 RNA expression analyses . . . . . . . . . . . . . 24

2.2 .6 Protein biochemistry . . . . . . . . . . . . . . . . . 25

2.2.6.1 Preparation of tissue lysates . . . . . . . . . . 25

2.2.6.2 Protein lysates . . . . . . . . . . . . . . . . 26

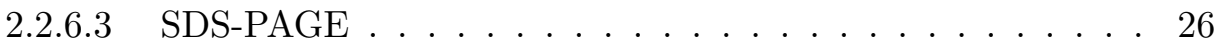

2.2.6.4 Western Blot . . . . . . . . . . . . . . . . 26

2.2.7 Immunocytochemistry and imaging . . . . . . . . . . . . . . . 26

2.2.7.1 Immunohistochemistry . . . . . . . . . . . . 26

2.2 .8 AAV virus production . . . . . . . . . . . . . . 27

2.2.8.1 Cell culture . . . . . . . . . . . . . . . . . . 27

2.2 .8 .2 Virus production . . . . . . . . . . . . . . 27

2.2 .8 .3 Virus titration . . . . . . . . . . . . . 28

$\begin{array}{lll}3 & \text { Results } & 29\end{array}$

3.1 Behavioral and molecular analyses of $S 1 / 2^{-/}$mice $\ldots \ldots \ldots . \ldots . \ldots$

3.1.1 Behavioral analyses of $S 1 / 2^{-/-}$mice $\ldots \ldots \ldots \ldots$

3.1.2 Molecular analyses of learning and memory associated pathway ac-

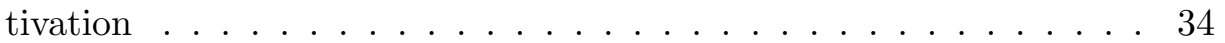

3.2 Analyses of insulin signaling in memory formation . . . . . . . . . . . 44

3.2.1 IGF2 enhances remote long term memory formation . . . . . . . . . 44

3.2.2 Behavioral analyses of neuronal Igf1r/Insr double knockout mice . . 44

3.3 Behavioral and molecular analyses of aged $S 1 / 2^{-/-}$mice $\ldots \ldots \ldots$

3.3.1 Early signs of aging in $S 1 / 2^{-/}$mice . . . . . . . . . 51 
3.3.2 Behavioral analyses with aged $S 1 / 2^{-/-}$mice $\ldots \ldots \ldots \ldots \ldots$

3.3.3 Molecular analyses of Igf2 and MAPK in aged $S 1 / 2^{-/-}$mice . . . . 54

3.4 RNA expression analyses in the ACC of human schizophrenic patients . . . 57

3.4 .1 Neuronal activity and clock genes . . . . . . . . . . . . . 57

3.4.2 ERBB4 variants . . . . . . . . . . . . . . . . . 58

4 Discussion $\quad 61$

4.1 Aspects of sleep regulation and memory consolidation . . . . . . . . . . . 61

4.2 Specificity of cognitive processes in the prefrontal cortex . . . . . . . . . 62

4.3 MAPK activity involved in cognitive processes . . . . . . . . . . . . . 63

4.4 Role of insulin signaling in memory consolidation . . . . . . . . . . . . . . . 64

4.5 Potential role of astrocytes in cognitive processes . . . . . . . . . . . 67

4.6 Aging . . . . . . . . . . . . . . . . . . . . . 68

$\begin{array}{lll}5 & \text { Summary and conclusion } & 71\end{array}$

$\begin{array}{ll}\text { Bibliography } & 73\end{array}$

$\begin{array}{lr}\text { Publications } & 91\end{array}$ 


\section{List of Figures}

1.1 Model of transfer from recent to remote memory $\ldots \ldots \ldots$

1.2 The structural homology of SHARP1 and SHARP2 . . . . . . . . . . 6

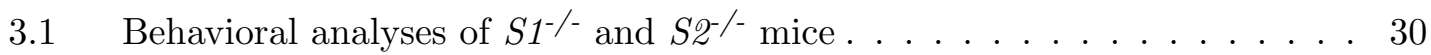

3.2 Increased remote fear memory formation and improved reversal learning

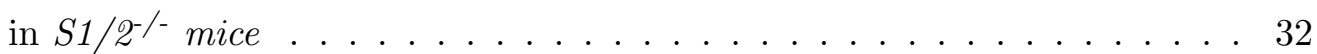

3.3 Signaling pathway activities in the ACx of $S 1 / 2^{-/}$mice $\ldots \ldots . \ldots 33$

3.4 Signaling pathway activities in the Hi of $S 1 / 2^{-/}$mice . . . . . . . . . 34

3.5 MAPK and $\mathrm{S} 6$ activity in the $\mathrm{ACx}$ and $\mathrm{Hi}$ of $\mathrm{S} 1 / 2^{-/}$mice . . . . . . . . 36

3.6 MAPK phosphorylation levels in the ACx and $\mathrm{Hi}$ of $S 1^{-/-}$and $S 2^{-/-}$single mutant mice . . . . . . . . . . . . . . . . . . . 37

3.7 Phospho-S6 positive cells in the ACC and Hi (CA1) of $S 1 / 2^{-/-}$mice before and after remote memory test . . . . . . . . . . . . . 38

3.8 Circadian MAPK phosphorylation levels in the ACx and Hi of $S 1 / 2^{-/-}$ mice after exposure to running wheel . . . . . . . . . . . . . . . 39

3.9 Circadian RNA expression of $c$-Fos and Per2 in the ACx of S1/2-/- mice 40

3.10 Elevated Igf2 and Igfbp5 RNA expression in the ACx of $S 1 / 2^{-/-}$mice . . . 41

3.11 Increased GFAP RNA expression and protein abundance exclusively in the ACx of $S 1 / 2^{-/}$mice $\ldots \ldots \ldots \ldots$. . . . . . . . . . . . . 42

3.12 Altered remote fear memory formation by virus mediated modulation of Igf2 signaling in the ACC of WT mice . . . . . . . . . . . . . . . . . 45

3.13 Neuronal knockout of Insr and Igf1r in the forebrain decreases MAPK activity in the $\mathrm{ACx} \ldots \ldots \ldots \ldots$. . . . . . . . . . . . 46

3.14 Standard behavior tests of Igf1r/InsrCaMKII-cre mice . . . . . . . . . . 47

3.15 Neuronal knockout of Insr and Igf1r in the cortex and hippocampus impairs contextual fear learning . . . . . . . . . . . . . . . . . . . 48

3.16 Weight analysis of $I g f 1 r / I n s r C a M K I I-$ cre mice . . . . . . . . . . . . . . 49 
3.17 GFAP and $\alpha$-tubulin protein deregulation in the $\mathrm{ACx}$ and $\mathrm{Hi}$ as a consequence of neuronal Insr and Igf1r knockout in the forebrain of mice . . . 50

3.18 Aging related decrease of weight and reduced life span in old $S 1 / 2^{-/-}$mice 51

3.19 Reduced vision in aged $S 1 / 2^{-/}$mice $\ldots \ldots \ldots \ldots \ldots$

3.20 Reduced memory performance exclusively in Hi dependent tasks in aged $S 1 / 2^{-/}$mice . . . . . . . . . . . . . . . . . 53

3.21 Increased Igf2 expression in the ACx and decreased MAPK activity in the Hi of aged $S 1 / 2^{-/-}$mice $\ldots \ldots \ldots \ldots \ldots$

3.22 GFAP up regulation in ACx and down regulation in Hi of aged $S 1 / 2^{-/-}$mice 56

3.23 RNA expression analyses of human ACC samples from schizophrenic pa-

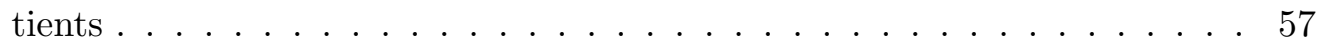

3.24 Expression levels of ERBB4 splice variants in the ACC of human schizophrenic

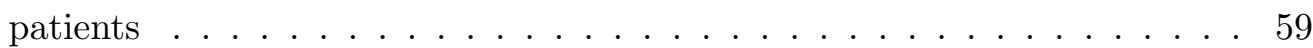

4.1 Circadian Igf2 expression and MAPK activation in the ACx of WT . . . 64

4.2 Potential receptor affinities of insulin signaling factors and downstream activation of MAPK and S6 . . . . . . . . . . . . . . . 65 


\section{List of Tables}

2.1 Primary antibodies . . . . . . . . . . . . . . . 17

2.2 Secondary antibodies . . . . . . . . . . . . . . . . 18

2.3 Mouse strains . . . . . . . . . . . . . . . . . . . . 18

2.4 Commercial media, sera and solutions . . . . . . . . . . . . . . 19

2.5 Softwares . . . . . . . . . . . . . . . . . . . 19

2.6 Genotyping primers . . . . . . . . . . . . . . . 20

$2.7 \quad$ RTPCR primers . . . . . . . . . . . . . . . . . 25 


\section{Abbreviations}

AAV Adeno-associated virus

ACC Anterior cingulate cortex

Actb Actin, beta

$\mathrm{ACx} \quad$ Anterior cortex

AMPK AMP-activated protein kinase

ANOVA Analysis of variance

ARNT Aryl hydrocarbon receptor nuclear translocator

Atp5b ATP synthase, $\mathrm{H}+$ transporting, mitochondrial F1 complex, beta polypeptide

bHLH Basic helix-loop-helix

BHLHE BHLH family, member

Bmal Brain and muscle ARNT-like

BSA Bovine serum albumine

CaMKII Calcium/calmodulin-dependent protein kinase II

CKII Casein Kinase II

Clock Circadian locomotor output cycle kaput

CNV Copy number variant

Cry Cryptochrome

CTD C-terminal domain

Cyc1 Cytochrome c-1

CYT C-terminal cytoplasmic

DEC Deleted in esophageal cancer

DMEM Dulbecco's Modified Eagle medium

drp DNase-resistant particles

DTT Dithiothreitol

E-Box Enhancer box

EDTA Ethylenediaminetetraacetic acid 
Egr1 Early growth response 1

ErbB V-erb-b2 avian erythroblastic leukemia viral oncogene homolog

FCS Fetal calve serum

fl Floxed, flanked by loxP

Fos $\quad$ FBJ murine osteosarcoma viral oncogene homolog

GAPDH Glyceraldehyde-3-phosphate dehydrogenase

GFAP Glial fibrillary acidic protein

GSK3 $\beta \quad$ Glycogen synthase kinase 3 beta

Hi Hippocampus

Hif- $1 \alpha \quad$ Hypoxia-inducible factor $1 \alpha$

i. p. Intraperitoneal

Igf Insulin-like Growth Factor

Igf1r Igf1 receptor

Igf2r Igf1 receptor

Igfbp Igf binding Protein

Insr Insulin receptor

JM Juxtramembrane

LB Luria and Beranti

LDS Lithium Dodecyl Sulfate

LTD Long-term depression

LTP Long-term potentiation

MAPK Mitogen-activated protein kinase

MES 2-(N-Morpholino)Ethanesulfonic Acid

MGB Modified Gitschier Buffer

mTOR Mechanistic target of rapamycin

NO Nitric oxide

Npas Neuronal PAS domain protein

NREM Non-REM

Nrg Neuregulin

PBS Phosphate Buffered Saline

Per Period

PFA Paraformaldehyde

PFC Prefrontal cortex

PI3K Phosphatidylinositol-4,5-bisphosphate 3-kinase 
Polr2b Polymerase (RNA) II (DNA directed) polypeptide B

REM Rapid eye movement

RIPA Radio-Immunoprecipitation Assay

ROS Reactive oxygen species

Rpl13a Ribosomal protein L13a

RTPCR Reverse Transcription PCR

S1 Sharp1

S2 Sharp2

S6 Ribosomal protein S6

s. c. Subcutane

SDS Sodium Dodecyl Sulfate

SEM Standard error of the mean

Sharp Enhancer-of-split- and hairy-related proteins

SNP Single nucleotide polymorphism

SOC Super Optimal broth with Catabolite repression

SWS Slow wave sleep

SWA Slow wave activity

TAE Tris/acetate/EDTA

TBE Tris/borate/EDTA

TBS Tris buffered Ssaline

TE Tris/EDTA

WT Wild type 


\section{Abstract}

The transition of recent experiences into stable and remote memory traces is an important task that mainly occurs during sleep. Sleep-associated consolidation of remote long-term memory is based on cortical networks that are concerted by the prefrontal cortex. The bHLH transcription factors SHARP1 and SHARP2, modulators of the circadian system, are expressed mainly in the hippocampus and cortex of the mammalian brain and are partially redundant in function. SHARP1/DEC2 has been shown to control sleep length and increased vigilance during wake in humans as well as in mice.

We hypothesized that these factors could be involved in cortex dependent memory consolidation. Therefore, we investigated the role of SHARP1 and SHARP2 in cognitive processing. In order to study prefrontal cortex-associated cognitive performance, we studied remote memory and flexible learning of Sharp1 and Sharp2 single and double mutant mice. Sharp1 and Sharp2 double mutant mice $\left(S 1 / 2^{-/-}\right)$showed enhanced anterior cortex (ACx) dependent remote fear memory formation as well as improved reversal learning, but did not display alterations in hippocampus (Hi) dependent recent fear memory formation. In contrast single mutants did not display any learning or memory phenotype. In line, molecular and biochemical analyses revealed elevated IGF2 signaling, p44/42-MAPK and $\mathrm{S} 6$ activity in the $\mathrm{ACx}$ but not the Hi of $S 1 / 2^{-/}$mice. We did not observe similar changes in single mutant mice. In order to study the effect of IGF2 on cognitive processes, we studied the function of its target receptors in the brain, the insulin receptor (INSR) and IGF1 receptor (IGF1R). The analysis of forebrain specific null mutants of the INSR and IGF1R revealed their implication in memory formation. Mice lacking both receptors in CaMKII positive neurons in the $\mathrm{Hi}$ and cortex exhibited a significantly reduced fear memory. Furthermore, AAV2 virus mediated IGF2 over-expression in the ACC enhanced remote fear memory formation.

In summary, we conclude that the bHLH transcription factors SHARP1 and SHARP2 are involved in cognitive processing by controlling Igf2 expression and associated signaling 
cascades. In parallel studies performed with aged $S 1 / 2^{-/-}$mice revealed reduced life span together with an overall loss of contextual fear memory. More specific, recent memory was significantly lower compared to WT and remote memory was attenuated to the level of the control mice. To exclude that memory enhancement via insulin signaling might trigger aging related processes, further studies are needed. Overall, our analyses provide evidence that the control of sleep and memory consolidation may share common molecular mechanisms. 


\section{Chapter 1}

\section{Introduction}

The mammalian brain has an extraordinary potential to process newly learned experiences into already available information networks. Retrieval of the saved information at later time points can be part of our personality and supports us with our decisions. This information processing is highly dependent on a fast storage of the new experience, following a consolidation of the information that supports an optimal retrieval at later time points. A number of psychiatric diseases are associated with cognitive decline and memory loss as schizophrenia, bipolar disorders and Alzheimer's disease (Larson et al., 1992; Vöhringer et al., 2013). Studies with schizophrenic and bipolar patients have identified a deregulated prefrontal cortex as a potential source of cognitive decline (Chai et al., 2011; Manoach, 2003). However, the mechanisms underlying the cortical processing in this brain region are still unknown. Understanding these mechanisms might introduce new therapeutic targets to address cognitive decline in a number of psychiatric diseases.

\subsection{Cognitive decline in psychiatric diseases}

Several well studied psychiatric diseases are known so far, that have cognitive impairments in common. Among those, schizophrenia, bipolar disorders, Alzheimer's disease and dementia are reported with impairments in cortical processes (Chai et al., 2011; Manoach, 2003; Perlstein et al., 2001; Vallortigara et al., 2014; Wong et al., 2014). Genome wide association studies with schizophrenic patients identified a number of genes that are deregulated in the prefrontal cortex, however little is known about the significance of these genes (Hosak, 2013). What becomes clear form available data is that schizophrenia is a multigenetic disease that is dependent on genetic as well as environmental factors (Cardno 
et al., 1999; Franzek and Beckmann, 1998; Gottesman and Shields, 1967; Ribbe et al., 2010). On genetic level increasing evidence suggests that susceptibility of schizophrenia might involve multiple single nucleotide polymorphisms (SNPs) and the course of disease might in addition be influenced by rare copy number variants (CNVs) (Levinson et al., 2012). However these data might support understanding the cause of the disease, but give no indication on the pathogenesis. Therefore genetic research on endophenotypes are at least as important to understand psychiatric diseases as schizophrenia (Allen et al., 2009; Braff and Light, 2005; Greenwood et al., 2012). Because of the accentuated role of the prefrontal cortex in schizophrenia and other psychiatric diseases with cognitive decline, genetic research of prefrontal cortex specific endophenotypes might reveal pathways and networks that are of relevance to find potential therapeutic candidates.

\subsection{Prefrontal cortex dependent memory formation}

The prefrontal cortex (PFC) is a centrally involved region in a network with cortical modules and might coordinates these in higher order cognitive processes (Alvarez and Emory, 2006; Frankland and Bontempi, 2005). Among the executive functions of the prefrontal cortex are working memory, stimulus-reward associations, error detection, theory of mind, conflict management and action inhibition (Botvinick et al., 2001; Frith and Frith, 2003; Miyake et al., 2000; Pardo et al., 1990; Rolls, 2000). Furthermore, the prefrontal cortex neuronal networks are involved in some aspects of social behavior as personality, social cognition and moral judgment (DeYoung et al., 2010; Forbes and Grafman, 2010). Longterm potentiations (LTPs), which are associated with learning and memory, are monitored in the prefrontal cortex and afferents to the PFC from the hippocampus, sensory cortex, amygdala and thalamus (Gurden et al., 1999; Herry et al., 1999; Kim et al., 2003; Malenka and Nicoll, 1999; Maroun and Richter-Levin, 2003; Otani et al., 2003). However not much is known about the networks from the prefrontal cortex so far.

The processing of context dependent experienced information is mainly mediated through the hippocampus (Hi) and the PFC, whereas the PFC is primarily responsible for higherorder cognitive abilities. The Hi and PFC have been associated with different aspects of cognitive processes as recent and remote long-term fear memory formation, respectively (Frankland et al., 2004). Recent memory formation in the hippocampus is mediated through highly dynamic changes in synaptic plasticity (Kandel, 2001; Martin et al., 2000). 
Disruption of the hippocampus can lead to a specific loss of recent fear memory, although remote memory stays unaffected (Kim and Fanselow, 1992; Zola-Morgan and Squire, 1990). Current concepts suggest that long term memory consolidation involves a gradual transfer of memory traces from hippocampal networks into stable cortical modules integrated by the anterior cingulate cortex (ACC) (Fig. 1.1) (Frankland and Bontempi, 2005). Along other aspects of prefrontal cortex specific cognitive performance is flexible learning, an ability to rewrite already learned false memory with new updated information (Rolls, 2004; Schoenbaum et al., 2009). Damages in areas of the prefrontal cortex can result in a specific loss of flexible learning in reversal learning tasks (de Bruin et al., 1994; Dias et al., 1996; Iversen and Mishkin, 1970). The gradual transfer of memory traces from the Hi to the ACx is thought to be dependent on different aspects of sleep (Diekelmann and Born, 2010).
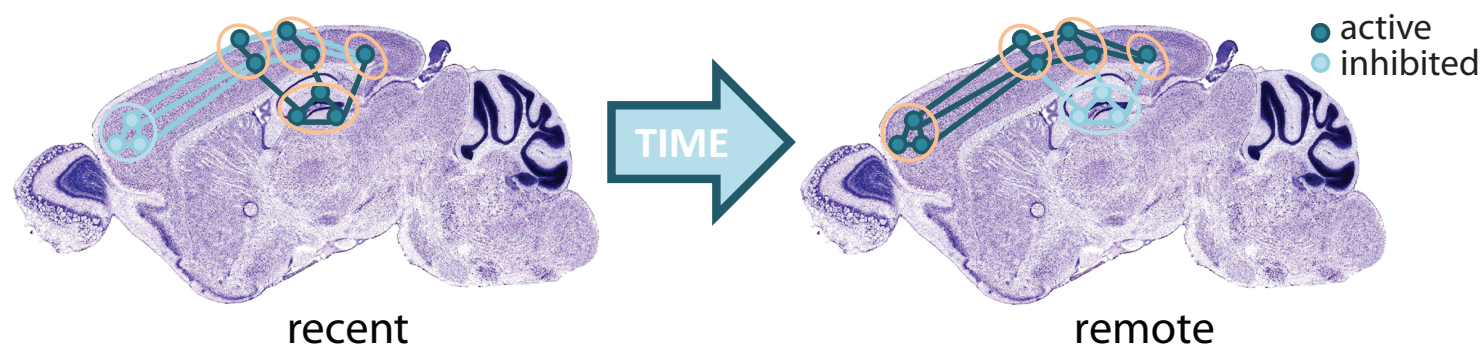

Figure 1.1: Model of transfer from recent to remote memory. It is thought that the formation of recent memory is based on the activation of the hippocampal networks to cortical modules. At this phase the activity level of the prefrontal cortex is low. However remote memory seems to be dependent on an activation of the prefrontal cortex and its connections to the cortical modules. At the same time, hippocampal networks are reduced in activity. Adapted from Frankland and Bontempi (2005)

In the 19th century, the german psychologist Hermann Ebbinghaus, who initiated the experimental approach in memory research, contributed a series of scientific publications on the importance of sleep for the consolidation of memory (Ebbinghaus, 1885). In studies performed on himself, he discovered the "forgetting curve" that represents the loss of recent memory over the first hours after learning. Here he also discovered that sleep can reduce the loss of memory (van Omer, 1933). Until today several studies of different approaches have shown the importance of post-learning sleep for long-term remote memory consolidation (Rasch and Born, 2013). Memory formation during sleep is closely associ- 
ated with the slow wave activities during NREM (non REM) sleep phase (Marshall et al., 2006). During this sleep phase the slowest waves with the highest voltages are located in the prefrontal cortex. Furthermore studies in human have shown strong correlations between disrupted NREM slow wave activities and impaired memory as a consequence of aging related prefrontal atrophy (Mander et al., 2013). In order to study processes that are specific for remote memory consolidation in the prefrontal cortex, aspects of sleep associated cognitive processes might help to identify potential candidates.

\subsection{Circadian rhythms and cognitive processes}

The controls of sleep and memory consolidation appear to be interconnected processes. Disturbance of sleep can lead to a decline in cognitive performance (Aleisa et al., 2011; Graves et al., 2003; Guan et al., 2004; Xu et al., 2010; Zhu et al., 2012). In particular specific phases of sleep seem to be important for memory consolidation (Marshall et al., 2006). The regulation of sleep homeostasis is crucial for optimal cognitive performance during wake. It is well known that many aspects of sleep-wake related behavior are controlled by clock genes. Emerging evidence suggests an involvement of the circadian system in the regulation of these cognitive processes (Eckel-Mahan and Storm, 2009).

For example, several signaling pathways have been studied in the context of hippocampal learning (Bekinschtein et al., 2007; Chen et al., 2005; Enriquez-Barreto et al., 2014; Fortress et al., 2013; Kelleher et al., 2004; Man et al., 2003; Potter et al., 2010), and it has been shown that the circadian timing of MAPK activity might be important for proper memory consolidation in the hippocampus (Eckel-Mahan et al., 2008). Thus, a circadian regulation of MAPK activity seems to be associated with physiologically intact memory performance. Moreover, MAPK as well as S6 activity is involved in processes of long term potentiation and memory formation (Kelleher et al., 2004; Orban et al., 1999; Philips et al., 2013). A number of clock associated transcription factors have been identified so far to be necessary for intact memory consolidation. These clock proteins interact in a densely regulated network to guarantee optimal adaptation to daily recurrent changes of the organism to the environment. Disruption of these transcription factors can lead to an impairment of the memory function of the brain. The core clock transcription factors BMAL1 (brain and muscle ARNT-like 1) and CLOCK/NPAS2 (circadian locomotor output cycle kaput / neuronal PAS domain protein 2) form heterodimers and are regulated by a negative feedback 
loop through the CRY (Cryptochrome) and PER (Period) circadian clock transcription factor proteins (Reppert and Weaver, 2001). In drosophila, a deletion of per induces a reduction in long term memory performance and over-expression leads to an improvement of long term memory in wild type (Sakai et al., 2004). Furthermore the disruption of the core clock transcription factor BMAL1 in mice leads to a reduction in hippocampus-dependent memory performance (Wardlaw et al., 2014). In parallel, the forebrain-expressed core clock transcription factor NPAS2, has been implicated in the control of NREM sleep and

Npas2 $2^{-}$mice display deficits in hippocampus dependent cognitive processing (Franken et al., 2006; Garcia et al., 2000; Reick et al., 2001). Altogether these finding increase the evidence that the circadian molecular machinery that adapts the organism to daily changes, is also involved in the fine tuning of memory formation. Yet, it is not known through which molecular mechanisms cognitive processes are regulated by clock genes.

\subsubsection{SHARP1 and SHARP2 transcription factors}

The basic loop helix (bHLH)) transcription factors SHARP1 (DEC2/BHLHE41) and SHARP2 (DEC1,BHLHE40) are modulators of the circadian system and have also been implicated in the control of homeostatic sleep, neuronal plasticity and working memory (He et al., 2009; Rossner et al., 1997, 2008) (Baier et al., manuscript in submission). Both transcription factors, as also other clock transcription factors, consist of a bHLH domain which can bind to the palindromic E-box sequence CACGTG (Ferré-D'Amaré et al., 1993). SHARP1 and SHARP2 have a high structural homology, especially in the bHLH and CKII (Casein Kinase II) domain (Fig. 1.2). CKII is important in the regulation of DNA repair, circadian regulation and other cell cycle processes (Meggio and Pinna, 2003; Ruzzene and Pinna, 2010).

The function of the orange domain is not determined so far. However it is proposed to play a role in dimerization and specificity of transcriptional repression (Davis and Turner, 2001; Steidl et al., 2000). Via indirect binding through NPAS2/BMAL1 heterodimers, or direct transcriptional interaction with target genes, SHARP1 and SHARP2 can act as repressors and co-activators in a context-specific manner (Honma et al., 2002; Rossner et al., 2008; Sato et al., 2004). In human, mouse and drosophila, a point mutation in the Sharp1 gene leads to reduced sleep length and increased vigilance during the activity phase (He et al., 2009). In contrast to core clock genes, disruption of SHARP1 and SHARP2 does not shift the phase of the circadian cycle nor does it change the frequency (Rossner et al., 2008). 
Depending on the context, SHARP1 and SHARP2 can increase or attenuate the amplitudes of circadian gene expression. Therefore SHARP1 and SHARP2 act as modulators of the circadian system.

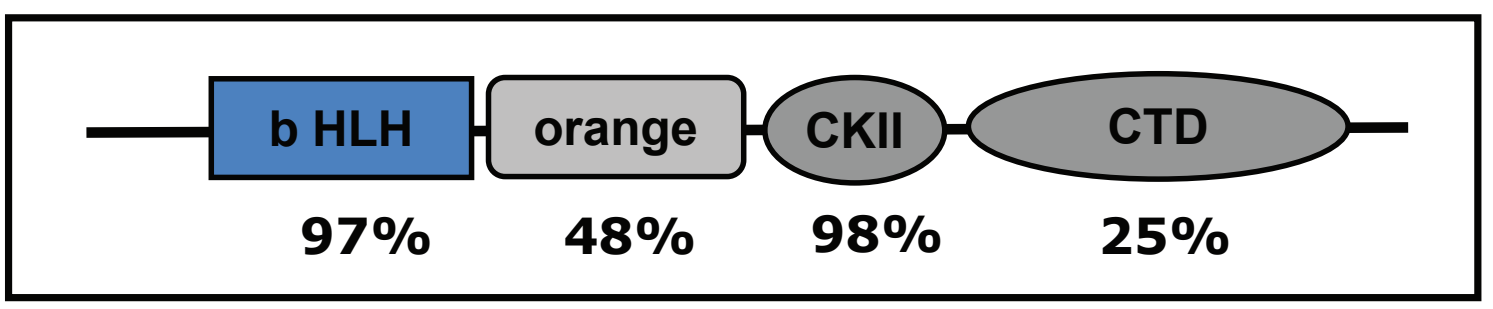

Figure 1.2: The structural homology of SHARP1 and SHARP2. Comparing the open reading frame of the SHARP1 and SHARP2 mouse sequence. Highest homology could be observed in the bHLH (97\%) and CKII (98\%) domains. Furthermore the orange domain (48\%) and the C-terminal domain (CTD) (25\%) display high to moderate homology in these regions.

Besides the function of Sharp1 and Sharp2 in the network of clock genes, they are also reported to act as tumor suppressor genes (Falvella et al., 2008; Liu et al., 2013). The disruption in the interaction of SHARP1 with hypoxia-inducible factor $1 \alpha$ (HIF-1 $\alpha)$ is reported in breast cancer metastasis (Montagner et al., 2012). Here SHARP1 can be regulated by the p63 metastasis suppressor. Generally oncogenetic regulatory factors of transcription and translation as MAPK and mTOR are also involved in cognitive processes (Krab et al., 2008). This might in parts explain the occurrence of cognitive impairment as a side effect of cancer treatment (Ahles and Saykin, 2007; Bower, 2008; Ganz et al., 2013; Vardy and Tannock, 2007; Wefel et al., 2004).

In the context of psychiatric diseases, association studies revealed significant frequency of Sharp2 SNPs in bipolar disorders, however no association was detected so far for Sharp1 SNPs (Mansour et al., 2009; Shi et al., 2008). In parallel, circadian gene expression analyses of human brain samples revealed a high circadian cyclic expression of Sharp1 and Sharp2 which was unique for regions of the prefrontal cortex, and attenuated in the hippocampus and amygdala (Li et al., 2013). However in in the prefrontal cortex of patients with major depressive disorder circadian pattern of Sharp1 and Sharp2 expression was attenuated. 


\subsection{Metabolism in the context of cognitive performance}

The regulation of the intensity and episodes of sleep, is regulated by circadian as well as homeostatic aspects (Borbély, 1982). Impairment of the circadian system alters sleep homeostasis and leads to obesity and metabolic disorders (Naylor et al., 2000; Turek et al., 2005). Overall the homeostatic sleep is a key regulator of neuronal activity synaptic plasticity (Tononi and Cirelli, 2006). One example is the circadian regulation of the nicotinamide adenine dinucleotide $\left(\mathrm{NAD}^{+}\right)$bio-availability and therefore mitochondrial oxidative function. Neuronal information processing is initially powered by oxidative phosphorylation and pre as well as post-synaptic mechanisms are essentially affected by changes in mitochondrial activities (Hall et al., 2012). Here, circadian regulation of mitochondria activity can directly control aspects of neuronal processes. In parallel disruption of clock genes causes oxidative stress and therefore leads to enhanced neurodegeneration (Musiek et al., 2013).

In order to regulate the plasticity in the central nervous system in adaptation to the actual need, whether in resting mode or in activity, circadian genes are involved in the regulation of the synaptic plasticity. The elevation of synaptic strength during cognitive tasks and cognitive standby condition correlates with an increase in energy consumption in order to synthesize and transport the involved protein machinery at the nucleus and at the synapses. Around $87 \%$ of the available energy for neuronal signaling is needed for the release of action potentials, synaptic ion-trafficking and transmitter recycling (Attwell and Gibb, 2005). Though synaptic plasticity is mainly limited by the available energy. An excess signaling of neurons is limited by the fact, that energy must be left for the maintenance of the resting potential. It is thought that sleep restores synaptic plasticity and cell homeostasis and in parallel reorganizes the synchronization of synapses (Tononi and Cirelli, 2014). Thus, a disruption of sleep architecture might negatively influence the rehabilitation of cortical networks. Already a slight reduction of sleep over a short time leads to a deregulation of genes that are involved in sleep homeostasis, circadian rhythmicity, oxidative stress and metabolism (Möller-Levet et al., 2013). Potentially the role of sleep might be to restore the protein machinery that is involved in energy intensive mechanisms as synaptic plasticity for maximal performance during activity.

The increased metabolism of active firing neurons is accompanied with elevated oxygen consumption and causes an accumulation of neurotoxic reactive oxygen species (ROS) (Drechsel and Patel, 2008). A network of antioxidants as superoxide dismutase, catalase 
and peroxidases keep the presence of antioxidants in the brain at physiological levels. Aging and neurodegenerative diseases are associated with increased levels of ROS in the brain (Butterfield and Kanski, 2001; Gabbita et al., 1998; Mecocci et al., 1993). Several studies implicate that an increase of ROS is associated to a decline in cognitive tasks (Forster et al., 1996; Fukui et al., 2001). Yet, besides the negative neurotoxic features, ROS molecules can also act positively on synaptic plasticity (Carney et al., 1991). In the hippocampus, ROS are able to regulate p44/42 MAPK and CaMKII, both molecules that are involved in the synaptic plasticity (Kanterewicz et al., 1998; Shetty et al., 2008). Overall disequilibrium of ROS in the cells might lead to disrupted synaptic plasticity. A deregulation of the circadian clock, which is often occurring during aging or psychiatric diseases, might induce oxidative stress responses and neurodegeneration (Lai et al., 2012; Musiek et al., 2013). Therefore, knockout of the circadian modulators SHARP1 and SHARP2 potentially might affect cognitive processes through mechanisms that are involved in metabolic aging. 


\subsection{Aims of the study}

Molecular mechanisms of sleep regulation and memory consolidation in the prefrontal cortex appear to be interconnected processes. However, little is known of a common link between these regulatory machineries. SHARP1 and SHARP2 transcription factors are modulators of sleep architecture and potentially involved in the autonomous circadian regulation of the prefrontal cortex.

Here, we analyzed at which quality and extend SHARP1 and SHARP2 might influence cognitive features in adult and aged mice. We investigated the specific function of SHARP1 and SHARP2 in the cellular context of the prefrontal cortex and studied the potential regulatory effect on signaling activities and gene expression. Furthermore, we identified and analyzed factors that are deregulated and might be involved in the metabolic regulation of synapse plasticity. The answers to these questions could provide evidence for the regulatory role of SHARP1 and SHARP2 and identify candidates that mediate mechanisms of cortical processes in the prefrontal cortex. Finally we explored the impact of identified signaling molecules on prefrontal cortex specific aspects of memory formation.

Investigating the role of SHARP1 and SHARP2 in cortical processes and identification of prefrontal cortex specific molecular markers for cognitive processes might provide insight into basic common mechanisms of the sleep and memory regulatory networks. 


\section{Chapter 2}

\section{Materials and Methods}

\subsection{Materials}

\subsubsection{Chemicals and consumables}

All chemicals and consumables were purchased from Life Technologies, Merck, Roche and Sigma-Aldrich unless stated different. DNA and RNA purification kits were purchased from Qiagen and Macherey-Nagel. Cell culture media supplements and sera were ordered from Life Technologies or Lonza. All general consumable materials were obtained from Eppendorf, Falcon and Nunc.

\subsubsection{Commercial kits}

DAB Zytomed

DC Protein Assay (Lowry)

ECL Plus Western-Blot Detection Reagents Amersham Biosciences

$\mathrm{LSAB}_{2}$

NucleoSpin Gel and PCR Clean-up

NucleoSpin Plasmid Quick Pure

NucleoBond PC100 Midiprep

pGEM-T Vector System

Polyethylenimine

Power SYBR Green Master Mix

RNaesy Mini Kit

TaqMan Universal PCR Master Mix
Zytomed Systems

Bio-Rad

Dako

Macherey-Nagel

Macherey-Nagel

Macherey-Nagel

Promega

Polysciences

Applied Biosystems

Qiagen

Applied Biosystems 


\subsubsection{Enzymes}

Alkaline Phosphatase

Roche

BP Clonase II

Invitrogen

Easy-A HiFi PCR cloning enzyme

Stratagene

GoTaq DNA Polymerase

Sigma-Aldrich

HotStarTaq DNA Polymerase

Qiagen

LR Clonase II

Invitrogen

LR Clonase II Plus

Invitrogen

Pfu Ultra Advanced DNA Polymerase

Stratagene

Proteinase K

Invitrogen

PWO Polymerase

Roche

Restriction enzymes

New England Biolabs

RQ1 DNase

Promega

SuperscriptIII Reverse Transcriptase

Invitrogen

T4 DNA-Ligase

Promega

\subsubsection{Buffers and stock solutions}

$50 \times$ TAE buffer

$242 \mathrm{~g} \quad$ Tris-Base, $\mathrm{pH} 8.0$

$57.1 \mathrm{~mL} \quad$ acetic acid (glacial)

$100 \mathrm{~mL} \quad 0.5 \mathrm{M}$ EDTA, pH 8.0

Adjust volume to $1 \mathrm{~L}$ with $\mathrm{H}_{2} \mathrm{O}$

$5 \times$ TBE buffer

$54 \mathrm{~g} \quad$ Tris-base

$27.5 \mathrm{~g} \quad$ boric acid

$20 \mathrm{~mL} \quad 0.5 \mathrm{M} \mathrm{EDTA}$

Adjust volume to $1 \mathrm{~L}$ with $\mathrm{H}_{2} \mathrm{O}$

$10 \times$ TE buffer 
$1 \mathrm{~mL} \quad 1 \mathrm{M}$ Tris, $\mathrm{pH} 7.5$

$200 \mu \mathrm{L} \quad 0.5 \mathrm{M}$ EDTA

Adjust volume to $10 \mathrm{~mL}$ with $\mathrm{H}_{2} \mathrm{O}$

10 $\times$ MGB buffer

$6.7 \mathrm{~mL} \quad 1 \mathrm{M}$ Tris-HCl, $\mathrm{pH} 8.8$

$1.66 \mathrm{~mL} \quad 1 \mathrm{M}\left(\mathrm{NH}_{4}\right)_{2} \mathrm{SO}_{4}$

$650 \mu \mathrm{L} \quad 1 \mathrm{M} \mathrm{MgCl}_{2}$

Adjust volume to $10 \mathrm{~mL}$ with $\mathrm{H}_{2} \mathrm{O}$

$1 \times$ MGB working solution

$1 \mathrm{~mL} \quad 10 \times$ MGB buffer

$500 \mu \mathrm{L} \quad 10 \%$ Triton $\mathrm{X}-100$

Adjust volume to $10 \mathrm{~mL}$ with $\mathrm{H}_{2} \mathrm{O}$

$10 \times$ PBS

$100 \mathrm{~g} \quad \mathrm{NaCl}$

$2.5 \mathrm{~g} \quad \mathrm{KCl}$

$7.2 \mathrm{~g} \quad \mathrm{Na}_{2} \mathrm{HPO}_{4} \cdot 2 \mathrm{H}_{2} \mathrm{O}$

$2.5 \mathrm{~g} \quad \mathrm{KH}_{2} \mathrm{PO}_{4}$

Adjust $\mathrm{pH}$ to 7.2 with $\mathrm{NaOH}$

Adjust volume to $1 \mathrm{~L}$ with $\mathrm{H}_{2} \mathrm{O}$

$20 \times$ TBS

$100 \mathrm{~mL} \quad 1 \mathrm{M}$ Tris-Base, $\mathrm{pH} 8$

$60 \mathrm{~mL} \quad \mathrm{NaCl}$

Adjust pH to 7.4 with $\mathrm{HCl}$

Adjust volume to $1 \mathrm{~L}$ with $\mathrm{H}_{2} \mathrm{O}$

$1 \times$ TBS-T

$500 \mathrm{~mL} \quad 20 \times \mathrm{TBS}, \mathrm{pH} 7.4$

$5 \mathrm{~mL} \quad$ Tween-20

Adjust volume to $10 \mathrm{~L}$ with $\mathrm{H}_{2} \mathrm{O}$ 
$20 \times$ MES running buffer

$97.6 \mathrm{~g} \quad \mathrm{MES}$

$60.6 \mathrm{~g} \quad$ Tris-Base

$10 \mathrm{~g} \quad$ SDS pellets

$3 \mathrm{~g} \quad$ EDTA

Adjust volume to $500 \mathrm{~mL}$ with $\mathrm{H}_{2} \mathrm{O}$

store at $4^{\circ} \mathrm{C}$

$4 \times$ LDS sample buffer

$0.666 \mathrm{~g} \quad$ Tris-HCl

$0.682 \mathrm{~g} \quad$ Tris-Base

$0.8 \mathrm{~g} \quad$ Lithium dodecyl sulfate

$0.006 \mathrm{~g} \quad$ EDTA

$4 \mathrm{~g} \quad$ Glycerol

$0.75 \mathrm{~mL} \quad 1 \%$ Serva Blue G250

$0.25 \mathrm{~mL} \quad 1 \%$ Phenol Red

Adjust volume to $10 \mathrm{~mL}$ with $\mathrm{H}_{2} \mathrm{O}$

store at $-20^{\circ} \mathrm{C}$

$20 \times$ Transfer buffer

$40.8 \mathrm{~g} \quad$ Bicine

$52.4 \mathrm{~g} \quad$ Bis-Tris (free base)

$3 \mathrm{~g} \quad$ EDTA

$1 \mathrm{mM} \quad$ Chlorobuthanol

Adjust volume to $500 \mathrm{~mL}$ with $\mathrm{H}_{2} \mathrm{O}$

store at $4^{\circ} \mathrm{C}$

$1 \times$ Transfer buffer

$25 \mathrm{~mL} \quad 20 \times$ Transfer buffer

$20 \% \quad$ Methanol

Adjust volume to $500 \mathrm{~mL}$ with $\mathrm{H}_{2} \mathrm{O}$

Western Blot stripping buffer

$0.2 \mathrm{M} \quad$ Glycine-HCl, $\mathrm{pH} 2.5$ 
$0.1 \% \quad$ Tween-20

\section{Blocking buffer}

$5 \%$ non-fat dry milk

$1 \% \quad$ BSA

in $1 \times$ TBS-T

\section{Sucrose lysis buffer for brain tissue}

$1,37 \mathrm{~mL} \quad 80 \%$ sucrose

$100 \mu \mathrm{L} \quad 1 \mathrm{M}$ Tris

$10 \mu \mathrm{L} \quad 1 \mathrm{M} \mathrm{NaHCO}_{3}$

$5 \mu \mathrm{L} \quad 2 \mathrm{M} \mathrm{MgCl}_{2}$

in $1 \times$ TBS-T

Adjust volume to $10 \mathrm{~mL}$ with $\mathrm{H}_{2} \mathrm{O}$

Add protease and phosphatase inhibitors directly before use

Modified RIPA buffer for cell culture

$50 \mathrm{mM} \quad$ Tris-HCl, $\mathrm{pH} 7.4$

$150 \mathrm{mM} \quad \mathrm{NaCl}$

$1 \mathrm{mM} \quad$ EDTA

$0.1 \% \quad$ SDS

1.0\% Sodium deoxycholate

1.0\% Triton X-100

Add protease and phosphatase inhibitors directly before use

\section{Inhibitors}

Protease inhibitor cOmplete, Mini, EDTA-free

Phosphatase inhibitor PhosSTOP

$10 \times$ DNA Orange loading dye

$50 \%$

glycerol

$0.1 \%$

Orange G

$49.9 \%$

$1 \times$ TAE buffer 
10 $\times$ GelRed/Orange loading buffer

$90 \% 10 \times$ DNA Orange loading dye

$10 \% \quad 10 \times$ GelRed

$49.9 \% \quad 1 \times$ TAE buffer

Ethidium bromide

$0.1 \% \quad 1 \mathrm{mg} / \mathrm{mL} \mathrm{EtBr}$

$50 \times$ dNTP mix

10mM dATP, dCTP, dGTP, dTTP

\section{LB-medium}

$0.5 \% \quad$ yeast extract

$1 \% \quad$ Bacto-Peptone, $\mathrm{pH} 7.5$

$1 \% \quad \mathrm{NaCl}$

low-salt LB-medium

$0.5 \%$ yeast extract

$1 \% \quad$ Bacto-Peptone, $\mathrm{pH} 7.5$

$0.5 \% \quad \mathrm{NaCl}$

\section{LB medium antibiotics}

$200 \mu \mathrm{g} / \mathrm{mL} \quad$ ampicillin

$50 \mu \mathrm{g} / \mathrm{mL} \quad$ kanamycin

$35 \mu \mathrm{g} / \mathrm{mL} \quad$ zeocin (in low-salt LB)

$25 \mu \mathrm{g} / \mathrm{mL} \quad$ chloramphenicol

$50 \mu \mathrm{g} / \mathrm{mL} \quad$ gentamycin

\section{SOC-Medium}

$\begin{array}{ll}0.5 \% & \text { yeast extract } \\ 2 \% & \text { Bacto/Peptone } \\ 20 \mathrm{mM} & \text { glucose } \\ 10 \mathrm{mM} & \mathrm{NaCl} \\ 2.5 \mathrm{mM} & \mathrm{KCl}\end{array}$


$10 \mathrm{mM} \quad \mathrm{MgSO}_{4}$

\section{LB-Agar plates}

$0.5 \% \quad$ yeast extract

$1 \%$ Bacto/Peptone

$1 \% \quad \mathrm{NaCl}$

1.5\% Agar

Autoclave

Add antibiotics after cooling

Low-salt LB-Agar plates

$0.5 \%$ yeast extract

$1 \%$ Bacto/Peptone

$0.5 \% \quad \mathrm{NaCl}$

1.5\% Agar

Autoclave

Add antibiotics after cooling

\subsubsection{Antibodies and labeling components}

Primary antibodies which are listed in table 2.1 were used in this study.

Table 2.1: Primary antibodies

\begin{tabular}{llll}
\hline Target & Host species & Application ${ }^{1}$ & Resource \\
\hline \hline AMPK $\beta 1 / 2$ (pan) & Rabbit & WB $(1: 1000)$ & Cell Signaling \\
AMPK $\beta 1$ (p-Ser-182) & Rabbit & WB $(1: 1000)$ & Cell Signaling \\
Akt (pan) & Rabbit & WB $(1: 1000)$ & Cell Signaling \\
Akt (p-Ser-473) & Rabbit & WB $(1: 1000)$ & Cell Signaling \\
CREB (pan) & Rabbit & WB $(1: 1000)$ & Cell Signaling \\
CREB (p-Ser-133) & Rabbit & WB $(1: 1000)$ & Cell Signaling \\
GAPDH & Mouse & WB $(1: 1000)$ & Stressgen \\
GFAP & Mouse & WB $(1: 5000)$ & Novocastra \\
GSK-3 (pan) & Rabbit & WB $(1: 1000)$ & Cell Signaling \\
GSK-3 (p-Ser-9) & Rabbit & WB $(1: 1000)$ & Cell Signaling \\
IGF-I Receptor $\beta 1$ (pan) & Rabbit & WB $(1: 1000)$ & Cell Signaling \\
Insulin Receptor $\beta$ (pan) & Rabbit & WB $(1: 1000)$ & Cell Signaling \\
IGF-I-R $\beta 1$ (p-Tyr-1135/1136) INS-R $\beta$ (p-Tyr-1150/1151) & Rabbit & WB $(1: 1000)$ & Cell Signaling \\
p44/42 MAPK (pan) & Rabbit & WB $(1: 1000)$ & Cell Signaling
\end{tabular}




\begin{tabular}{llll} 
p44/42 MAPK (p-Ser-473) & Rabbit & WB $(1: 1000)$ & Cell Signaling \\
mTOR (pan) & Rabbit & WB $(1: 1000)$ & Cell Signaling \\
mTOR (p-Ser-2448) & Rabbit & WB $(1: 1000)$ & Cell Signaling \\
PI3K p85 (pan) & Rabbit & WB $(1: 1000)$ & Cell Signaling \\
PI3K p85 (p-Tyr) & Rabbit & WB $(1: 1000)$ & Cell Signaling \\
Ribosomal S6 (pan) & Rabbit & WB $(1: 1000)$ & Cell Signaling \\
Ribosomal S6 (p-Ser-235/236) & Rabbit & WB $(1: 1000)$ & Cell Signaling \\
Tubulin, $\alpha$ & Mouse & WB $(1: 10000)$ & Sigma \\
\hline
\end{tabular}

The secondary antibodies used in this study are listed in table 2.2.

Table 2.2: Secondary antibodies

\begin{tabular}{ll}
\hline Name & Obtained from \\
\hline \hline HRP-anti mouse & Dianova, Hamburg, Germany \\
HRP-anti rabbit & Dianova, Hamburg, Germany \\
\hline
\end{tabular}

\subsubsection{Animals}

The following mouse strains were utilized in this study.

Table 2.3: Mouse strains

\begin{tabular}{lll}
\hline Strain & Genetic alteration & Origin \\
\hline \hline C57/N WT mice & No mutation & Animal core facility, MPI of Experimental Medicine \\
$S 1^{-/-}$mice & Sharp1 knockout & M. J. Rossner (Rossner et al., 2008) \\
$S 2^{-/-}$mice & Sharp2 knockout & M. J. Rossner (Rossner et al., 2008) \\
$I g f 1 r^{f l / f l}$ mice & Igf1r conditional knockout & J. C. Brüning (Klöting et al., 2008) \\
$I n s r^{f / f l}$ mice & Insr conditional knockout & J. C. Brüning (Brüning et al., 1998) \\
$C a M K I I-c r e ~ m i c e$ & CaMKII-cre & R. Klein (Minichiello et al., 1999) \\
\hline
\end{tabular}

\subsubsection{Plasmids}

The Igf2 and Igfbp5 expression sequences were cloned into an AAV2 plasmid with a CAG promoter.

${ }^{1}$ IF: immunocytochemistry, WB: western blot, DB: dot blot 


\title{
2.1.8 Media and sera
}

\subsubsection{Commercial media, sera and solutions}

Table 2.4: Commercial media, sera and solutions

\begin{tabular}{ll}
\hline Media, sera, and solution & Manufacturer \\
\hline \hline Dulbecco's Modified Eagle Medium (DMEM) & Lonza \\
Fetal Calf Serum (FCS) & Lonza \\
GlutaMAX ${ }^{T M}$ supplement & Gibco \\
Opti-MEM & Gibco \\
Trypsin-EDTA & Lonza \\
\hline
\end{tabular}

\subsubsection{Media preparation}

HEK293FT cells medium

\author{
$10 \%$ FCS \\ $1 \times$ GlutaMAX $^{\top M}$ \\ in DMEM with high glucose and without glutamine.
}

\subsubsection{Softwares}

Table 2.5: Softwares

\begin{tabular}{ll}
\hline Softwares & Source \\
\hline \hline Adobe Illustrator CS 5 & Adobe Systems Incorporated \\
GraphPad Prism & GraphPad Software, Incorporated \\
ImageJ & http://rsbweb.nih.gov/ij/ \\
ZEN Microscope Software & ZEISS \\
\hline
\end{tabular}

\subsection{Methods}

\subsubsection{Animal experiments}

All animal experiments were performed in accordance with institutional guidelines and were approved by the Government of Lower Saxony, Germany. Mice were housed at 
a 12-hour light/12-hour dark cycle and received food and water available ad libitum. All experiments were performed with cohorts of adult male mice at the same age between 4-5 months for most experiments and 12-16 months for aging studies. $S 1^{-/}, S 2^{-/-}$, $I g f 1 r^{f l / f l}$ and $I n s r^{f / f l}$ single knockout mice as well as CaMKII-cre heterozygous mice were backcrossed to $\mathrm{C} 57 \mathrm{Bl} / 6 \mathrm{~J}$ for more than ten generations as described previously (Rossner et al., 2008; Minichiello et al., 1999; Brüning et al., 1998; Klöting et al., 2008). Wildtype (WT) and Sharp1 and -2 double mutant mice $\left(S 1 / 2^{-/-}\right)$were obtained from double heterozygous breeding pairs (Rossner et al., 2008; Sun et al., 2001). Igf1r/Insr $r^{f / f l}$ and Igf1r/Insr CaMKII-cre mice were obtained from Igf1r/Insr ${ }^{f / f l}$ homozygous and CaMKIIcre heterozygous breeding pairs. Igf $1 \mathrm{r} / \operatorname{Ins} r^{f / f l}$ homozygous mice were obtained from Igf1r $/$ Insr $\mathrm{fl}^{\mathrm{f} /+}$ double heterozygous breeding pairs. Igf $1 \mathrm{r} / \mathrm{Ins} \mathrm{r}^{\mathrm{fl} /+}$ mice were obtained from $I g f 1 r^{f l / f l}$ and $I n s r^{f l / f l}$ breeding pairs. All experiments were performed blinded to genotypes.

\subsubsection{Genotyping PCR}

For the preparation of genomic DNA for genotyping, 2-3 $\mathrm{mm}$ of mouse tails were digested with $180 \mu \mathrm{L}$ of $1 \times \mathrm{MGB}$ and $20 \mu \mathrm{L}$ of proteinase $\mathrm{K}(10 \mathrm{mg} / \mathrm{mL})$. This mixture was incubated at $52^{\circ} \mathrm{C}$ over night while shaking. At the end, proteinase $\mathrm{K}$ was heat inactivated by incubation at $95^{\circ} \mathrm{C}$ for $10 \mathrm{~min}$. Genotyping PCR amplification was performed with $0.1 \mu \mathrm{L}$ of the obtained genomic DNA with respective primers (Table 2.6).

Table 2.6: Genotyping primers

\begin{tabular}{lll}
\hline Gene & & $\mathbf{5}$ '-3' Sequence \\
\hline \hline Sharp1 & WT/KO fwd & ACCTACAAGTTACCGCACAG \\
& WT rev & TTTCTCCAAATGCCCCAGTG \\
& KO rev & GCAATCCATCTTGTTCAATGGC \\
Sharp2 & KO fwd & TGGGCTGACCGCCTCGTGC \\
& WT fwd & GGAAGCTCAGGCTAGCTCAT \\
& WT/KO rev & CGTTTTATTCCCCGCCTGGA \\
CaMKII-cre & fwd & CGAGTGGCCCCTAGTTCTGGGGGCAGC \\
& rev & CGTTGCATCGACCGGTAATGCAGGC \\
Igfir & fwd & TCCCTCAGGCTTCATCCGCAA \\
& rev & CTTCAGCTTTGCAGGTGCACG \\
Insr & fwd & CTGAATAGCTGAGACCACAG \\
& rev & GATGTGCACCCCATGTCTG \\
\hline
\end{tabular}




\subsubsection{Behavioral analyses}

All performed behavior experiments were previously described unless stated otherwise (Brzózka et al., 2010).

\subsubsection{Memory tests}

\section{Morris water maze test}

Spatial learning and memory was analyzed in the Morris water maze test. The test started with a two-day visible platform task to allow the mice to learn the platform position. For initial and reversal learning the flag was removed from the platform. During the following 6 days of spatial learning (initial learning) each mouse was released in the tank 4 times per day, and was allowed to swim until they found the hidden platform. After 6 days, a probe trial was performed to assess the memory of the mice. Therefore, the platform was removed and the following parameters were analyzed: time spent in the target quadrant, number of crossings of the platform position and swim speed. After 7 days of break the reversal memory test was performed. The hidden platform was placed in the opposite quadrant and 6 days of testing as for the initial learning phase was performed. Finally the probe trial was performed again to test long term memory.

\section{Fear conditioning test}

Contextual fear memory was assessed in the fear conditioning paradigm with several cohorts of mice. All animals were tested with equipment provided by TSE Systems, except of AAV injected mice which were analyzed with a testing system of Ugo Basile. However, parameters for shock intensity and duration $(0.4 \mathrm{~mA}, 2 \mathrm{~s})$ were identical. The freezing rate of the AAV injected mice was analyzed automatically by the Any Maze software (Stoelting). Tone depending cue fear conditioning was performed with a modified setup with a $10 \mathrm{kHz}$ and $75 \mathrm{~dB}$ tone played for $30 \mathrm{~s}$ directly before the applied shock. Later cue dependent fear memory regarding the associated tone was tested in a separate new context.

\subsubsection{Standard behavior tests}

\section{Light-dark preference}

To analyze anxiety behavior, the light-dark preference test was performed in a box consisting of two equal parts, a dark and a transparent compartment connected by a door. 
Within 5 min of testing, time spent in the dark compartment was analyzed.

\section{Open field test}

The spontaneous loco-motor activity of mice was assessed in the open field test for 10 minutes. In this time the total time of activity, number of rearings, total time of rearings, traveled distance, time spent at the center, time spent at the periphery and corner visits were analyzed.

\section{Hole board test}

The open field setup was modified for the hole board test by inserting a plastic plate with 16 symmetrical holes to the ground. Within $10 \mathrm{~min}$ of time the traveled distance, number of visits of the holes, total exploration time as well as time spent for one exploration were measured.

\section{Hot plate test}

To test the pain threshold with the hot plate test, each mouse was placed on a $52^{\circ} \mathrm{C}$ hot metal plate, and the time until the mice licked the hind paw was measured.

\section{Tail suspension}

To test the overall motivation behavior of mice the tail suspension test was performed. For this purpose mice were suspended by their tails for $6 \mathrm{~min}$ and the time of struggling to get free were scored.

\section{Elevated plus maze test}

To assess the anxiety behavior, mice were analyzed in the elevated plus maze test. The test setup has two opened arms and two closed arms, and preference of mice was tested. For a duration of $5 \mathrm{~min}$, total distance traveled, distance traveled in closed arms, time spent in center, running speed, and relative time in closed arms were analyzed.

\subsubsection{Stereotactic injections}

Surgery was performed under intra-peritoneal (i.p.) anesthesia with ketamine/xylazine $(100 \mathrm{mg} / \mathrm{kg} ; 10 \mathrm{mg} / \mathrm{kg}$ ). Viral vectors (AAV, AAV-Igf2, AAV-Igfbp5) were injected into the anterior cingulate cortex $(1 \mathrm{~mm}$ anterior to bregma, $0.5 \mathrm{~mm}$ lateral to midline, $1 \mathrm{~mm}$ 
ventral to surface). One $\mu \mathrm{L}$ was administered at each injection site using a $10 \mu \mathrm{L}$ Hamilton syringe at a rate of $0.5 \mu \mathrm{L} / \mathrm{min}$ for a total of $4 \times 10^{11}$ drp (DNase-resistant particles) per injection site. Immediately after surgery, mice were given buprenorphine $(0.2 \mathrm{mg} / \mathrm{kg}$, s.c. $)$ for analgesia.

\subsubsection{Molecular biology}

All molecular biology standard methods that are not described in detail were performed according to "Molecular Cloning: A Laboratory Manual" (Sambrook and Russel, 2001) and to the manufacturer's protocols.

\subsubsection{E.coli DNA transformation}

\section{Chemically competent bacteria}

Transformation-competent bacteria (E.coli, strain DH5 $\alpha$, Mach1, XL1 blue) were thawed on ice. To $100 \mu \mathrm{L}$ of cells, $5-10 \mu \mathrm{L}$ of a ligation or recombination reaction was added and incubated on ice for $30 \mathrm{~min}$. The bacteria were heat-shocked at $42^{\circ} \mathrm{C}$ for $42 \mathrm{~s}$ and cooled on ice for $2 \mathrm{~min}$. Subsequently $600 \mu \mathrm{L}$ of cold SOC medium was added and incubated for 45 min at $37^{\circ} \mathrm{C}$ with gentle shaking. This first incubation step at $37^{\circ} \mathrm{C}$ is required for the cells to express the antibiotic's resistance. Then, the samples were centrifuged, the supernatant was discarded and the bacteria were plated on a LB-agar plate containing the appropriate antibiotic. The bacteria were distributed by using sterile glass beads. The plates were incubated overnight at $30-37^{\circ} \mathrm{C}$.

\section{Electro-competent bacteria}

Commercially available DH10B E.coli were diluted 1:4 with sterile $10 \%$ glycerol and $20 \mu \mathrm{L}$ aliquots were made. $2-2.5 \mu \mathrm{L}$ of a recombination or ligation reaction was added to the bacteria and transferred into a $1 \mathrm{~mm}$ electroporation cuvette (BioRad). The electroporation was performed using the 'GenePulserII' (BioRad) with the following settings: $1.75 \mathrm{kV}$, $25 \mu \mathrm{F}$ capacitance and resistance of $200 \Omega$. The cells were resuspended in $600 \mu \mathrm{L}$ cooled $\mathrm{LB}$, or alternatively in SOC medium, without antibiotics and incubated at $37^{\circ} \mathrm{C}$ for 45 min with moderate shaking. The bacteria were processed and plated as described above for chemically competent bacteria. 


\subsubsection{Purification of plasmid DNA}

\section{General plasmid DNA purification}

Preparation of plasmid DNA is based on alkaline cell lysis, followed by SDS precipitation (Birnboim and Doly, 1979). A silica membrane binds the plasmid DNA under high-salt conditions. After binding, the DNA can be washed and eluted with appropriate buffers. To isolate plasmid DNA from fresh overnight bacterial LB cultures, we used plasmid DNA purification kits provided by Macherey-Nagel. Detailed protocols are provided by the manufacturer.

\section{Mini plasmid DNA preparation}

In brief, 2-4 $\mathrm{mL}$ LB medium with antibiotics was inoculated with the selected bacterial clone and incubated overnight at $30-37^{\circ} \mathrm{C}$. Amplified bacteria were centrifuged and resuspended in $250 \mu \mathrm{L}$ buffer A1 with RNAse. Cells were lysed by adding $300 \mu \mathrm{L}$ buffer A2. After 5 min incubation, the lysis reaction was stopped by adding buffer A3. The lysed bacteria were centrifuged and the clear supernatant was loaded to the column. Then, the column was washed with buffer $\mathrm{AQ}$, dried by additional centrifugation and eluted with $100 \mu \mathrm{L} \mathrm{H}_{2} \mathrm{O}$ or TE buffer.

\section{Midi plasmid DNA preparation}

$200 \mathrm{~mL}$ LB medium with antibiotics was inoculated with selected bacterial clone and incubated overnight at $30-37^{\circ} \mathrm{C}$. DNA was purified and isolated according to manufacturer's protocol

\section{Concentration determination of nucleic acid}

To determine the purity and concentration of nucleic acids, spectrometry was used.

\subsubsection{RNA expression analyses}

RNA was isolated according to the manufacturer's protocol using RNeasy columns (Qiagen, Hilden, Germany). All isolated RNA samples were tested for quality and quantity with the Bioanalyzer (Agilent Technologies). RNA-integrity (RIN) values were higher than 8. SYBRgreen real time PCR experiments were performed with a LC480 detection system (Roche). All used primers were designed online at the assay design center of the 
Roche Universal Probe Library.

Table 2.7: RTPCR primers

\begin{tabular}{|c|c|c|}
\hline Gene & sense & antisense \\
\hline \multicolumn{3}{|l|}{ Mouse } \\
\hline Actb & ATTGGCAATGAGCGGTTC & GGATGCCACAGGACTCCAT \\
\hline Atp $5 b$ & GGATCTGCTGGCCCCATAC & CTTTCCAACGCCAGCACCT \\
\hline$c-F o s$ & TCGACCTAGGGAGGACCTTACC & CCAGATGTGGATGCTTGCAA \\
\hline Cyc1 & CAGAGCATGACCATCGAAAA & CACTTATGCCGCTTCATGG \\
\hline Igf2 & CGCTTCAGTTTGTCTGTTCG & GCAGCACTCTTCCACGATG \\
\hline Igfbp 5 & CTACCGCGAGCAAGTCAAG & GTCTCCTCGGCCATCTCA \\
\hline Per2 & CAACACAGACGACAGCATCA & TCCTGGTCCTCCTTCAACAC \\
\hline Rpl13a & ATCCCTCCACCCTATGACAA & GCCCCAGGTAAGCAAACTT \\
\hline \multicolumn{3}{|l|}{ Human } \\
\hline$A T P 5 B$ & TGATGAAAGAGGTCCCATCAA & ACCAGAATTTCCTGCTCAACA \\
\hline$B M A L 1$ & CAGGAAAAATAGGCCGAATG & AGGCGATGACCCTCTTATCC \\
\hline$C L O C K$ & CACCAGGATGATGATGAATAATG & CGTTTTCGTCTTGTAGTAGACATTTG \\
\hline$E G R 1$ & AGCCCTACGAGCACCTGAC & GGTTTGGCTGGGGTAACTG \\
\hline FOS & CTACCACTCACCCGCAGACT & AGGTCCGTGCAGAAGTCCT \\
\hline$G A P D H$ & GCTCTCTGCTCCTCCTGTTC & ACGACCAAATCCGTTGACTC \\
\hline PER1 & CTCTTCCACAGCTCCCTCA & CTTTGGATCGGCAGTGGT \\
\hline PER2 & CTGCAAACCTGGCACTTCTC & GTGTCTGAGGGTTCATCACG \\
\hline POLR2B & ACCTACTTAAAGCTATGGCAAAGG & TGTTGCACAAATAACGACACTG \\
\hline$R P L 13 A$ & CCCCTGTTTCAAGGGATAAGA & GACCATCAAGCACCAGGAC \\
\hline$S H A R P 1$ & GTACAGAGCCCCAAAAATCG & TTCCTTCGTCCATGTTCAACT \\
\hline SHARP2 & AAGCATGTGAAAGCACTAACAAA & TCTCCCTGACAGCTCACCA \\
\hline$E R B B 4-C Y T 1$ & TGAGGAGTACTTGGTCCCTCAGGC & GCAGGAGGAGGGCTGTGTCCA \\
\hline$E R B B 4-C Y T 2$ & AGGCTTTCAACATCCCACCTCCCA & ACAAACTGGTTCCTATTCGAGTCA \\
\hline$E R B B 4-C Y T 1 / 2$ & GGCTTTCAACATCCCACCTCCCA & GCAGCAAAACCTCCATCTCGGT \\
\hline$E R B B 4-J M a$ & TGGACGGGCCATTCCACTTTACCA & TGACCAGAATGAAGAGCCCACCA \\
\hline$E R B B 4-J M b$ & CACCCAAGGGTGCATAGGCTCA & TGACCAGAATGAAGAGCCCACCA \\
\hline$E R B B 4-J M a / b$ & GCCATCCAAACTGCACCCAAGG & TACTCCAGCTGCAATCAGGGGA \\
\hline
\end{tabular}

\subsubsection{Protein biochemistry}

\subsubsection{Preparation of tissue lysates}

Dissected tissue samples were directly frozen on dry ice and lysed with a Polytron PT 2000 homogenizer in an appropriate volume of sucrose buffer. For preservation of proteins as well of protein phosphorylation cOmplete (Roche) and PhosSTOP tablets were freshly 
added to the buffer.

\subsubsection{Protein lysates}

Before processing the protein lysate, a fraction of the lysate was removed and added to an appropriate volume of RLT buffer (Qiagen) for further RNA extraction. Protein lysates were quantified with a Lowry based DC Protein Assay Kit II (BIO-RAD) and adjusted to a final concentration of $1 \mu \mathrm{g} / \mu \mathrm{L}$ with $1 \mathrm{mM}$ DTT and $1 \mathrm{xNuPAGER}$ lithium dodecyl sulphate (LDS) sample buffer. Finally samples were heated for $10 \mathrm{~min}$ at $70^{\circ} \mathrm{C}$.

\subsubsection{SDS-PAGE}

Sodium dodecyl sulfate polyacrylamide gel electrophoresis (SDS-PAGE) was performed under denaturing conditions for protein analyses. Samples were separated in 4-12\% NuPAGE Bis-Tris gel in $1 \times$ Mes buffer (Invitrogen) for 30 min at $200 \mathrm{~V}$.

\subsubsection{Western Blot}

Following SDS-PAGE gel electrophoresis, the proteins were transferred to a $0.2 \mu \mathrm{m}$ PVDF membrane (Roche) for $2 \mathrm{~h}$ at $30 \mathrm{~V}$ in transfer buffer with $20 \%$ methanol at $4^{\circ} \mathrm{C}$.

After successful transfer, unspecific epitopes were blocked for 30 min at RT in $5 \%$ milk and 1xTBS with $0.05 \%$ Tween20. Blocked membranes were incubated with the primary antibody in TBS-T at $4{ }^{\circ} \mathrm{C}$ overnight. The membranes were washed $3 \times 5$ min at RT with TBS- $T$, then the membranes were incubated with the appropriate secondary antibodies conjugated to horseradish peroxidase (HRP) for $1 \mathrm{~h}$ at RT, and washed again $5 \times 5 \mathrm{~min}$ at RT with TBS-T.

Finally, the proteins were visualized by enhanced chemiluminescence (Pierce/Thermo Scientific) with an INTAS ECL Imager. Detected protein bands were quantified with ImageJ.

\subsubsection{Immunocytochemistry and imaging}

\subsubsection{Immunohistochemistry}

Mice were anesthetized with avertin and perfused with gassed ACSF following 4\% PFA in PBS. Brains were treated overnight in $4 \% \mathrm{PFA}$ at $4^{\circ} \mathrm{C}$ and embedded in paraffin at the 
next day. Immunohistochemical analysis was performed on $10 \mu \mathrm{m}$ thick coronal brain sections. Haematoxylin-eosin (HE) stain as well as DAB based immunostaining (DakoLSAB2 kit) was used according to manufacturer's manual. Primary antibodies were used against phospho-S6 (1:100, Cell Signaling) and GFAP (1:200, Novocastra).

\title{
2.2.8 AAV virus production
}

\subsubsection{Cell culture}

HEK293FT cells were maintained in DMEM medium with 10\% FCS with regular passaging on PLL coated plates (Javanbakht et al., 2003). After obtaining the desired confluency, cells were used for virus production and amplification.

\subsubsection{Virus production}

HEK293FT with a confluency of $50 \%$ were transfected with packaging plasmids.

\author{
AAV packaging plasmids \\ $\mathrm{pF} \Delta 6 \quad$ adenovirus helper proteins for replication (E2, E4, VA) \\ pH21 replication/capsid proteins for serotype 1 \\ pRV1 replication/capsid proteins for serotype 2
}

The transfection reaction was performed with polyethylenimine (PEI). 1 pmol of the packaging plasmids as well as the insert containing AAV plasmid were used for transfection of HEK293FT cells with PEI according to manufacturer's instructions. Transfected cells were maintained for 3 days with daily medium changes. The cells were collected in a 50 $\mathrm{mL}$ tube (Falcon) and centrifuged at 1,000 rpm for $10 \mathrm{~min}$. The medium was removed and replaced with $5 \mathrm{~mL}$ cell lysis buffer ( $3 \mathrm{~mL} 5 \mathrm{M} \mathrm{NaCl}, 5 \mathrm{~mL} 1 \mathrm{M}$ Tris-HCl, $\mathrm{pH} 8.5)$. The cells were lysed with 3 cycles of freezing at $-80^{\circ} \mathrm{C}$ for $20 \mathrm{~min}$, and thawing at $37^{\circ} \mathrm{C}$ for 10 min. After lysis, $1 \mu \mathrm{L}$ benzonase was added and incubated at $37^{\circ} \mathrm{C}$ for $30 \mathrm{~min}$. Then, the suspension was centrifuged at 3,000 rpm for $10 \mathrm{~min}$. The virus containing supernatant was filtered with a $0.45 \mu \mathrm{m}$ filter and added to an Amicon Ultra-15 Centrifugal Filter Unit. $10 \mathrm{~mL}$ of the medium later used for transduction was added to the filter unit and 
centrifuged at 3,000 $\mathrm{rpm}$ for $15 \mathrm{~min}$. The filter was washed twice by transducing $10 \mathrm{~mL}$ of the medium and finally centrifuged until a volume of $2 \mathrm{~mL}$ in the filter unit.

\subsubsection{Virus titration}

To determine the concentration of virus particles, the virus was titrated. First, $5 \mu \mathrm{L}$ of the virus containing solution was digested with $20 \mu \mathrm{L}$ proteinase $\mathrm{K}$ in $200 \mu \mathrm{L}$ PBS for 10 min at $50^{\circ} \mathrm{C}$ to break the viral capsid proteins. Viral DNA was isolated with a NucleoSpin Gel and PCR Clean-up kit according to manufacturer's protocol and eluted in $30 \mu \mathrm{L} \mathrm{H}_{2} \mathrm{O}$. The number of viral particles was assessed by quantitative RTPCR with calibrated virus particle samples. 


\title{
Chapter 3
}

\section{Results}

Parts of the results in Section 3.1-3.3 have been prepared for publication in:

\begin{abstract}
Enhanced remote fear memory in Sharp1 and Sharp2 double mutant mice caused by relaxed lgf2 signaling in the anterior cingulate cortex.
\end{abstract}

Ali Shahmoradi, Konstantin Radyushkin and Moritz J. Rossner (2015)

Proceedings of the National Academy of Sciences

\subsection{Behavioral and molecular analyses of $S 1 / 2^{-/-}$mice}

\subsubsection{Behavioral analyses of $S 1 / 2^{-\sim}$ mice}

To address the function of SHARP1 and SHARP2 in the context of learning and memory formation, we analyzed wild type (WT) and Sharp1 $\left(S 1^{-/-}\right)$and Sharp2 $\left(S 2^{-/-}\right)$single null mutants (Rossner et al., 2008) in the contextual fear conditioning paradigm (Kim and Fanselow, 1992). Sharp1 and -2 prominently expressed in hippocampal and cortical regions and are coupled to physiologically and pathologically altered neuronal activity in the cortex (Honma et al., 2002; Rossner et al., 1997). Therefore, we tested recent fear memory formation (1 day after shock) to study hippocampal as well as remote fear memory (28 days after shock) to also assess cortical functions (Fig. 3.1A and B). Frontal cortex regions such as the anterior cingulate gyrus (ACC) appear to be critically involved in remote memory formation (Frankland et al., 2004). To assess recent memory, we first conditioned WT and single mutant mice with two electric shocks. At the next day we placed them again into the same environment of the fear conditioning and tested the memory of the shock. To test remote memory, we tested the mice again after 28 days. In 

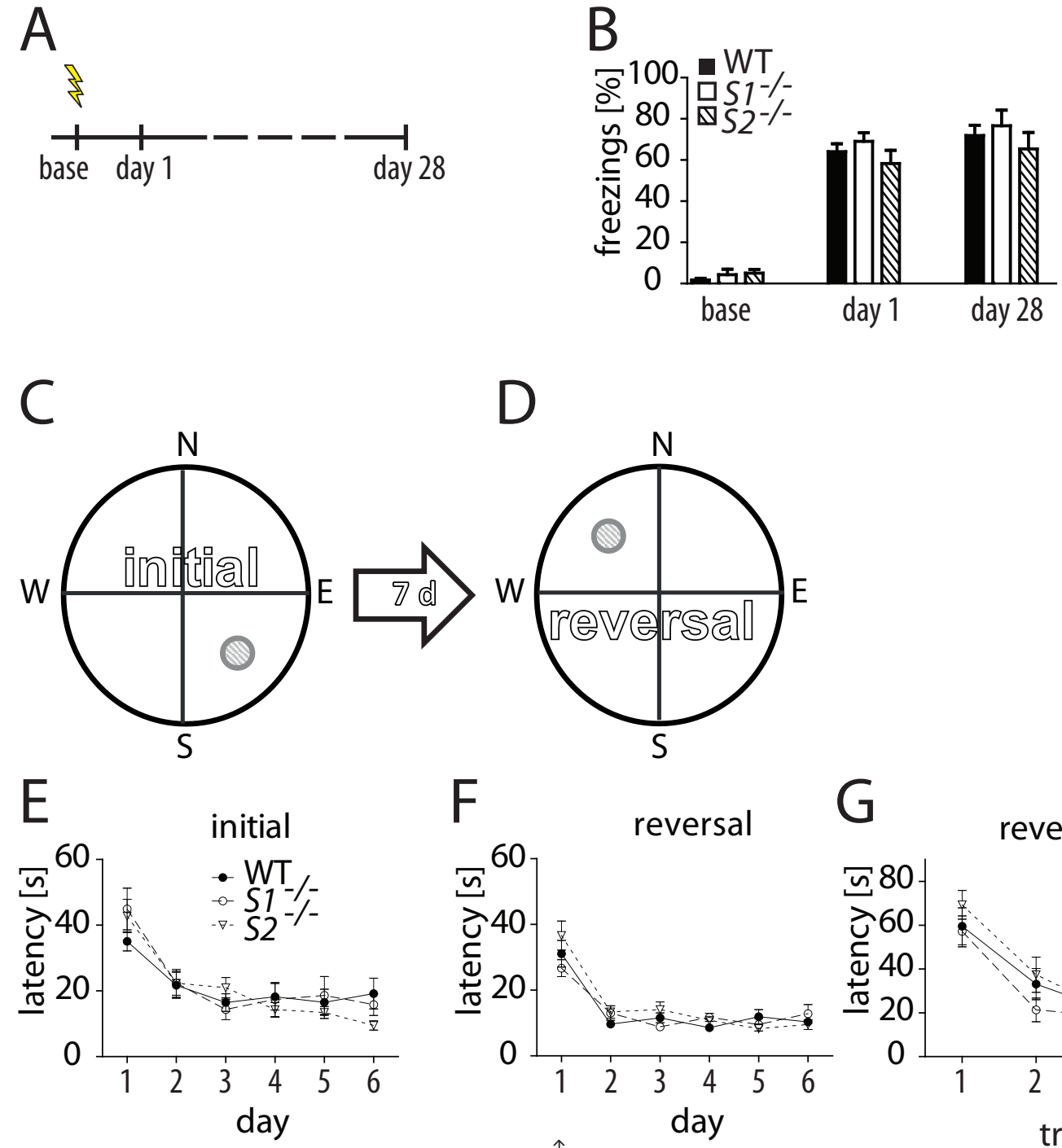

$\mathrm{F}$

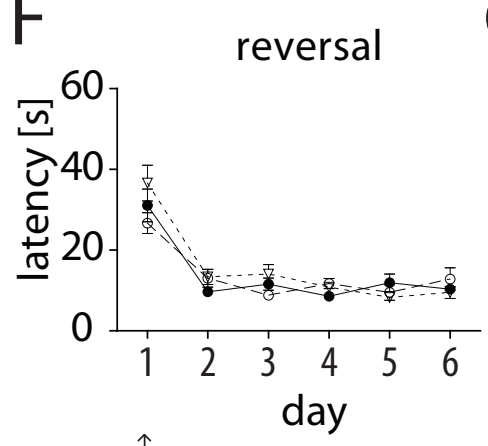

G reversal day 1

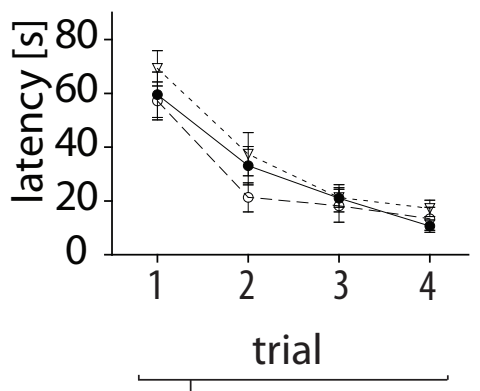

Figure 3.1: Behavioral analyses of $S 1^{-/}$and $S 2^{-/}$mice. A-B) Fear conditioning with WT, $S 1^{-/}$ and $\mathrm{S2}^{-/}$mice. No genotype difference was observed 1 day and 28 days after shock. C-G) Water maze experiment with WT, $S 1^{-/}$and $S 2^{--}$mice. No difference was observed in initial and reversal water maze in 6 days of trials. Data shown are means \pm SEM (error bars), $n=7-10$ [A) and $B$ )], $n=8$ $[E-G)]$. Statistical significance was assessed by two-tailed Mann-Whitney $U$ test [B)] and two-way ANOVA followed by Bonferroni's post-hoc test [E-G)].

all of the performed time points of the fear conditioning test $S 1^{-/-}$and $S 2^{-/-}$single mutants performed as WT animals (Fig. 3.1A and $B$ ). Recent, as well as remote long-term memory was not altered. 
Further, we applied a modified water maze task including a reversal test that monitors learning flexibility depend of the anterior cortex (de Bruin et al., 1994). To test hippocampus based spatial memory, mice were placed for 6 days with 4 trials per day into a water bath with a hidden platform. In order to find rescue from the water, mice prefer to stay on the platform whenever they find it. With every repeat, the previously acquired memory reduces the time to find the platform. To test anterior cortex dependent flexible learning, we added 6 days of training with the platform moved to the opposite quadrant of the water bath. This way we test how effective the mice can rewrite already learned memory that is not valid anymore. However, in the initial test as well as after changing the platform position (reversal test), learning performance of $S 1^{-/-}$and $S 2^{-/-}$remained unaltered compared to WT (Fig. 3.1C - F). No phenotype of $S 1^{-/-}$and $S 2^{-/-}$single mutants in the water maze and fear conditioning test supported a potential functional redundancy of both genes in cognitive processing.

Because of a high structural homology of SHARP1 and SHARP2 and their potential functional redundancy in cognitive processes, we next analyzed $S 1 / 2^{-/-}$double knockout mice. In fear conditioning test, 1 day after conditioning $S 1 / 2^{-/-}$double mutant mice did not reveal any differences in recent memory performance compared to WT (Fig. 3.2A and $C)$. However when tested 28 days later, remote memory of $S 1 / 2^{-/-}$mice was significantly improved. In order to exclude an additional effect on memory due to the repetition of the test, we repeated the experiment with two separate mouse cohorts only testing at 1 or 28 days after fear conditioning (Fig. 3.2B). We could observe a significant increase of remote memory performance of $S 1 / 2^{-/-}$mice only at the remote long-term fear memory test. (Fig. 3.2D).

Next, we performed an initial and reversal water maze experiment with $S 1 / 2^{-/-}$and WT mice. We saw no differences in memory performance of $S 1 / 2^{-/-}$mice compared to WT in the initial learning phase (Fig. 3.2E). However, in probe trial test, after removing the platform at the end of the experiment, $S 1 / 2^{-/-}$mice spent significatly more time at the target quadrant (Fig. 3.2F). To exclude that this is an effect of a lack of forgetting, we changed the location of the hidden platform to the opposite quadrant and repeated the water maze experiment. After changing the platform position, $S 1 / 2^{-/-}$mice relearned the new platform faster than WT. In the end of the water maze test again we removed the platform and analyzed the memory of the relearned position. 


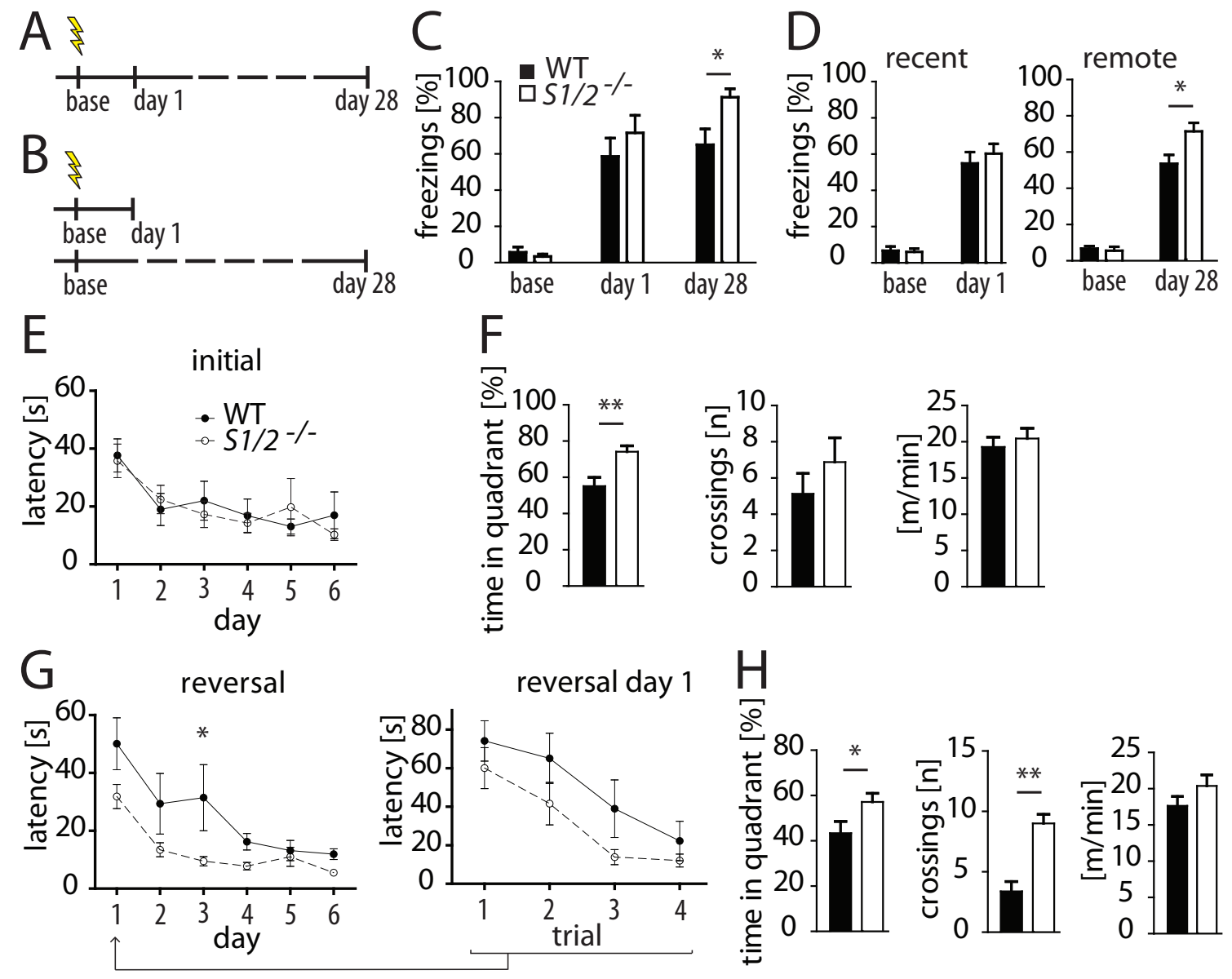

Figure 3.2: Increased remote fear memory formation and improved reversal learning in S1/2/- mice. A, B) Experimental procedure of recent and remote memory testing upon contextual fear conditioning. C) Freezing behavior of mice tested 1 day and 28 days after training. No significant difference was observed at day 1 between genotypes. Increased remote fear memory formation was observed in $S 1 / 2^{--}$mice compared to WT mice as measured by significantly increased freezing rates 28 days after shock. D) Increased remote fear memory in $S 1 / 2^{-/}$mice was observed when tested only once 28 days post shock, but no change at 1 day after shock. E, F) Water maze showed no difference between genotypes in the initial learning phase (E) but increased spatial memory formation of $S 1 / 2^{--}$mice in the probe trial $(F)$. The number of exact crossings of the platform location and the swim speed remained unaltered. $\mathbf{G}, \mathbf{H}$ ) In the reversal water maze experiment (upon exchanging the position of the platform), $S 1 / 2^{-/}$mice relearned to find the new platform position faster compared to WT mice (G). Time spent in the target quadrant and numbers of crossings of the platform location $(\mathrm{H})$ were increased in $S 1 / 2^{-/}$mice compared to WT controls indicating improved memory consolidation. Speed of swimming remained unaltered. Data shown are means \pm SEM (error bars), $n=8-10$ [(C)], $n=10$ [(C,recent)], $n=12-16$ [(C,remote)], $\mathrm{n}=8[(\mathrm{E})-(\mathrm{H})]$. Statistical significance $(* \mathrm{p}<0.05, * * \mathrm{p}<0.01)$ was assessed by two-tailed MannWhitney $U$ test $[(C),(D),(F)$ and $(H)]$ and two-way ANOVA followed by Bonferroni's post-hoc test $[(E)$ and $(G)]$. Effect of genotype $\left(F_{(1,14)}=5.76 ; p=0.0309 ;[(G)]\right)$. Fear conditioning experiment $[(C)]$ was performed by Lisa Reinecke. Water maze experiments $[(E)-(H)]$ were performed by Konstantin Radyushkin. 
The time swimming in the quadrant of the hidden platform was again significantly higher compared to WT (Fig. 3.2H).

Furthermore, in the probe trial test the number of crossings of the exact position of the former platform location was significantly increased. Altogether, these observations support an anterior cortex specific phenotype in $S 1 / \mathscr{2}^{-/-}$mice and indicate that improved learning and not an impaired forgetting underlies the enhanced memory consolidation seen in the remote fear conditioning and reversal water maze (Fig. 3.2).
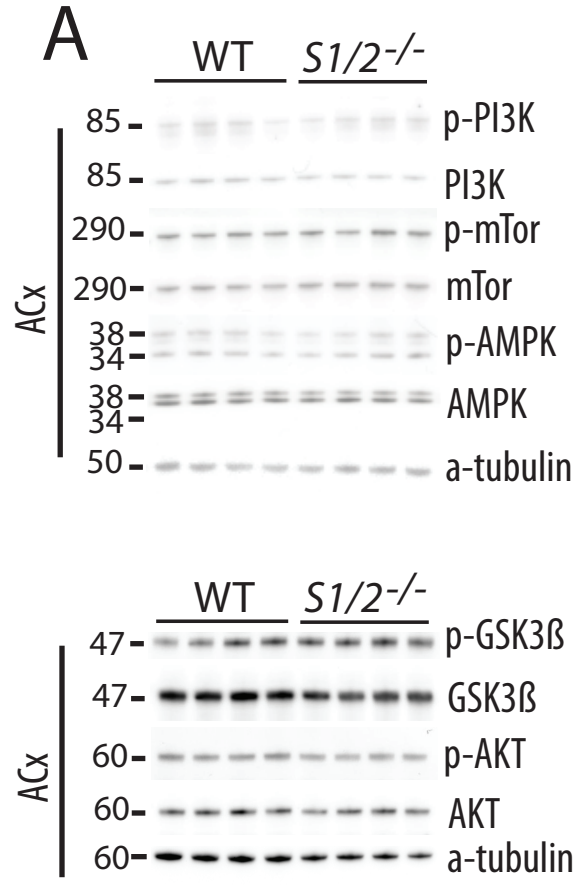
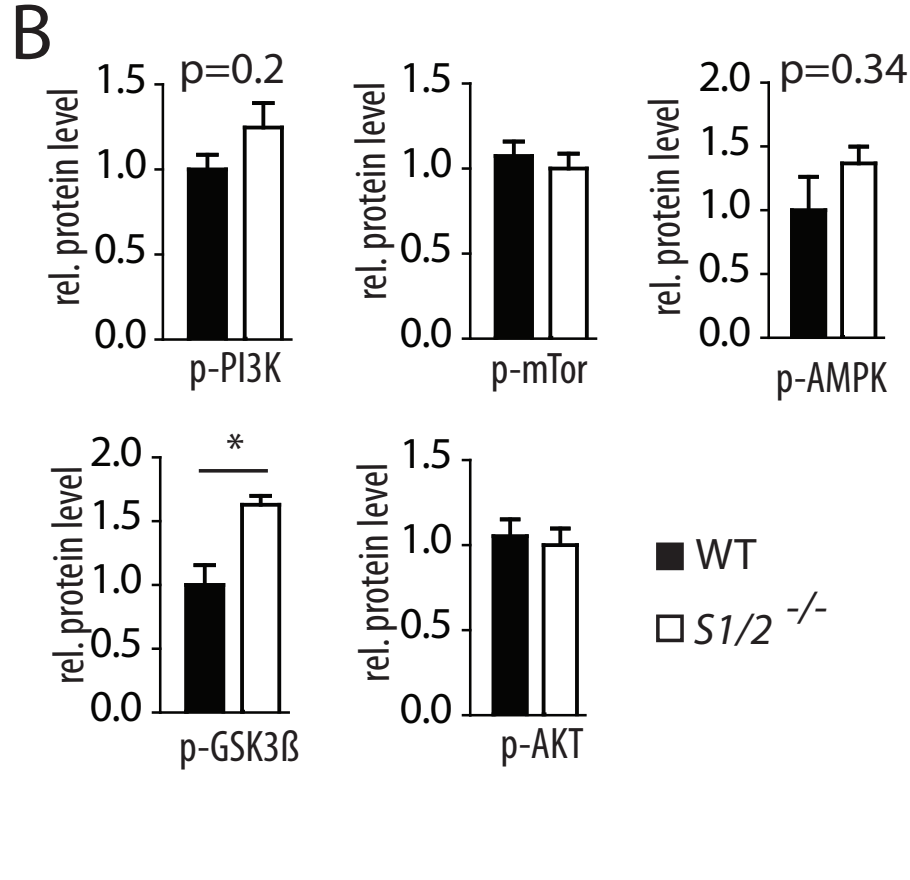

Figure 3.3: Signaling pathway activities in the ACx of $51 / 2^{-/}$mice. A, B) Learning and memory related signaling pathways in the ACx of $S 1 / 2^{--}$mice. A) Western blot analyses of PI3K, mTOR, AMPK, GSK3 $\beta$ and AKT phosphorylation levels in the ACx of WT and S1/2- mice. B) Quantification of phosphorylation levels relative to respective total protein level. Phosphorylation of PI3K, mTOR, AMPK and AKT was unaltered in the ACx of $S 1 / 2^{-/}$compared to WT mice. GSK3 $\beta$ phosphorylation was increased in the ACx compared to WT. Data shown are means \pm SEM (error bars), $\mathrm{n}=4[(\mathrm{~B})]$. Statistical significance $(* \mathrm{p}<0.05)$ was assessed by two-tailed Mann-Whitney $U$ test $[(\mathrm{B})]$. 
3.1.2 Molecular analyses of learning and memory associated pathway activation

In order to further characterize the ACx specific phenotype in $S 1 /^{-/-}$mice, we analyzed a set of surrogate markers of several signaling pathways (i.e. phosphorylation/ activation states of p44/42-MAPK, S6, PI3K, mTOR, AMPK, GSK3 $\beta$ and AKT) that are implicated in neuronal plasticity and hippocampal learning (Man et al., 2003; Fortress et al., 2013; Enriquez-Barreto et al., 2014; Potter et al., 2010; Bekinschtein et al., 2007; Chen et al., 2005; Kelleher et al., 2004).

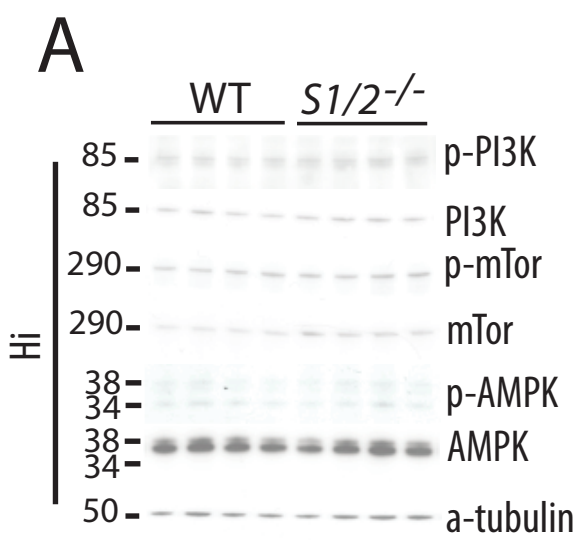

B
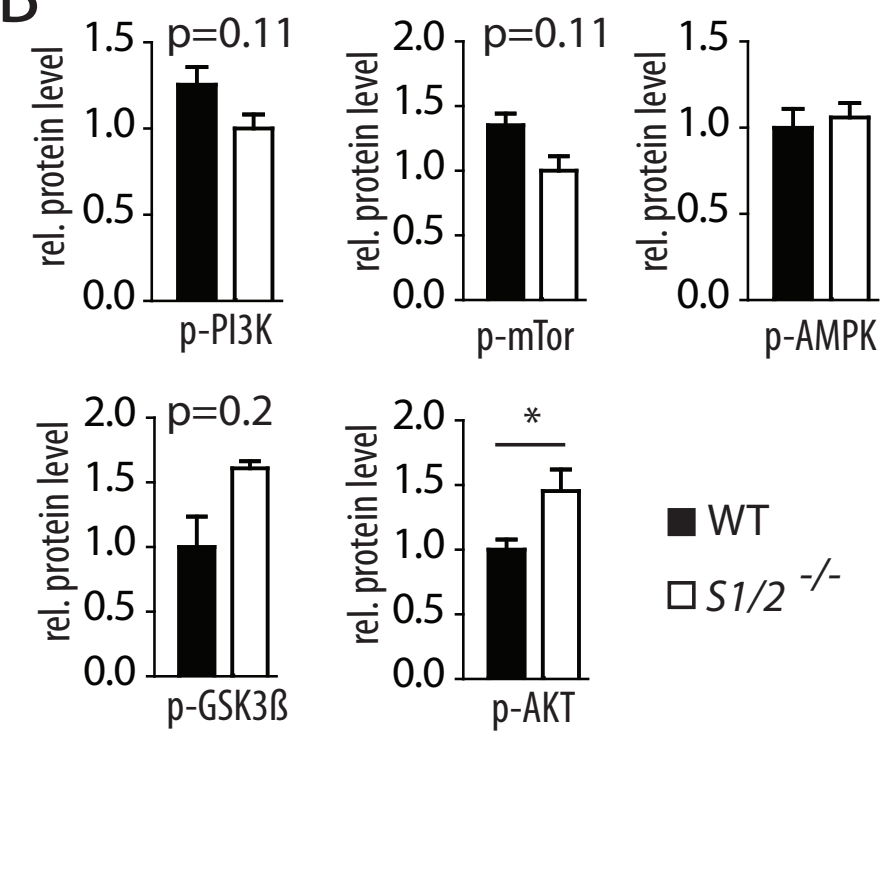

포

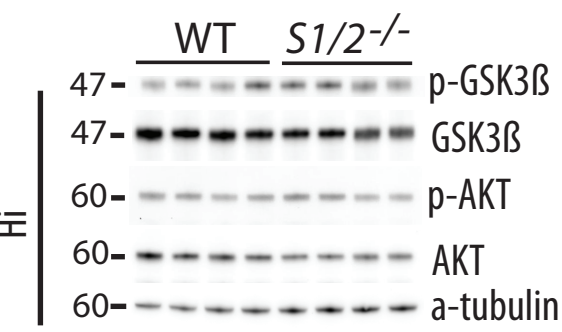

Figure 3.4: Signaling pathway activities in the Hi of S1/2/- mice. A, B) Learning and memory related signaling pathways in the $\mathrm{Hi}$ of $S 1 / 2^{-/}$mice. A) Western blot analyses of $\mathrm{PI} 3 \mathrm{~K}, \mathrm{mTOR}$, AMPK, GSK3 $\beta$ and AKT phosphorylation levels in the Hi of WT and S1/2/- mice. B) Quantification of phosphorylation levels relative to respective total protein level. Phosphorylation of PI3K, mTOR, AMPK and GSK3 $\beta$ was unaltered in the Hi of $S 1 / 2^{-/}$compared to WT mice. AKT phosphorylation was increased in the Hi compared to WT. Data shown are means \pm SEM (error bars), $n=4[(B)]$. Statistical significance $(* p<0.05)$ was assessed by two-tailed Mann-Whitney $U$ test $[(B)]$. 
We speculated that elevated signaling selectively operating in the $\mathrm{ACx}$ and not the $\mathrm{Hi}$ could mediate the underlying processes of the cortex-selective learning and memory enhancement in $S 1 / 2^{-/-}$mice. After quantification of the phosphorylated proteins relative to the total amount of the respective protein, we could observe a significant increase of phosphorylated GSK3 $\beta$ in the ACx. However, when we analyzed the respective Hi samples, we could determine the same tendency of GSK3 $\beta$ activation of $S 1 / 2^{-/-}$mice (Fig. 3.4). Furthermore, studying the samples of the Hi of $S 1 / 2^{-/-}$mice, we could also observe elevated AKT phosphorylation levels. All other signaling markers remained unaltered between the genotypes and brain regions (Fig. 3.4). 


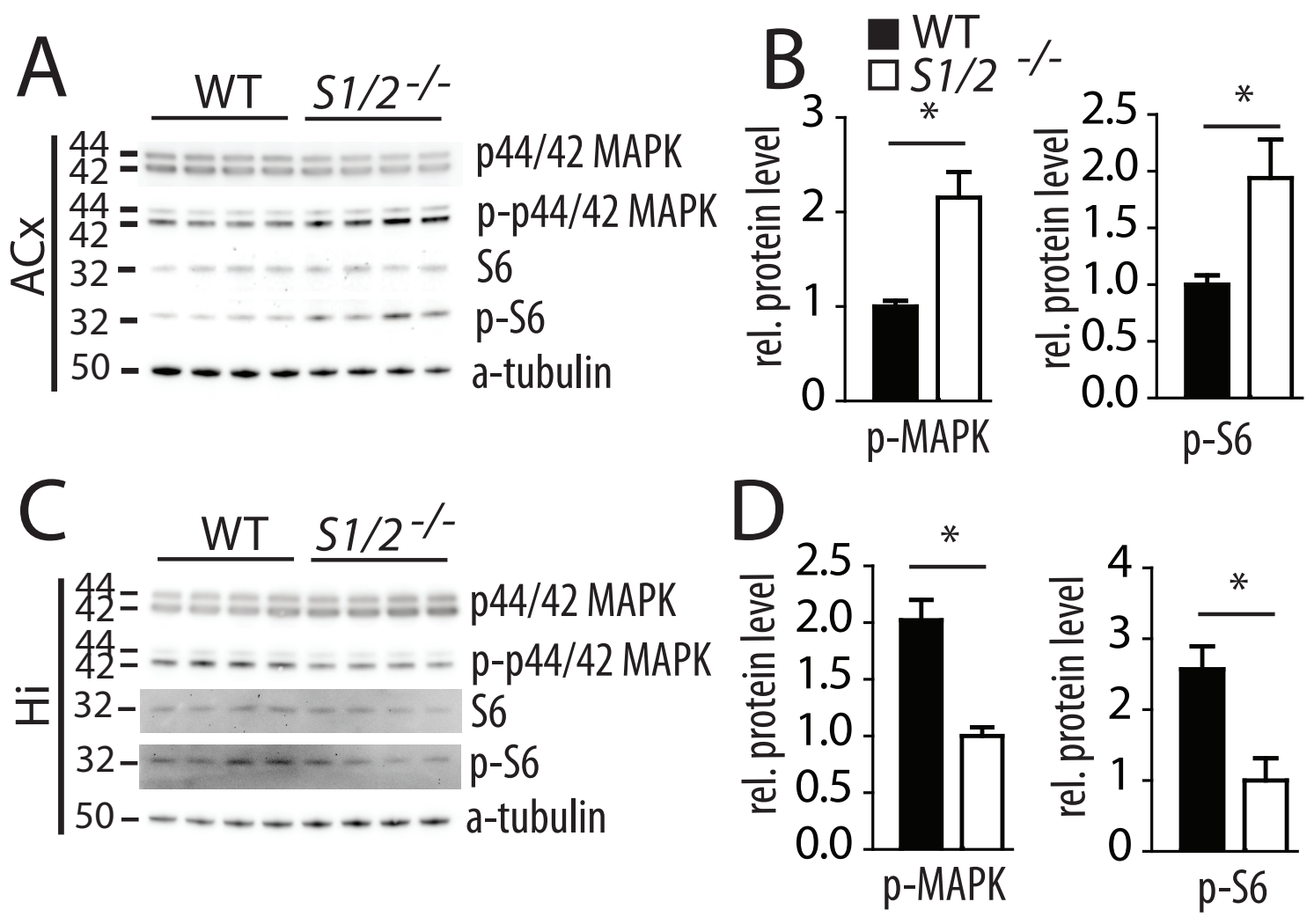

Figure 3.5: MAPK and $\mathrm{S} 6$ activity in the ACx and $\mathrm{Hi}$ of $\mathbf{S 1 / 2 ^ { - / }}$ mice. A, C) Western blot analyses of p44/42-MAPK and S6 phosphorylation levels in the ACx and Hi of WT and S1/2-mice. B, D) Quantification of p44/42-MAPK and S6 phosphorylation levels relative to respective total protein amount. Phosphorylation of p44/42-MAPK and S6 was increased in the ACx and decreased in the Hi of $S 1 / 2^{-/}$compared to WT mice. Data shown are means \pm SEM (error bars), $n=4[(B, D)]$. Statistical significance $(* p<0.05)$ was assessed by two-tailed Mann-Whitney $U$ test $[(B, D)]$.

Western blot analyses with ACx samples obtained from $S 1 / 2^{-/-}$mice revealed an increase in the phosphorylation of p44/42-MAPK as well as S6 in $S 1 / 2^{-/-}$mice in the ACx compared to WT (Fig. 3.5A and $B$ ). However, in the respective Hi samples of the same mice we rather observed a reduction of p44/42-MAPK and S6 phosphorylation compared to controls (Fig. $3.5 C$ and $D$ ).

To test if the MAPK pathway activation is specific for $S 1 / 2^{-/-}$double mutant mice, we repeated the test with $\mathrm{ACx}$ and Hi samples of $S 1^{-/-}, S 2^{-/-}$and WT mice. However, analyses of the MAPK phosphorylation level in ACx and Hi samples of single mutant mice, 
revealed no change in MAPK activity in both brain regions (Fig. 3.6).
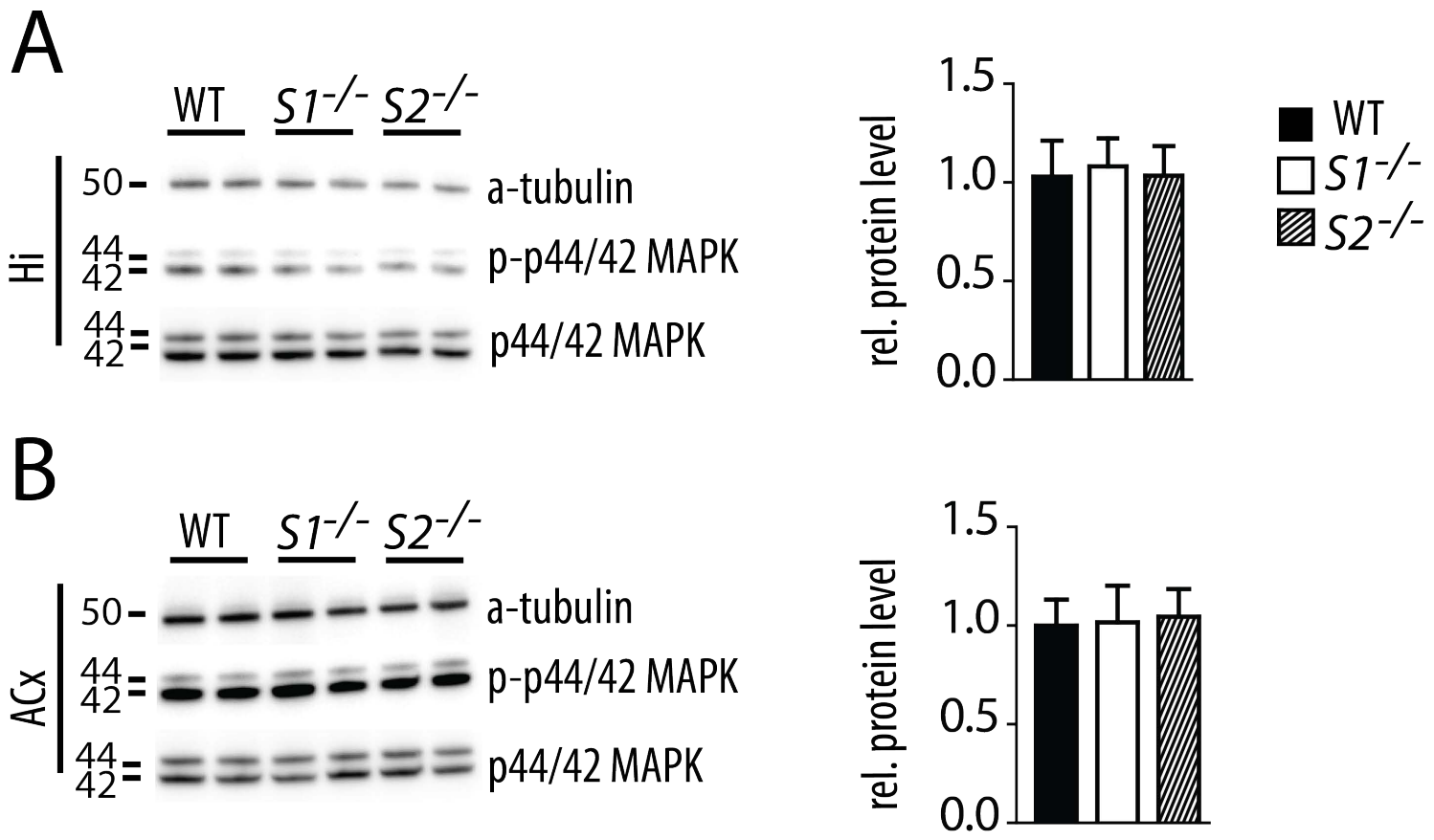

Figure 3.6: MAPK phosphorylation levels in the $\mathrm{ACx}$ and $\mathrm{Hi}$ of $\mathrm{S1}^{-/}$and $\mathrm{S2}^{-/}$single mutant mice. A) Phosphorylation levels of p44/42-MAPK in the $\mathrm{Hi}$ of $\mathrm{S}^{-1}$ and $\mathrm{S}^{-/}$mice. Quantification of phosphorylated protein signals resulted in no detectable change of p44/42-MAPK phosphorylation levels in the $\mathrm{Hi}$ of WT and $\mathrm{S1}^{-\%}$ and $\mathrm{S2}^{-}$mice. B) Phosphorylation level of p44/42-MAPK in the $\mathrm{ACx}$ of $\mathrm{S1}^{-}$and $\mathrm{S2}^{-}$mice. Quantification of phosphorylated protein signal resulted in no detectable change in p44/42-MAPK phosphorylation levels in the ACx of $\mathrm{S1}^{-/}$and $\mathrm{S2}^{--}$mice compared to WT. Data shown are means \pm SEM (error bars), $n=4$ [(B, D)]. Statistical significance $(* p<0.05)$ was assessed by two-tailed Mann-Whitney $U$ test $[(A, B)]$.

To understand if the activity of S6 can be altered as a consequence of cognitive stimulation, we decided to analyze $\mathrm{ACx}$ and $\mathrm{Hi}$ samples before fear conditioning and after the remote memory test time point. For this purpose we analyzed the number of cells that were phospho-S6 positive in the anterior cingulate cortex (ACC) area of the ACx and the CA1 region of the Hi before fear conditioning test, and after the remote memory test at day 28 (Fig. 3.7B). In agreement with published observations (Knight et al., 2012), the number of phospho-S6 positive cells was increased in the ACC of WT mice selectively upon learning, but was constitutively elevated in $S 1 / 2^{-/-}$mice at both time points. 
A

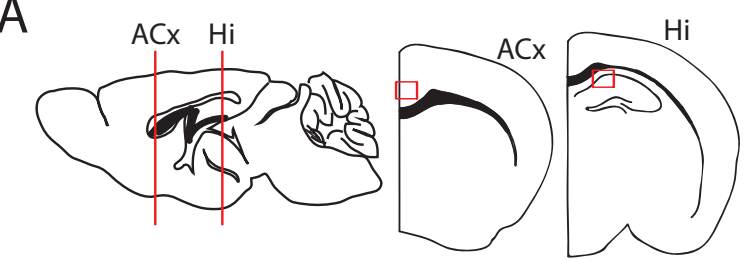

C

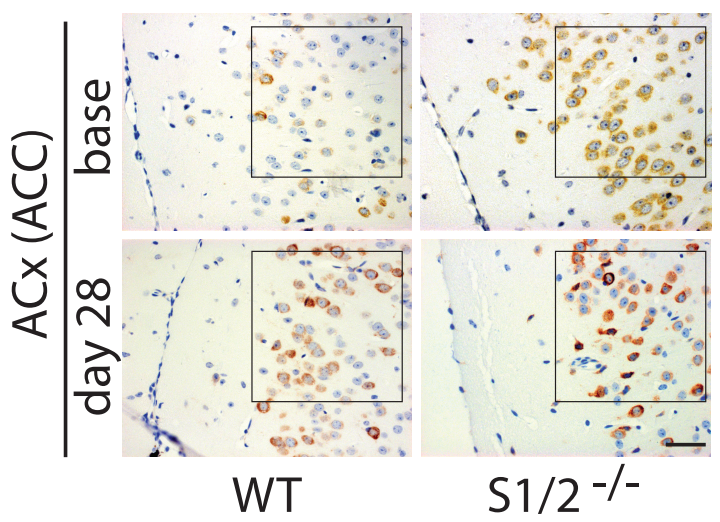

B
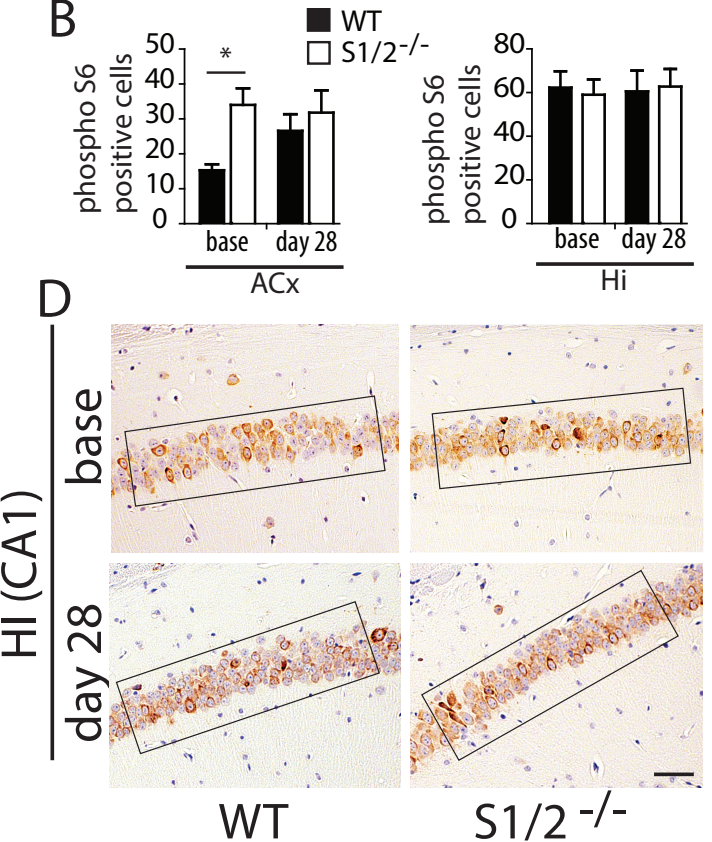

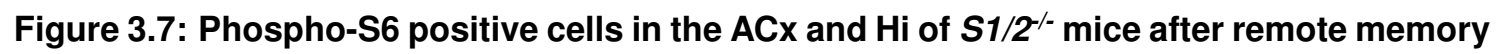

test. A) Locations of analyzed images in the ACC region of the ACx and CA1 region of the $\mathrm{Hi}$. B) Quantification of phospho-S6 immunohistochemistry performed with samples before fear conditioning (base) and immediately after remote memory test reveals constitutively increased numbers of phospho-S6 positive cells in the ACC of $S 1 / 2^{-/-}$mice independent of fear conditioning which causes an increase of phospho-S6 positive cells in WT animals. C) Representative images of the ACC of $S 1 / 2^{--}$and WT mice before fear conditioning and immediately after remote fear memory test at day 28. D) Representative images of the CA1 region of the Hi of $S 1 / 2^{-/}$and WT mice before fear conditioning and immediately after remote fear memory test at day 28 . Cells were counted within a defined identical square, whereas only cells were counted that were entirely in the square. Scale bar is $30 \mu \mathrm{m}$. Data shown are means \pm SEM (error bars), $\mathrm{n}=3-5$ [(B)]. Statistical significance $(* \mathrm{p}<0.05)$ was assessed by two-tailed Mann-Whitney $U$ test.

Next, we planned to dissect potential circadian activity patterns of the identified signaling pathway. The formation of memory in the $\mathrm{ACx}$ seems to be closely related to sleep dependent factors. Since SHARP1 and SHARP2 are transcription factors which are associated with circadian factors, we decided to analyze the observed increased p44/42-MAPK activity in a kinetic experiment at different time points of the day. To promote neuronal activity we housed the mice in cages with running wheels for 2 weeks before dissection. Western blot analyses and quantification of p44/42-MAPK phosphorylation revealed increased p44/42-MAPK activity in the ACx of $S 1 / 2^{-/-}$compared to WT at all time points 
of a zeitgeber day $3.8 A$ and $B$ ). However, when analyzing the Hi samples of $S 1 / 2^{-/-}$mice, the p44/42-MAPK activation seemed to be attenuated to the level of WT after running wheel exposure (Fig. $3.8 C$ and $D$ ).
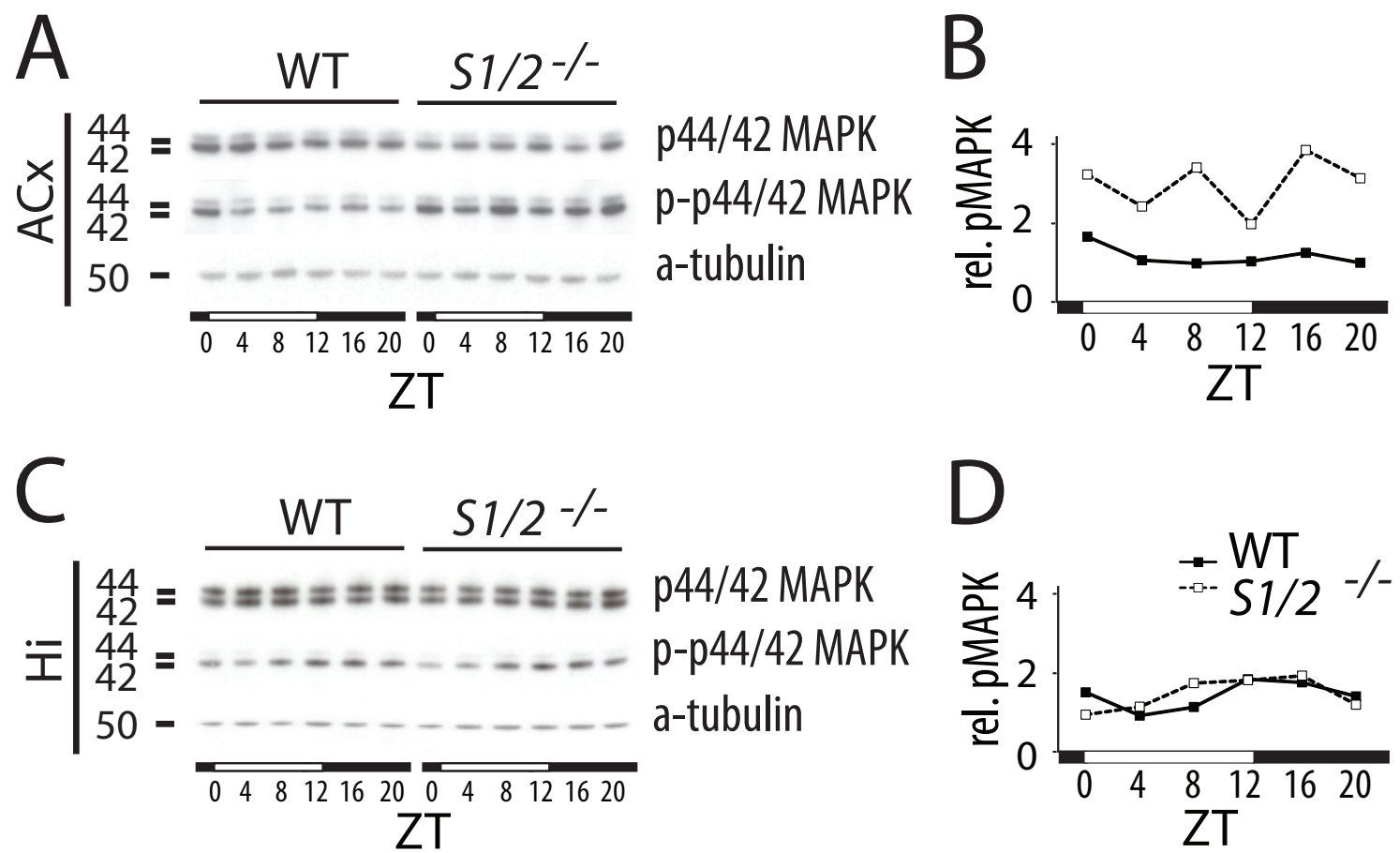

Figure 3.8: Circadian MAPK phosphorylation levels in the ACx and Hi of S1/2/- mice after exposure to running wheel. A), B) Western blot analyses of $A C x$ and Hi tissue samples prepared from WT and $S 1 / 2^{-/}$mice housed with running wheel access showing an increase of $\mathrm{p} 44 / 42$ MAPK phosphorylation at all 6 time points of Zeitgeber Time over a 24h period in the ACx (A) but not in the $\mathrm{Hi}(\mathrm{B})$ compared to WT. Statistical significance was assessed by two-way ANOVA followed by Bonferroni's post-hoc test $[(B)$ and $(D)]$. Effect of genotype $\left(F_{(1,5)}=47.83 ; p=0.001 ;[(B)]\right)$

To get insight on the general circadian activity and the neuronal activity in the ACx, we performed RNA expression analyses of Per2 and c-Fos with tissue samples that were obtained during 1 Zeitgeber day (Fig. 3.9). Although the expression of Per2 in $S 1 / 2^{-/-}$ mice seems to be regulated similarly to WT, c-Fos expression at ZT16 is decreased in $S 1 / 2^{-/-}$mice relative to $\mathrm{WT}$. 

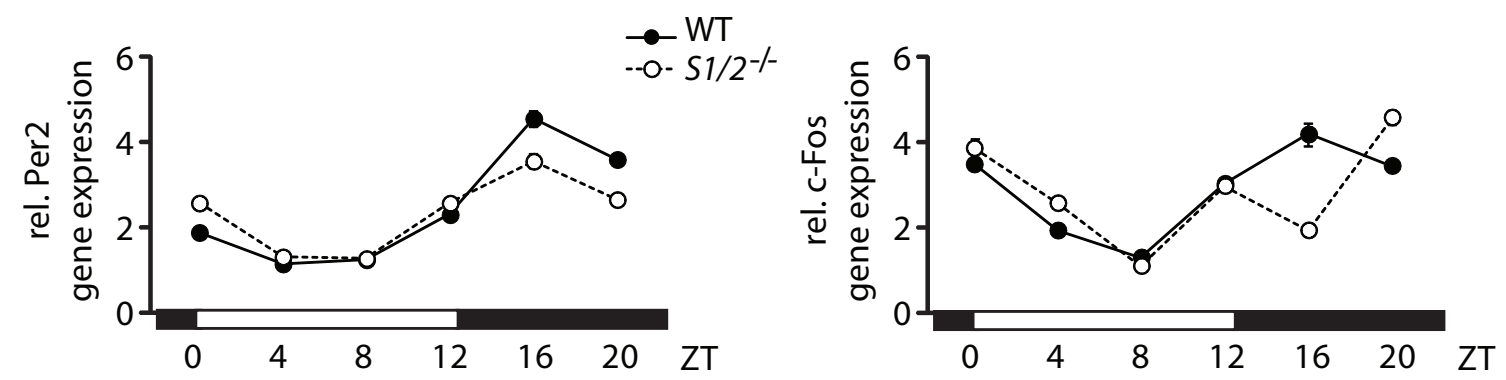

Figure 3.9: Circadian RNA expression of $c$-Fos and Per2 in the ACx of $51 / \mathbf{2}^{-/-}$mice. RNA expression Per2 and c-Fos was analyzed and normalized to Atp5b and Actb. The RNA expression of Per2 and $c$-Fos was regulated in a highly similar circadian manner, although the difference in c-Fos expression was highest at ZT16.

Thus far, we observed an elevated level of phospho-MAPK and -S6 in the ACx that correlated with the improved anterior cortex-dependent learning performance in $S 1 / 2^{-/-}$mice. Since MAPK and S6 signaling are coordinately activated upon growth factors and insulin signaling (Avruch et al., 2001; Hu et al., 2011; Seger et al., 1995; Um et al., 2006), we scanned available microarray data (Baier et al., 2014) at lowered significance thresholds for growth factor candidates with a differential expression in the cortex of $S 1 / 2^{-/-}$versus WT mice. The only relevant candidates identified were insulin-related growth factor 2 (Igf2) and the IGF binding protein 5 (Igfbp5) as potentially up- and down regulated in $S 1 / 2^{-/-}$mice. To validate these findings we used qRT-PCR to analyze differential mRNA expression in the ACx of $S 1 / 2^{-/-}$and WT mice over the complete circadian cycle and could reproduce the up- and down regulation of $I g f 2$ and $I g f b p 5$, respectively, in comparison to two housekeeping genes that did not display genotype or time dependent changes (Rpl13a and Atp5b) (Fig. 3.10A - D). Moreover, we also validated increased Igf2 and decreased Igfbp5 expression in the ACx of $S 1 / 2^{-/-}$versus WT mice (Fig. 3.10F). Studied genes were normalized to unregulated housekeeping genes (Rpl13a and Cyc1) (Fig. 3.10E). No differences in Igf2 and Igfbp5 mRNA expression was detected in the Hi (Fig. 3.10F). 

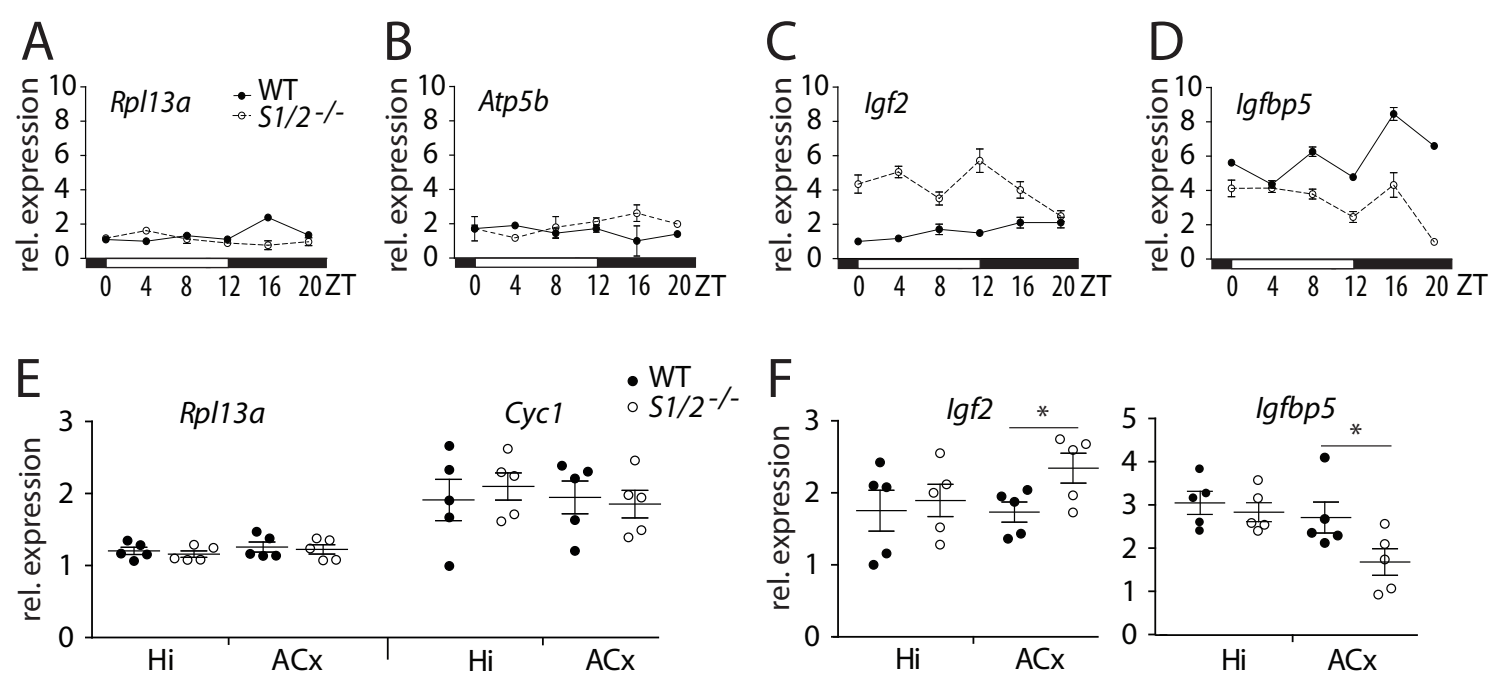

Figure 3.10: Elevated Igf2 and Igfbp5 RNA expression in the ACx of S1/2/- mice. A - D) RTPCR analyses with ACx samples obtained every 4 hours during 1 zeitgeber day from WT and $S 1 / 2^{-/}$mice housed with constant access to running wheels. A, B) Housekeeping genes used for normalization of Igf2 and Igfbp5. C) Elevated Igf2 RNA expression in the ACx of $S 1 / 2^{-/}$mice mice compared to WT mice throughout all Zeitgeber time points except ZT20. D) The level of lgfbp5 mRNA expression was reduced in the ACx of $S 1 / 2^{--}$mice compared to WT mice throughout all time points except ZT4. E, F) RNA expression analyses in ACx and $\mathrm{Hi}$ of standard housed mice. E) No genotype dependent changes were detectd in Rp/13a and Cyc1 mRNA expression levels in ACx and Hi of individual S1/2-/ mice compared to WT. F) Increased Igf2 and decreased Igfbp5 mRNA expression were detected in the ACx of individual $S 1 / 2^{-/}$mice compared to WT. No differences were observed in the Hi. Data shown are means \pm SEM (error bars), $n=3[(C)$ and $(D)] n=5[(F)]$. Statistical significance $(* p<0.05)$ was assessed by two-tailed Mann-Whitney $U$ and two-way ANOVA followed by Bonferroni's post-hoc test $[(C)$ and $(D)]$. Effect of genotype $(F(1,5)=18.47 ; p=0.0077 ;[(C)])$ and $\left(F_{(1,5)}=12.07 ; p=0.0178 ;[(D)]\right)$. 


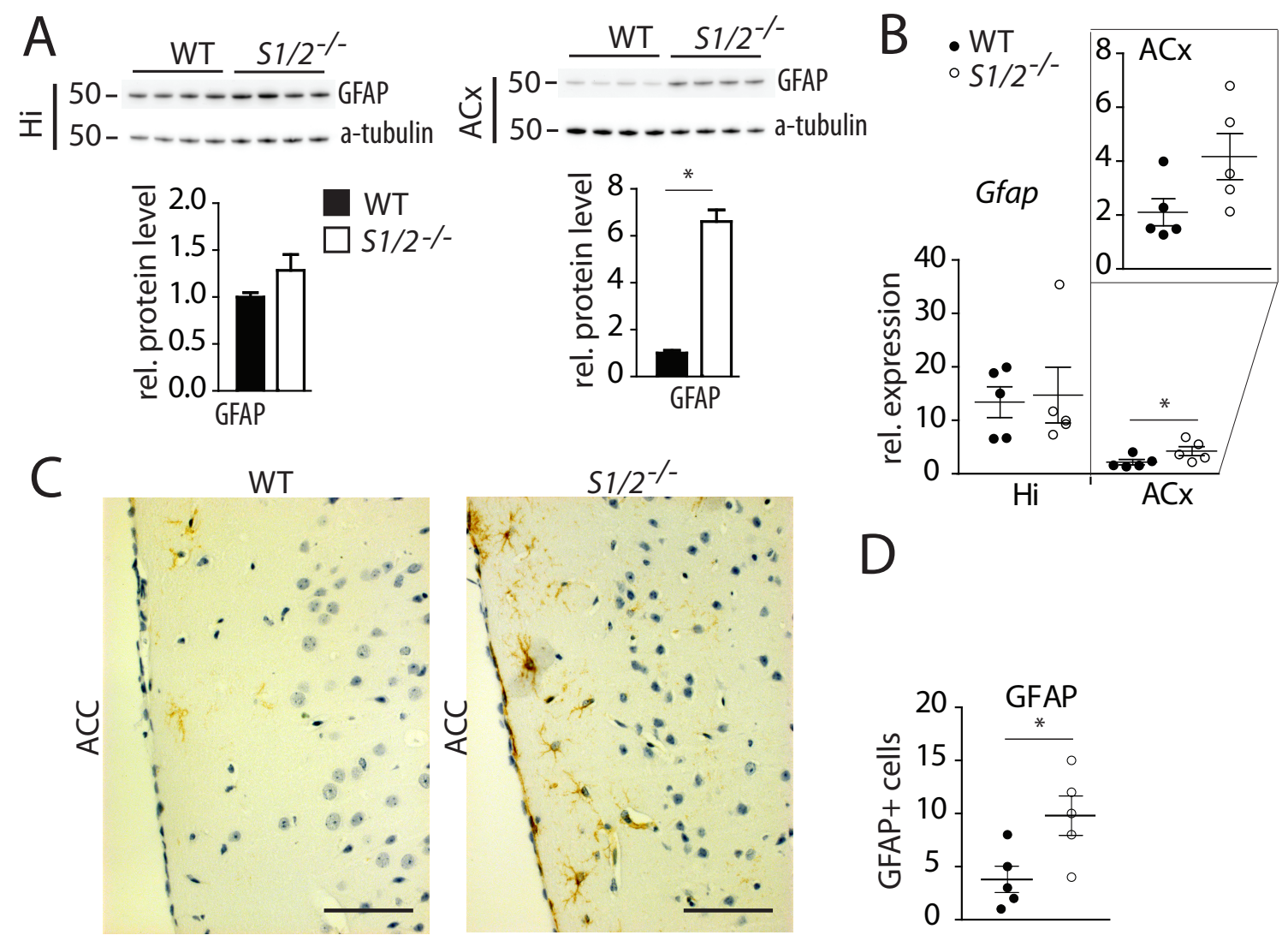

Figure 3.11: Increased GFAP RNA expression and protein abundance exclusively in the ACx of S1/2- mice. A) Western blot analyses and quantification of ACx and Hi tissue samples prepared from standard housed $S 1 / 2^{-/}$mice. An increase of GFAP protein abundance was observed in the ACx and not in $\mathrm{Hi}$ of $S 1 / 2^{-/}$mutant mice compared to WT. A) RNA expression analyses from $A C x$ and $H i$ samples obtained from standard group housed WT and $S 1 / 2^{-/}$mice. GFAP gene expression was increased in the ACx of $S 1 / 2^{-/}$mice and not altered in the Hi of these mice compared to WT. C), D) Representative figures and quantification of GFAP positive astrocytes in the ACC of WT and S1/2-- mutant mice. The number of GFAP positive astrocytes was increased in the ACC of $S 1 / 2^{--}$mice. Scale bar is $50 \mu \mathrm{m}$. Data shown are means \pm SEM (error bars), $n=4[(A)], n=5[(B)$ and $(D)]$. Statistical significance $(* p<0.05)$ was assessed by two-tailed Mann-Whitney $U$ test.

An increase in memory performance might be coupled to elevated cellular activities and therefore increased energy consumption. Due to the improved ACx based memory performance of the $S 1 / 2^{-/-}$mice we hypothesized that an improved energy demand that might be linked to an activation of astrocytes. To test our hypothesis, we analyzed the level of astrocyte activity which correlates with increased GFAP levels. We performed western blot 
analyses with $\mathrm{Hi}$ and $\mathrm{ACx}$ tissue samples from WT and S1/2-/- mutant mice (Fig. 3.11A). Quantification of these data displayed an increase of GFAP which was specific for the ACx and not observed in the Hi of $S 1 / 2^{-/-}$mice. The increase of GFAP levels in the ACx could also be confirmed on RNA level (Fig. 3.11B). In parallel, immunohistochemical analyses of the ACC of these mice, showed a significant increase of GFAP positive cells in $S 1 / 2^{-/-}$ mice compared to WT. 


\subsection{Analyses of insulin signaling in memory formation}

\subsubsection{IGF2 enhances remote long term memory formation}

Taken together, increased Igf2 levels along with a decreased expression of the IGF antagonist Igfbp5 indicated an overall elevated IGF2 signaling in the ACx of $S 1 / 2^{-/-}$mice that may explain the enhanced 'cortical' learning performance observed in $S 1 / 2^{-/-}$mice (Fig. 3.2). In consequence, we hypothesized that elevating or reducing IGF2 signaling in the ACC of WT mice should enhance and inhibit remote fear memory formation, accordingly. Therefore, we generated AAV2 constructs expressing Igf2 and Igfbp5 under the control of the CAG promoter (Niwa et al., 1991) and injected corresponding viruses including an empty control virus bilaterally into the ACC of WT mice (Fig. 3.12A). Four weeks after injection and recovery, animals were subjected to fear conditioning and were analyzed for recent and remote memory formation. Mice with virus mediated over-expression of Igf2 in the ACC displayed a slight yet significant improvement of remote fear memory formation (Fig. 3.12A). In contrast, animals that were injected with an Igfbp 5 encoding virus showed a significantly impaired remote fear memory formation compared to the control (Fig. 3.12A). However, a modulation of IGF2 signaling by exclusive Igf2/Igfbp5 expression in the ACC did not affect hippocampus dependent recent fear memory (Fig. 3.12A). Moreover, Igf2 over-expression does not alter amygdala based memory formation $3.12 C$ and D) (Phillips and LeDoux, 1992).

\subsubsection{Behavioral analyses of neuronal Igf1r/Insr double knockout mice}

The receptors that are targeted by IGF2 in the brain during memory consolidation are highly discussed. It is not clear whether an activation of the IGF1R or IGF2R is involved in the IGF2 mediated memory enhancement (Agis-Balboa et al., 2011; Chen et al., 2011). Furthermore it is thought that in the brain, mainly the INSR isoform A (INSR-A) rather than INSR isoform B (INSR-B) is expressed, which has a high affinity to IGF2 (Frasca et al., 1999; Hernández-Sánchez et al., 2008). However neuronal INSR knockout studies did not reveal changes in memory consolidation so far (Schubert et al., 2004). 
A

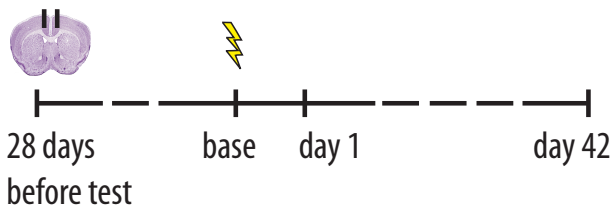

before test

\section{C}

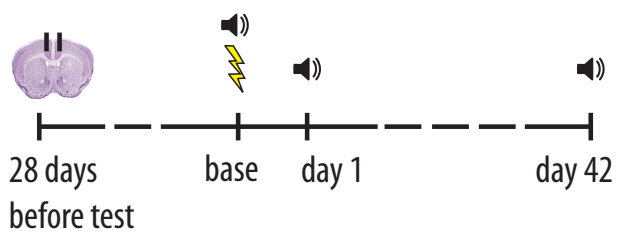

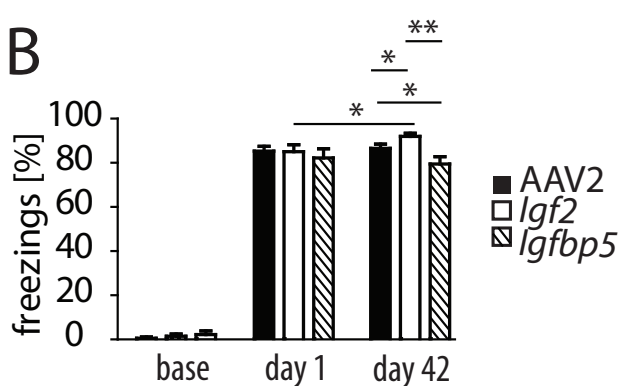

$\mathrm{D}$

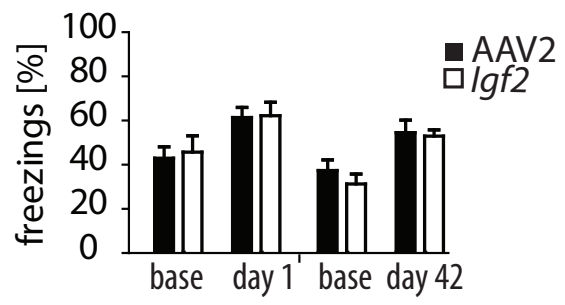

Figure 3.12: Altered remote fear memory formation by virus mediated modulation of Igf2 signaling in the ACC of WT mice. A - D) lgf2 and lgfbp5 expressing AAV2 viruses were introduced via stereotactic injection bilaterally into the ACC of wild type mice 28 days prior fear conditioning test. As a control empty AAV2 virus was injected. Remote memory was assessed 42 days after fear conditioning. A, B) Context based fear conditioning, triggered by learned context. B) No changes in recent fear memory formation were observed 1 day after fear conditioning, although remote fear memory formation (after 42 days) was significantly enhanced by expression of Igf2 and reduced by Igfbp5, respectively. C, D) Cue based fear conditioning, triggered by learned tone in new context. D) No difference could be measured in this test after lgf2 overexpression in the ACC of WT. Data shown are means \pm SEM (error bars), $n=7-19$ [(B)], $n=10-12$ $[(D)]$. Statistical significance $(* \mathrm{p}<0.05, * * \mathrm{p}<0.01)$ was assessed by two-tailed Mann-Whitney $U$ test.

Among the receptors that bind insulin-like peptides, the receptor tyrosine kinases INSR and IGF1R are best known to mediate signaling also via the ERK/MAPK pathways (Siddle, 2011). To address both receptors in order to exclude functional redundancy, we knocked out Igf1r as well as Insr in CaMKII positive neurons of the frontal cortex and hippocampus. Therefore, we generated forebrain specific neuronal Insr and Igf1r double null mutant mice by crossing Insr $/ \operatorname{Igf1} r^{f / / f l}$ mice (Brüning et al., 1998; Klöting et al., 2008) with CamKII-Cre expressing mice (Minichiello et al., 1999) to study MAPK signaling and fear memory formation. As expected by the expression pattern of CamKII, INSR and IGF1R protein levels were highly reduced in the ACx (Fig. 3.13A and $B$ ) and 
Hi (Fig. 3.13D and E) of Igf1r/InsrCaMKII-cre compared to Igf1r/Insr ${ }^{f / f l}$ mice.
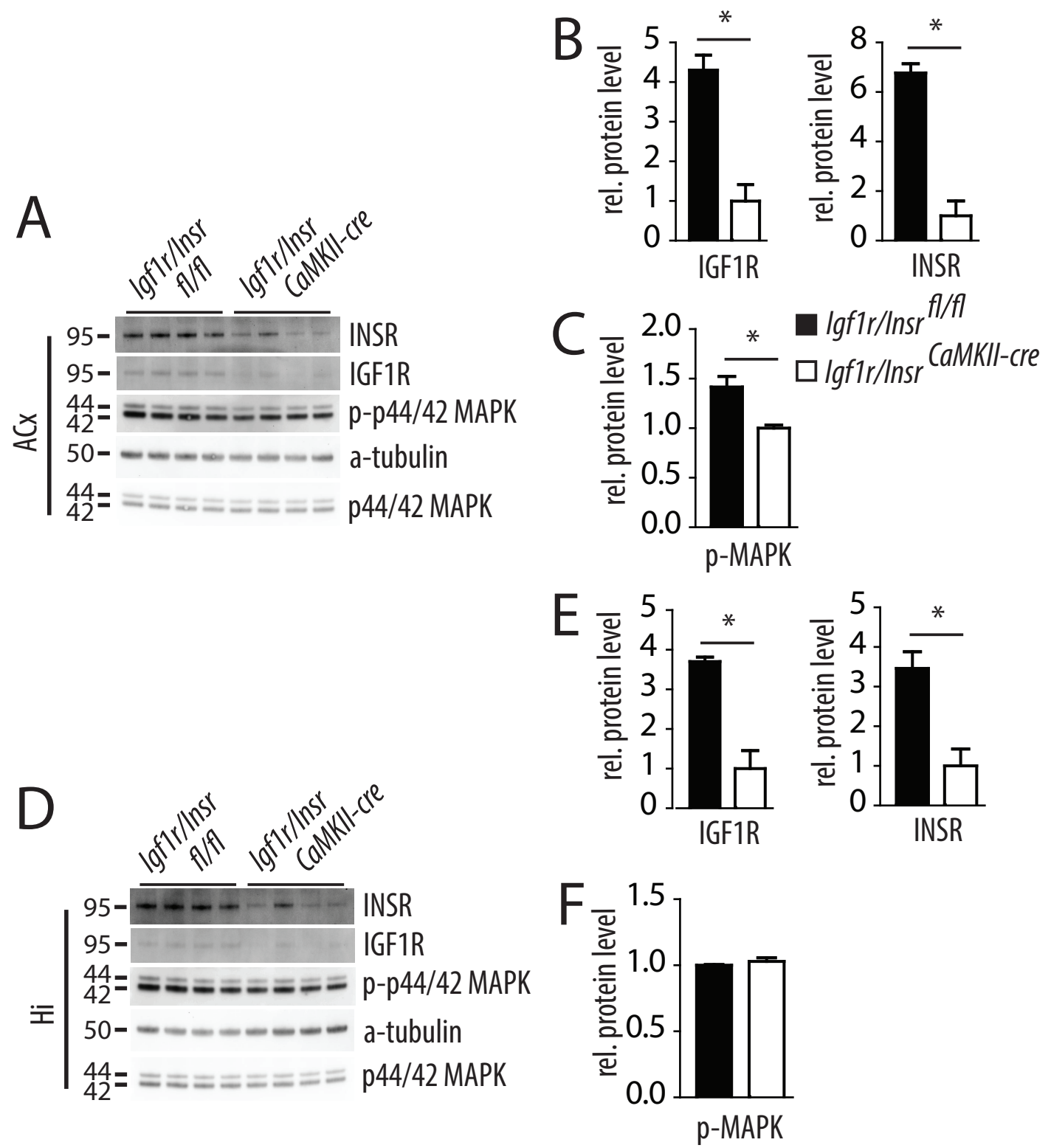

Figure 3.13: Neuronal knockout of Insr and Igf1r in the forebrain decreases MAPK activity in the ACx. A, D) Western blot analyses of samples obtained from the ACx and Hi of $/ g f 1 r / / n s r^{f / / f l}$ and Igf1r/InsrCaMKII-cre mice. B-C, E-F) Quantification of Western blot data showing reduced phosphorylation of MAPK in the ACx but not the Hi. Data shown are means \pm SEM (error bars), $n=4$ $[(\mathrm{A}-\mathrm{F})]$. Statistical significance $(* \mathrm{p}<0.05)$ was assessed by two-tailed Mann-Whitney $U$ test. 
Phosphorylation levels of p44/42-MAPK were, however, significantly reduced only in the ACx (Fig. 3.13C) but not in the Hi (Fig. 3.13D) of the double mutants.

A light
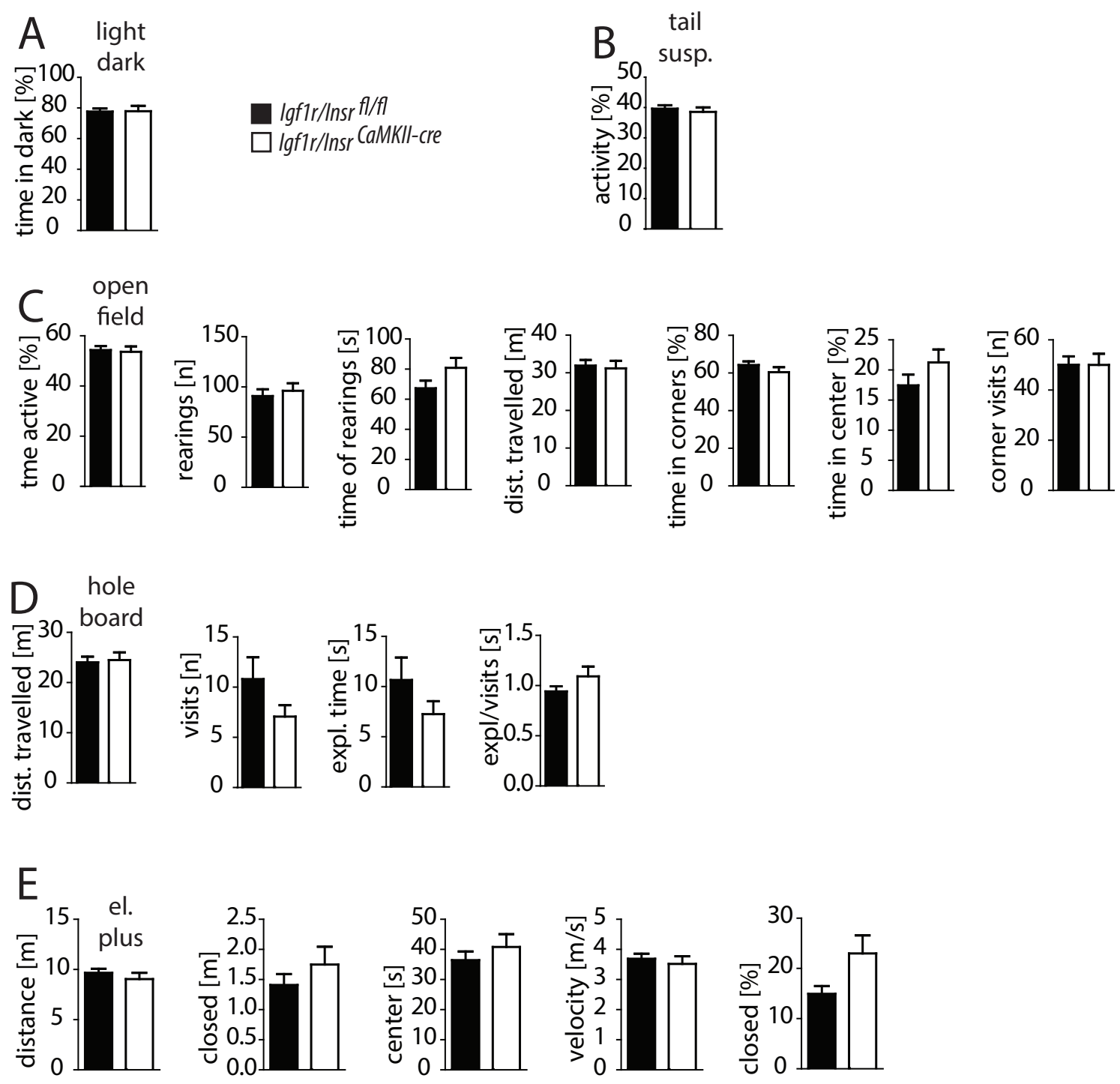

Figure 3.14: Standard behavior tests of Igf1r/Insr CaMKIl-cre mice. A - F) No significant alterations were observed in Igf1r/InsrCaMKIl-cre compared to Igf1r/Insr fl/fl. Performed experiments: A) Light/dark box test, B) Tail suspension test, C) Open field test, D) Hole board test, E) Elevated plus maze test. Data shown are means \pm SEM (error bars), $n=13-17$. Statistical significance was assessed by two-tailed Mann-Whitney $U$ test. 
We first subjected Igf1r/Insr CaMKII-cre and Igf1r/Insr ${ }^{f / f l}$ mice to a series of standard behavioral tests as light/dark preference (anxiety), tail suspension (motivation), open field (spontaneous locomotor activity and anxiety), hole board (curiosity) and elevated plus maze (anxiety). In none of the control behavior tests any altered behavior could be observed among the groups (Fig. 3.14). Thus, forebrain restricted deletion of the INSR and IGF1R in CaMKII positive neurons does not alter basic behavior.

A

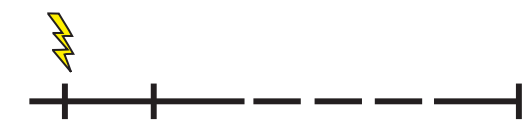

base day 1

C

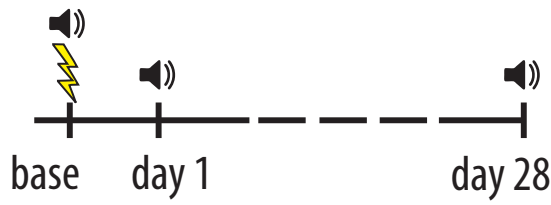

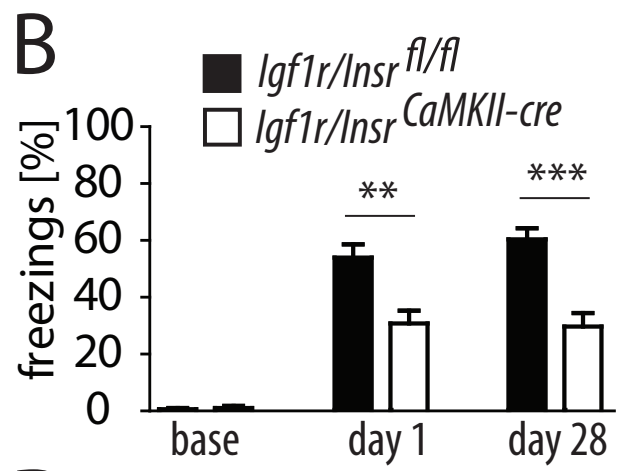

D

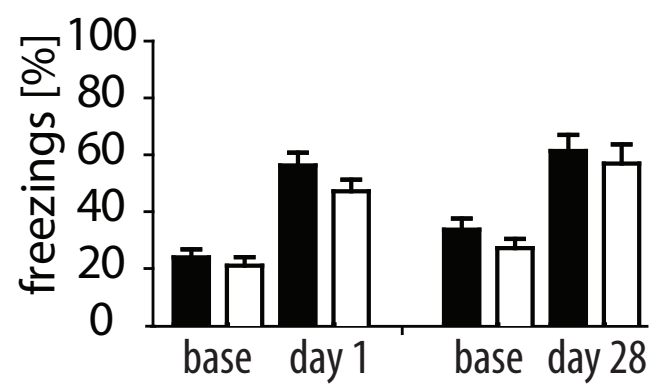

Figure 3.15: Neuronal knockout of Insr and Igf1r in the cortex and hippocampus impairs contextual fear learning. A, B) Igf1r/InsrCaMKII-cre display highly significant reduced contextual fear learning compared to $/ \mathrm{gf} / \mathrm{r} / \mathrm{Ins} \mathrm{r}^{f / / f l}$ control mice at 1 day and 28 days after conditioning. C, D) Cued fear memory was not altered in any of the tested time points. Data shown are means \pm SEM (error bars), $\mathrm{n}=13-17$ [(B, D)]. Statistical significance $(* * \mathrm{p}<0.01, * * * \mathrm{p}<0.001)$ was assessed by two-tailed Mann-Whitney $U$ test.

In order to address $\mathrm{Hi}$ and $\mathrm{ACx}$ dependent recent and remote long-term fear memory, we used the contextual fear conditioning paradigm (Fig. 3.15A). Igf1r/InsrCaMKII-cre mice tested 1 day after fear conditioning displayed significantly decreased memory performance compared to the control group. Furthermore, significance was even higher when memory 
was tested 28 days after fear conditioning (Fig. 3.15B). In addition we performed amygdala dependent cued fear memory, that is based on a learned tone (Fig. 3.15C). Cued fear memory was unaffected by a knockout of Igf1r and Insr at all time points of the test (Fig. 3.15D).

As it was shown before for neuronal Insr knockout mice under high fat diet, the double knockout mice displayed a significant gain of weight already under standard diet, which has been attributed to reduced insulin signaling (Fig. 3.16) (Brüning et al., 2000). Altogether, these data reveal that INSR and IGF1R are functionally redundant in the forebrain and the loss of both receptors impairs MAPK signaling in the ACx but not the Hi. In addition, our observations indirectly support the implication of the IGF2-INSR/IGF1RMAPK signaling axis in cortex-dependent memory consolidation processes.

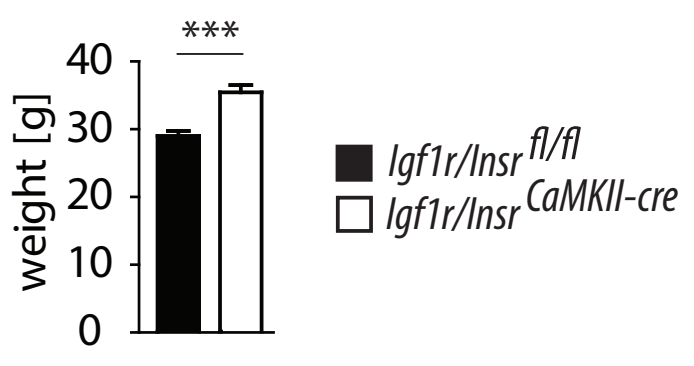

Figure 3.16: Weight analysis of Igf1r/InsrCaMKII-cre mice. Weight of Igf1r/Insr CaMKII-cre mice was significantly increased compared to control mice. Data shown are means \pm SEM (error bars), $\mathrm{n}=13-17$. Statistical significance $(* * * \mathrm{p}<0.001)$ was assessed by two-tailed Mann-Whitney $U$ test.

Finally, we were interested if we can find a correlation between astrocyte activity and memory performance in Igf1r/InsrCaMKII-cre mice. Therefore we analyzed brain tissue samples obtained from the ACx and Hi of WT and Igf1r/InsrCaMKII-cre mice and determined the level of GFAP (Fig. 3.17). Since we observed a deregulation of $\alpha$-tubulin as a consequence of neuronal Igf1r/Insr knockout, we decided to quantify to the total amount of p44/42-MAPK which seems to be unregulated. Potentially, $\alpha$-tubulin could not be used to normalize and quantify our data, yet tubulin mRNA was previously reported to be stabilized by insulin and IGF1 signaling during neurite formation (Fernyhough et al., 1989). After quantification of detected GFAP we observed no change in the ACx, however in the Hi GFAP was significantly decreased in Igf1r/InsrCaMKII-cre mice compared to control (Fig. 3.17B and $E$ ). Quantification of $\alpha$-tubulin revealed a significant down reg- 
ulation in the ACx and in parallel a significant up regulation in the Hi (Fig. 3.17C and $F$ ).

A

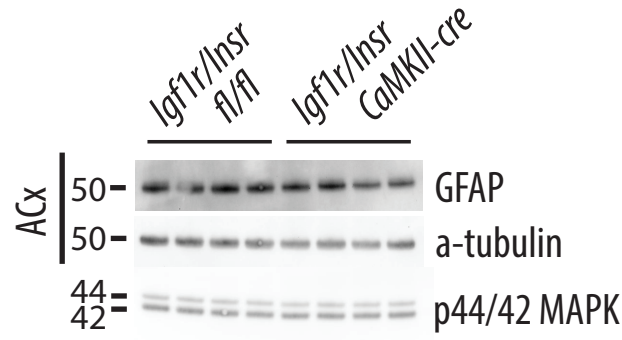

$\mathrm{D}$

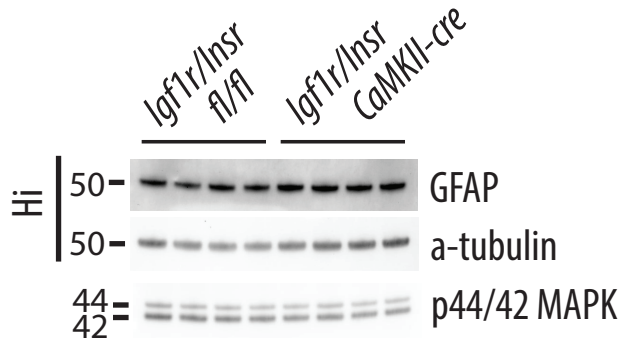

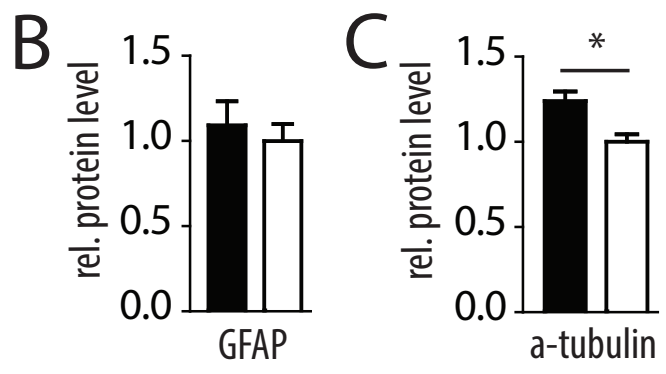

- lgfir/Inst $f / f f$

口Igf1r/Insr CaMKII-cre
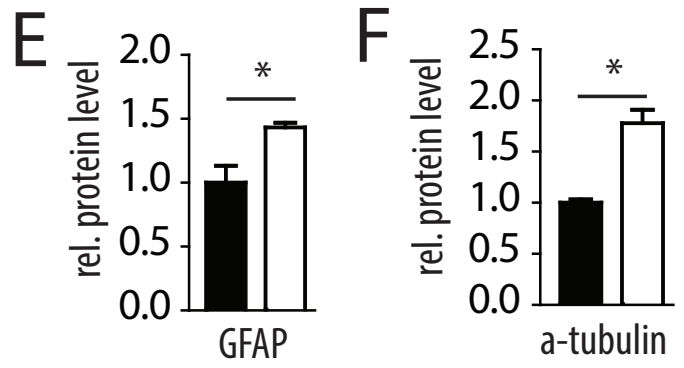

Figure 3.17: GFAP and $\alpha$-tubulin protein deregulation in the $\mathrm{ACx}$ and $\mathrm{Hi}$ as a consequence of neuronal Insr and Igf1r knockout in the forebrain of mice. A, D) Western blot analyses

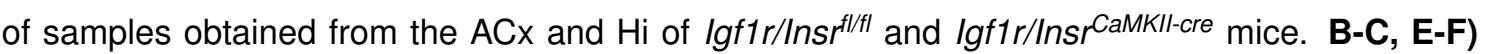
Quantification of Western blot data showing increased GFAP level in the Hi but not the ACx. In parallel, $\alpha$-tubulin was decreased in the ACx and increased in the Hi of Igf1r/Insr CaMKII-cre compared to control mice. Protein data were quantified to total amount of detected p44/42-MAPK. Data shown are means \pm SEM (error bars), $n=4[(A-F)]$. Statistical significance $(* p<0.05)$ was assessed by two-tailed Mann-Whitney $U$ test. 


\subsection{Behavioral and molecular analyses of aged $S 1 / 2^{-/}$mice}

\subsubsection{Early signs of aging in $S 1 / 2^{-/}$mice}

To investigate long-term effects of SHARP1 and SHARP2 deficiency and coupled Igf2 signaling, we studied aged WT and $S 1 / 2^{-/-}$mice. For this purpose we housed animals for 20 months in standard group cages. Between 6 months and 15 months of age weight was analyzed every month. We observed a significant decrease of weight in old adults and aged animals (Fig. 3.18B). In contrast, at an earlier age of 12 weeks no difference in weight of $S 1 / 2^{-/-}$mice could be observed compared to control mice (Fig. 3.18A). The analyses of death events revealed a significantly increased mortality rate of aged $S 1 / 2^{-/-}$animals compared to control (Fig. 3.18C).
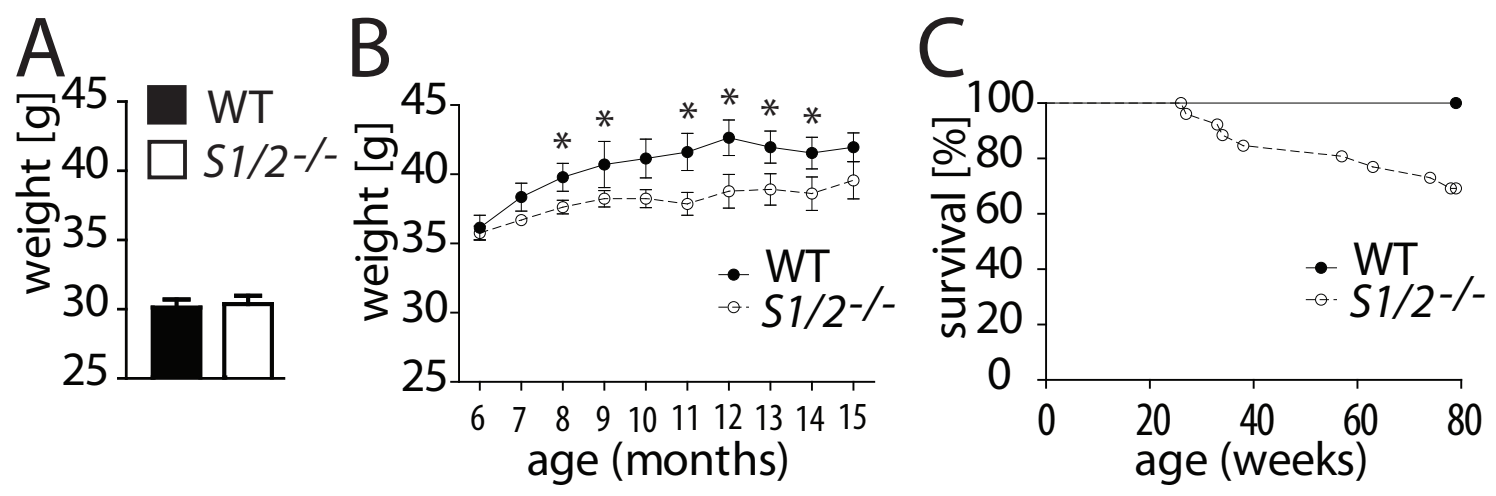

Figure 3.18: Aging related decrease in weight and reduced life span in old $S \mathbf{1} \mathbf{2}^{-/}$mice. $A$, B) Weight of $S 1 / 2^{--}$mice at 12 weeks of age (A) and between 8 and 15 months of age (B). C) Furthermore survival analyses of aged mice until the age of 20 months, revealed a significantly reduced life-span of $S 1 / 2^{-/}$mice compared to WT. Data shown are means \pm SEM (error bars), $n=8$ [(A)], $n=13-14[(B)], n=26-30[(C)]$. Statistical significance $(* p<0.05)$ was assessed by two-tailed Mann-Whitney $U$ test, Log-rank test $[(B)]$ and two-way ANOVA followed by Bonferroni's post-hoc test $[(A)]$. Effect of genotype $\left(F_{(1,25)}=3.51 ; p=0.0729 ;[(A)]\right)$. Log-rank analysis showed that the survival curves for the WT and $S 1 / 2^{--}$mice differed significantly $(* p<0.05)$.

\subsubsection{Behavioral analyses with aged $S 1 / 2^{-/}$mice}

Next, we planned to study ACx and Hi dependent memory performance in aged WT and $S 1 / 2^{-/-}$mice. First, we analyzed these mice in a water maze experimental setup. However, the aged $S 1 / 2^{-/-}$mutant animals were not remembering the platform position at all when 
testing for 2 days, 4 trials each day (Fig. 3.19A). At the first day of learning as well as on the second day of learning, S1/2-/- mutant mice found the platform with the same delay. In contrast the analyzed aged WT mice found the platform significantly faster with repeated trials at day 1 , and showed constantly increased memory of the platform position at day 2. To further study the vision ability of the aged $S 1 / 2^{-/-}$and WT mice, we performed a visual cliff test (Fig. 3.19B). Here, we analyzed the time mice spent on the opaque platform and not on the transparent platform. Mice generally prefer the opaque platform, since the transparent part is pretending depth. $S 1 / 2^{-/-}$mutant mice did not distinguish between opaque and transparent platform as WT mice. This suggests reduced sight of the aged $S 1 / 2^{-/-}$mutant mice, most probably because of observed increased incidence of cataracts, and has to be taken into account in further tests. Since the water maze test is highly dependent on functional vision of the animals we did not proceed with this test.

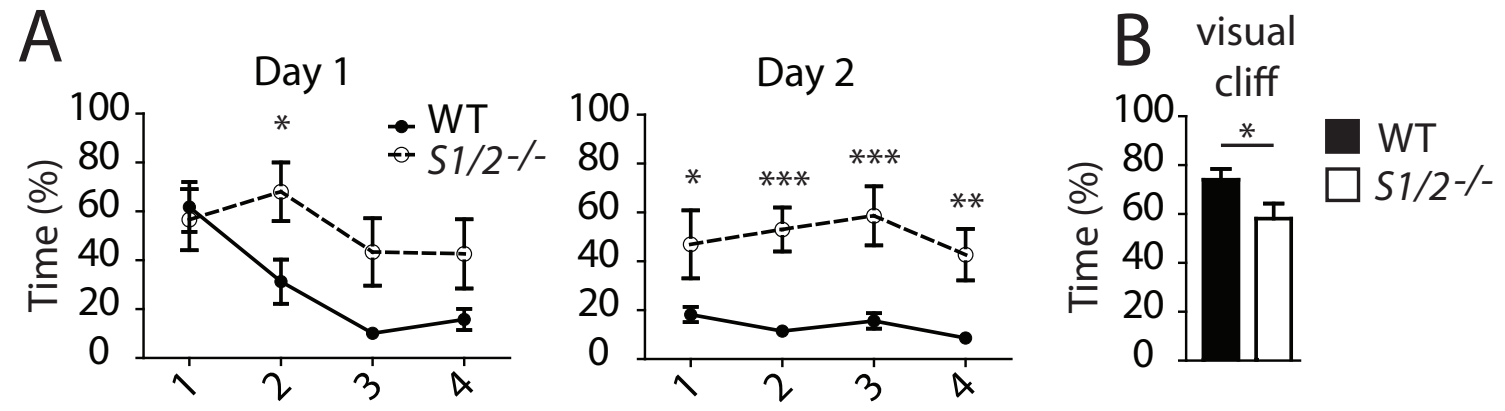

Figure 3.19: Reduced vision in aged S1/2/- mice. A) First 2 days of learning phase in water maze experiment. $S 1 / 2^{-/}$mice are not able to learn platform position as WT. A) Visual cliff test to analyze vision ability of $S 1 / 2^{--}$mice. Here, the time that animals prefer the opaque platform to the transparent platform was tested. $S 1 / 2^{-/}$mice seem to prefer the opaque platform significantly less compared to WT mice. Data shown are means \pm SEM (error bars), $n=9-12$ [(A)], $n=12-13$ [(B)]. Statistical significance $(* \mathrm{p}<0.05, * * \mathrm{p}<0.01, * * * \mathrm{p}<0.001)$ was assessed by two-tailed Mann-Whitney $U$ test $[(B)]$ and two-way ANOVA followed by Bonferroni's post-hoc test $[(A)]$. Effect of genotype $\left(F_{(1,18)}=8.26 ; p=0.0101 ;\left[(A)\right.\right.$, Day 1]), $\left(F_{(1,18)}=36.95 ; p=0.0001 ;[(A)\right.$, Day 2]).

To address Hi based recent and $\mathrm{ACx}$ based remote long-term memory performance in aged $S 1 / 2^{-/-}$mice, we planned to perform a contextual fear conditioning test (Fig. 3.20A). To avoid influence of vision differnces we performed fear conditioning in complete darkness. Here, $S 1 / 2^{-/-}$mutant mice that were analyzed 1 day after fear conditioning (Hi-dependent) 
remembered the shock significantly less compared to WT (Fig. 3.20B). However, no difference in memory performance could be observed after 28 days (ACx-dependent). To control for further fear memory related brain regions, we used a tone-dependent fear conditioning paradigm (amygdala-based) (Fig. 3.20C). Here the mice are tested in a new context. As a trigger for memory activation a tone was used, that was associated with the shock at the previous conditioning phase. In contrast to the context based fear conditioning, tone based fear conditioning did not reveal any significant difference between WT and $S 1 / 2^{-/-}$ mutant animals at any of the tested time points. Altogether it seems that only Hi based fear memory is reduced in aged $S 1 / 2^{-/-}$mice compared to WT. At the same time, the ACx dependent remote memory of $S 1 / 2^{-/-}$mice is attenuated to the level of WT mice after aging.

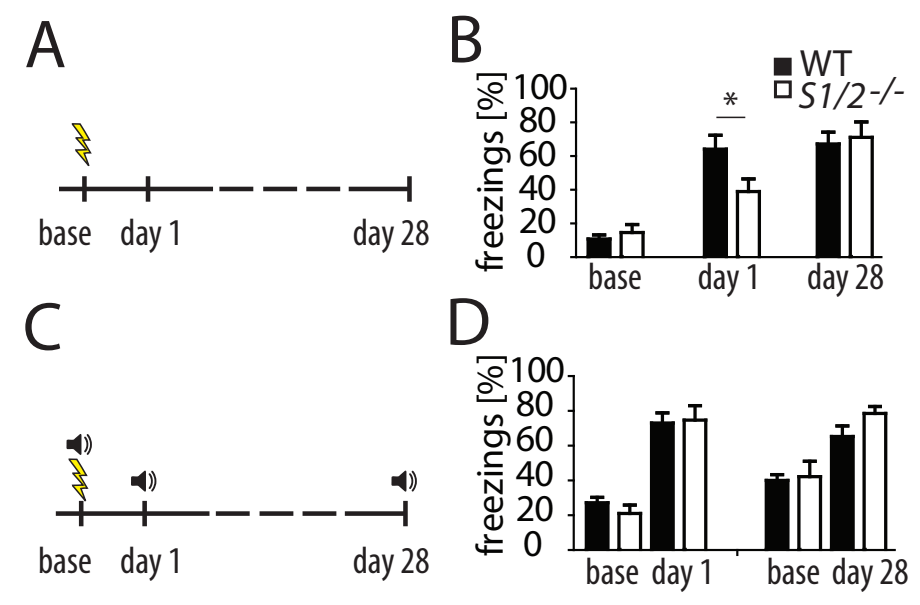

Figure 3.20: Reduced memory performance exclusively in $\mathrm{Hi}$ dependent tasks in aged S1/2/- mice. A) Context dependent fear conditioning with tests at day 1 and day 28 after conditioning in the same context. B) $S 1 / 2^{-/}$mice show reduced memory when tested at next day. However, no difference to WT could be observed when tested 28 days after conditioning. C) Tone dependent fear conditioning paradigm with memory test at day 1 and day 28 after conditioning in a new context. D) No differences in tone dependent memory performance could be observed in any of the testing time points. Data shown are means \pm SEM (error bars), $n=10-12$ [(B) and (D)]. Statistical significance $(* p<0.05)$ was assessed by two-tailed Mann-Whitney $U$ test $[(B)$ and (D)]. 
3.3.3 Molecular analyses of $\lg f 2$ and MAPK in aged $S 1 / 2^{-/}$mice
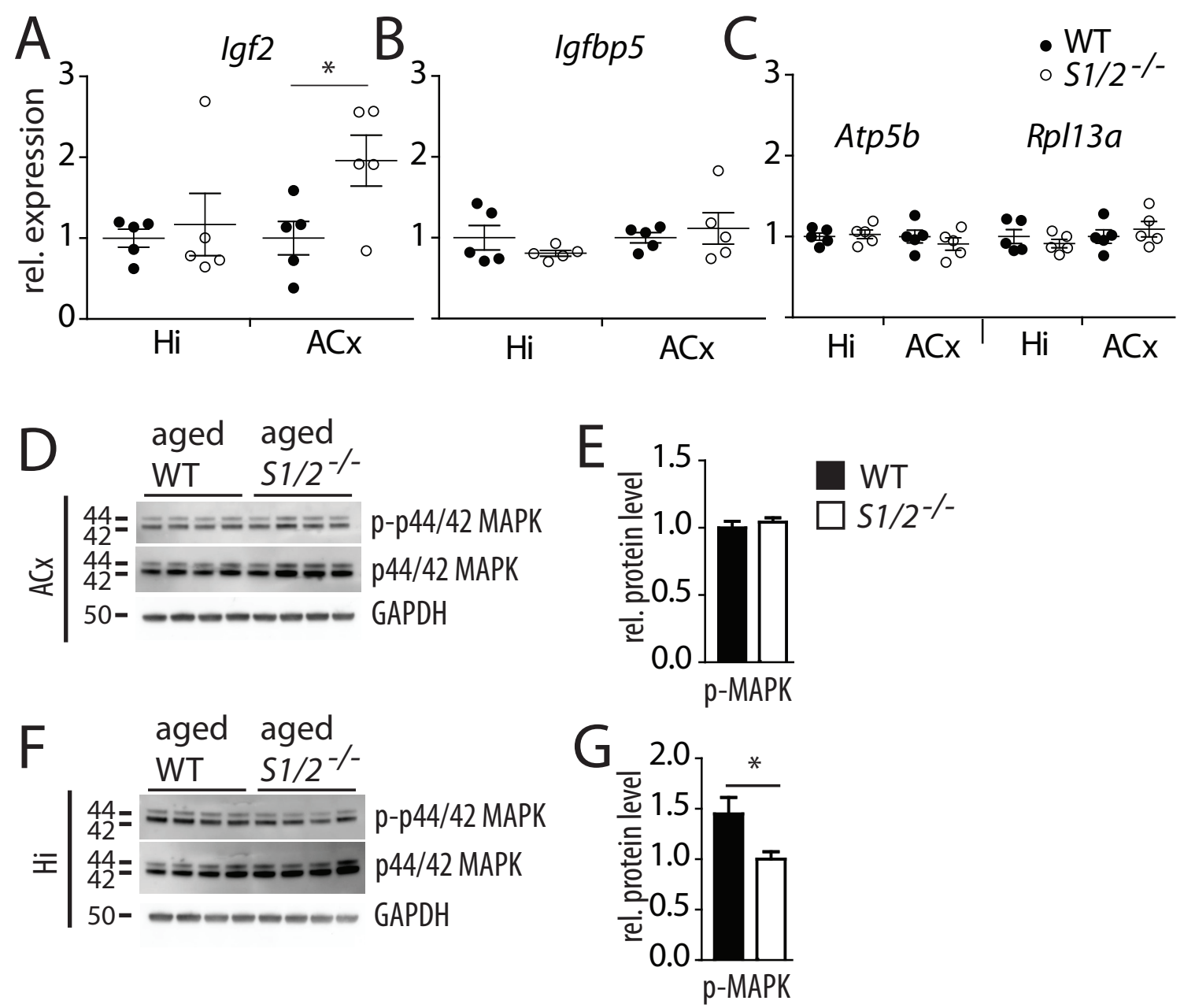

Figure 3.21: Increased Igf2 expression in the ACx and decreased MAPK activity in the Hi of aged S1/2 ${ }^{-/}$mice. A) - C) RTPCR analyses of ACx and Hi samples from aged WT and $S 1 / 2^{-/}$mice. A) Igf2 expression levels were increased only in the ACx of aged $S 1 / 2^{-/}$mice, and not in the hippocampus. B) No difference could be observed in lgfbp5 expression in any of the analyzed tissues. C) Applied housekeeping genes. D) Western Blot analyses of ACx samples from aged WT and $S 1 / 2^{-/}$mice. E) Quantification of ACx western blot analyses. No difference could be observed in phosphorylation levels of p44/42 MAPK of aged $S 1 / 2^{-/}$mice compared to WT. F) Western Blot analyses of Hi samples from aged WT and $S 1 / 2^{-/}$mice. G) Quantification of $\mathrm{Hi}$ western blot analyses. Phosphorylation levels of p44/42 MAPK were significantly decreased in the $\mathrm{Hi}$ of aged S1/2-- mice compared to WT. Data shown are means \pm SEM (error bars), $n=5$ $[(A)-(C)], n=4[(E)$ and $(G)]$. Statistical significance $(* p<0.05)$ was assessed by two-tailed Mann-Whitney $U$ test $[(A)-(C),(E)$ and $(G)]$. 
To compare the role of Igf2 expression and p44/42 MAPK activity in aged mice to the context memory performance of $S 1 / 2^{-/-}$mice, we analyzed the $\mathrm{ACx}$ as well as $\mathrm{Hi}$ of aged WT and mutant animals. First we analyzed RNA expression levels of Igf2 and Igfbp5 in aged WT and $S 1 / 2^{-/-}$mice. In these analyses we observed an increase of Igf2 expression exclusively in the ACx of aged $S 1 / 2^{-/-}$mice (Fig. 3.21A). No difference in Igf2 expression could be observed in the Hi of these mice. In parallel, the expression levels of Igfbp 5 in the ACx and Hi of aged $S 1 / 2^{-/-}$mice were on the same level as WT (Fig. 3.21B). In young adult mice, the activity level of p44/42 MAPK seemed to correlate directly to the observed memory performance of $S 1 / 2^{-/-}$mice. To study p44/42 MAPK activity in aged mice we performed western blot analyses and quantified the p44/42 MAPK phosphorylation levels (Fig. 3.21D - G). Quantification of phospho-p44/42 MAPK in the ACx did not reveal any difference to WT mice (Fig. 3.21E). Though, analyses of phosho-p44/42 MAPK levels in the Hi indicate a significant decrease of p44/42 MAPK activity in the Hi of aged $S 1 / 2^{-/-}$ mice (Fig. 3.21G). 

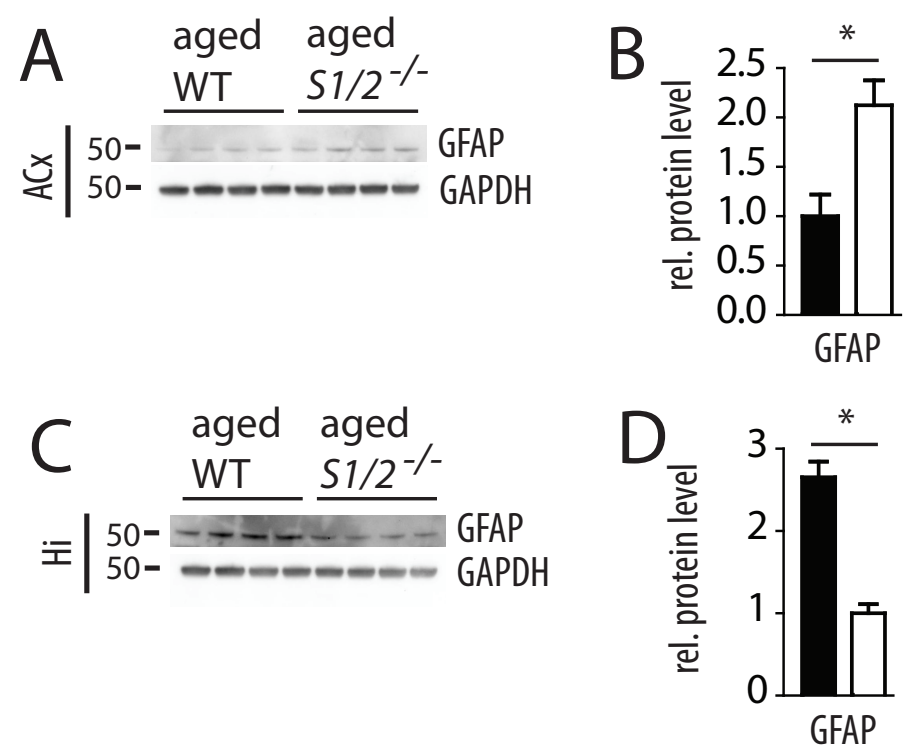

Figure 3.22: GFAP up regulation in ACx and down regulation in $\mathrm{Hi}$ of aged $\mathrm{S1}^{-/-}$mice. A, C) Western blot analyses of samples obtained from the ACx and Hi of GFAP up regulation in $\mathrm{ACx}$ and down regulation in $\mathrm{Hi}$ of aged $S 1 / 2^{-/}$mice. B, D) Quantification of Western blot data showing increased GFAP level in the ACx. In in the $\mathrm{Hi}$ of aged $S 1 / 2^{--}$mice, however, GFAP was significantly decreased. Protein data were quantified to total amount of detected GAPDH. Data shown are means \pm SEM (error bars), $n=4[(A-D)]$. Statistical significance $(* p<0.05)$ was assessed by two-tailed Mann-Whitney $U$ test.

After detected drastic up regulation of GFAP, specific for the ACx region of young adult $S 1 / 2^{-/-}$mutant mice (Fig. 3.11), we were interested if this is stable throughout later lifetime of these mice. Therefore we analyzed brain tissue samples from the Hi and ACx of WT and $S 1 / 2^{-/-}$mice (Fig. 3.22A and $C$ ). GFAP protein signals obtained by western blot analyses were quantified to the total amount of GAPDH (Fig. 3.22B and D). Quantification of GFAP revealed an up regulation of GFAP which was specific for the ACx region of aged $S 1 / 2^{-/-}$mutant mice. Furthermore, in the Hi of aged $S 1 / 2^{-/-}$mice, a reduction of GFAP could be observed. 


\subsection{RNA expression analyses in the ACC of human schizophrenic patients}

\subsubsection{Neuronal activity and clock genes}

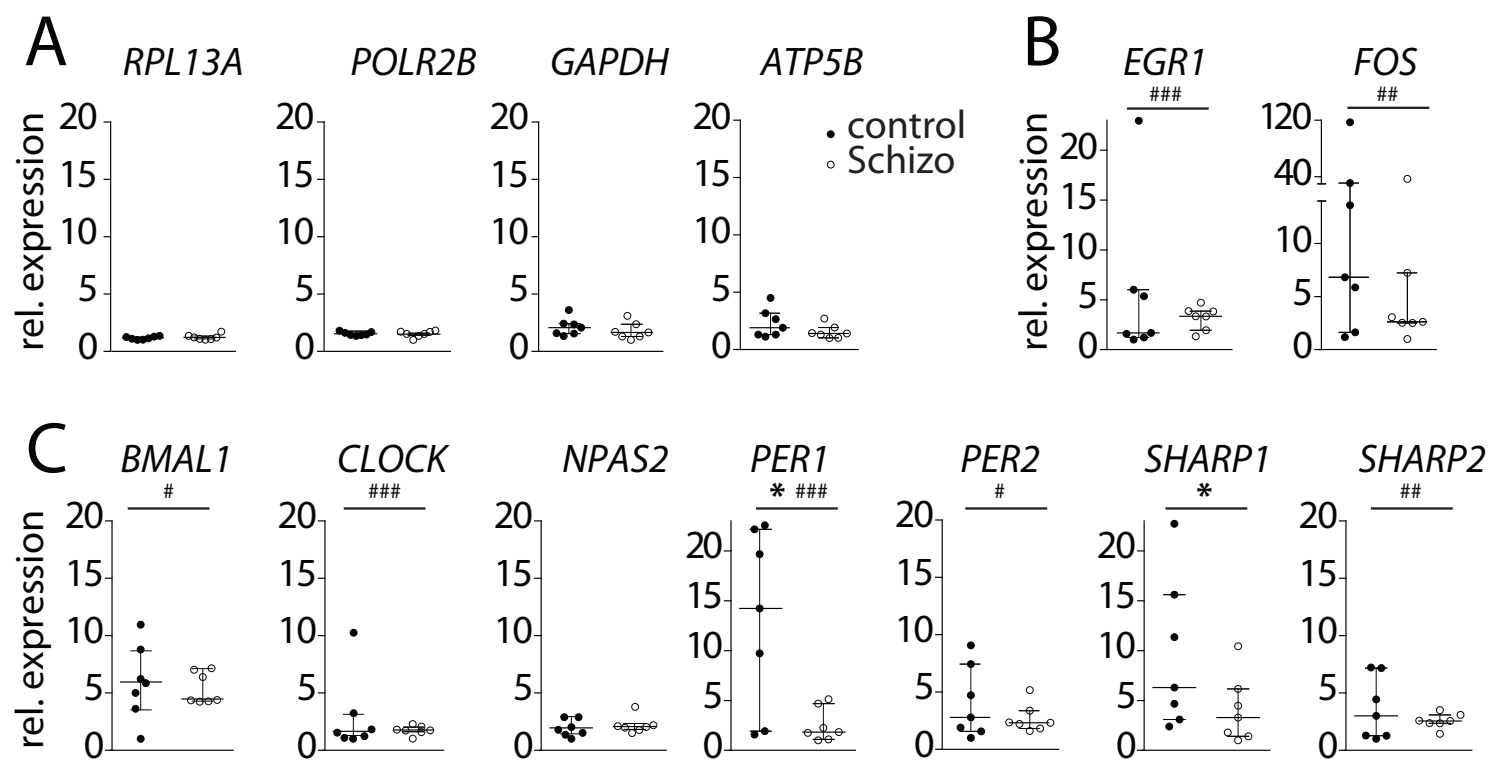

Figure 3.23: RNA expression analyses of human ACC samples from schizophrenic patients. A) Housekeeping genes used for RTPCR analyses of ACC samples from human schizophrenic and control patients. B) RNA expression analyses of immediate early genes EGR1 and FOS. No significant difference could be observed compared to the control patients, however schizophrenic patients revealed a reduced variance in expression levels compared to the control group. C) Among the analyzed clock related transcription factors BMAl1, CLOCK, NPAS2, PER1, PER2, SHARP1 and SHARP2 only PER1 and SHARP2 were significantly deregulated in the ACC of schizophrenic patients. In addition we observed reduced variance of BMAL1, CLOCK, PER1, $P E R 2$ and SHARP2 expression levels. Data shown are means \pm SEM (error bars), $n=7$. Statistical significance $(* \mathrm{p}<0.05)$ was assessed by two-tailed Mann-Whitney $U$ test and $F$ test was applied to compare variance ( $\# \mathrm{p}<0.05$, \#\# $\mathrm{p}<0.01$, \#\#\# $\mathrm{p}<0.001$ ).

Schizophrenia, bipolar disorder and Alzheimer's disease are associated with gene expression changes in the PFC (Vawter et al., 2002; Kim et al., 2010; Mirnics et al., 2000; Bossers et al., 2010). In order to stuy SHARP1 and SHARP2 genes in the context of PFC associated psychiatric diseases, we analyzed brain samples of human schizophrenic patients on 
RNA level. Moreover, we studied the expression of circadian clock factors and neuronal activity genes.

As a part of the prefrontal cortex, we analyzed the ACC of schizophrenia patients on RNA expression level. Samples were obtained post-mortem and provided by Dr. Andrea Schmitt (BrainNet Europe). Several housekeeping genes were tested and the 2 genes RPL13A and POLR2B were selected for normalization (Fig. 3.23A). To study the general state of neuronal activity in the ACC of schizophrenic patients, we were interested in expression levels of the immediate early genes EGR1 and FOS (Fig. 3.23B) (Dragunow and Faull, 1989; Guzowski et al., 2001). Although no significant difference was detected in expression levels, we could observe a reduction in the variance of expression levels for schizophrenic patients compared to control patients. Furthermore we analyzed the expression of core clock transcription factors BMAL1, CLOCK, NPAS2, PER1 and PER2 as well as the circadian modulators SHARP1 and SHARP2. Among the studied genes, the expression levels of SHARP1 and PER1 were significantly reduced in the ACC of schizophrenic patients. In parallel we could observe a significant reduction in gene expression variances for BMAL1, CLOCK, PER1, PER2 and SHARP2 in the ACC of the analyzed schizophrenic individuals.

\subsubsection{ERBB4 variants}

During the past years increasing evidence suggested an important role of ERBB4 receptor and its ligand NRGI in schizophrenia (Silberberg et al., 2006; Norton et al., 2006; Nicodemus et al., 2006). ERBB4 is mainly expressed in interneurons (Neddens and Buonanno, 2010). There are 4 major isoforms known for ERBB4; however, it is not understood so far in which extend particular isoforms might be involved in the disease of schizophrenia (Corfas et al., 2004; Mei and Xiong, 2008). These splice variants are JMa (exon 16) and $\mathrm{JMb}$ (exon15) which are variants of the extra-cellular juxtamembrane (JM) domain or variants of the C-terminal cytoplasmic (CYT) tail that differ in the sequence of 16 amino acids of exon 26, CYT1 (with exon 26) and CYT2 (without exon 26) (Junttila et al., 2000, 2003). So far CYT1 and JMa have been reported previously to be expressed at higher levels in schizophrenic patients (Law et al., 2007; Silberberg et al., 2006). CYT1 is known to activate PI3K signaling, and CYT2 activates the MAPK pathway (Kainulainen et al., 2000; Junttila et al., 2000). To distinguish between these 4 isoforms, we designed specific primers that exclusively recognized the respective addressed isoform. In respect to 
CYT1/CYT2 isoforms, RNA expression analyses by RTPCR identified a highly significant over-expression of CYT2 in the ACC of the schizophrenic patients compared to control patients (Fig. 3.24A). In our studies no significant change of $C Y T 1$ could be discovered from health to disease status.

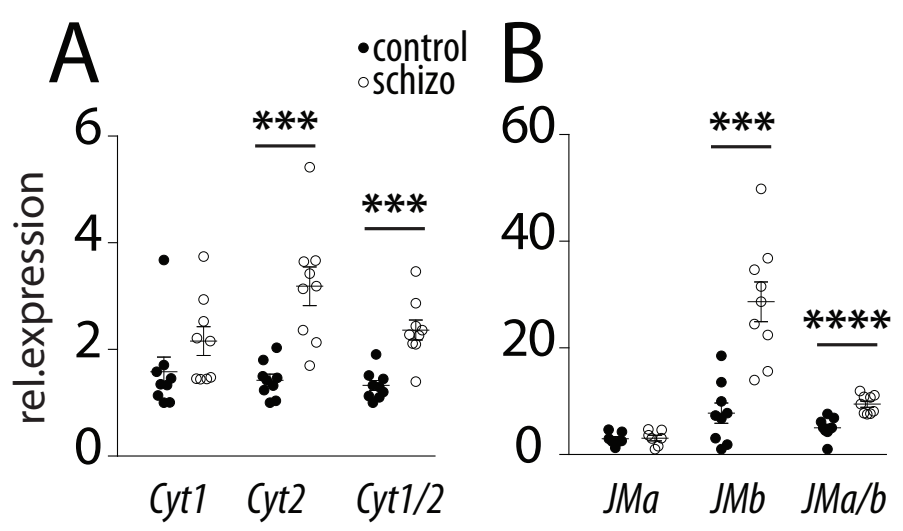

Figure 3.24: Expression levels of ErbB4 splice variants in the ACC of human schizophrenic patients. RNA isolated from the ACC of postmortem human control patients and schizophrenic patients was anaysed by RTPCR. Primers were selected to exclusively detect respective CYT1, CYT2, JMa and JMb splice variants. A) CYT1 and CYT2 RNA expression levels in the ACC of control and schizophrenic patients. CYT2 RNA expression was significantly increased in schizophrenic patients. Primer pairs that were specific for the CYT1 splicing variant did not reveal any significant change in expression levels. In addition non selective primers detecting both variants of CYT1 and CYT2 detected significant increase of a sum of JMa and JMb splice variants of ERBB4 expression in the ACC schizophrenic patients. A) JMa and JMb RNA expression levels in the ACC of control and schizophrenic patients. JMb RNA expression was significantly increased in schizophrenic patients. Primer pairs that were specific for the JMa splicing variant did not reveal any significant change in expression levels. In addition non selective primers detecting both variants of $J M a$ and $J M b$ detected significant increase of a sum of $J M a$ and $J M b$ splice variants of ERBB4 expression in the ACC schizophrenic patients. POLR2B and RPL13A. Data shown are means \pm SEM (error bars), $\mathrm{n}=9$. Statistical significance $(* * * \mathrm{p}<0.001, * * * * \mathrm{p}<0.0001)$ was assessed by two-tailed Mann-Whitney $U$ test.

As a control RTPCR with the same cohort was performed with pan primers that recognize both CYT1 and CYT2 isoforms in the same reaction. In respect of JMa/b isoforms we could identify a significantly higher expression of the $J M b$ isoform in the ACC of schizophrenic patients, and no change in $J M a$ expression compared to control patients 
(Fig. 3.24B). RTPCR analyses with pan primers for JMa/b ErbB4 revealed an overall over-expression of ERBB4 in this brain region of schizophrenic patients. So far these results do not reflect, previous postmortem observations in human schizophrenic patients, however due to the small cohort, it might reflect only a sub-type of a schizophrenia phenotype. Furthermore, additional factors of unknown impact might be medication that were potentially applied. To fully understand the role of ERBB4 isoforms, further detailed studies must be performed with human databases, regarding the expression levels of these splicing variants. 


\section{Chapter 4}

\section{Discussion}

The consolidation of hippocampal recent memory to remote memory is based on cortical networks governed by the prefrontal cortex (Frankland and Bontempi, 2005). In parallel observations of learning-associated brain activities during sleep identified an essential role of prefrontal cortex activities. To study the memory function of the prefrontal cortex in relation to sleep-related mechanisms, we analyzed the cognitive performance of SHARP1 and SHARP2 double mutant mice and investigated altered signaling activities which are specific for the prefrontal cortex of these mice. Furthermore we tested the effect of identified factors on cognitive processes of memory consolidation.

\subsection{Aspects of sleep regulation and memory consolidation}

A physiological sleep architecture is crucial for optimal memory consolidation (Diekelmann and Born, 2010). Moreover, EEG measurements could identify characteristic learningassociated patterns of brain activities during sleep, most prominent in the prefrontal cortex (Born, 2010).

Here we analyzed a mouse model, deficient for the modulators of the circadian system SHARP1 and SHARP2. We analyzed SHARP1 and SHARP2 single and double mutant mice, and observed improved remote long-term memory only in double mutant mice (Fig. 3.2). Analyses of hippocampal recent fear memory did not reveal any difference. Moreover, further cortical memory tasks as flexible learning were improved. In parallel SHARP1 and SHARP2 potentially underlie a functional redundancy in certain tested behavioral aspects. Altogether the $S 1 / 2^{-/-}$mouse model manifests an improvement of cognitive tasks that might be associated with functional improvement of the prefrontal 
cortex. However, knockouts of the core clock genes as Bmal1, Clock and Npas2 result in memory impairment (Garcia et al., 2000; A.Kondratova et al., 2010; Wardlaw et al., 2014). In contrast to clock genes, SHARP1 and SHARP2 do not disrupt the circadian cycle, they rather act as amplitude modifiers in a context-dependent manner (Rossner et al., 2008). Therefore it seems likely that specific mechanisms which are altered locally in the prefrontal cortex of the $S 1 / 2^{-/-}$double mutant mice might induce processes of cortical activities.

\subsection{Specificity of cognitive processes in the prefrontal cortex}

What happens during sleep might be a progressive conversion of recently learned memory tracks from hippocampal structures to cortical networks located in the anterior cingulate cortex within the prefrontal cortex (Diekelmann and Born, 2010). Based on an improved performance in tasks that rely on processes of the prefrontal cortex in SHARP1 and SHARP2 double mutant mice, we decided to further dissect the underlying hippocampal and cortical mechanisms. Understanding pathways that can locally improve cognitive characteristics, might enable us to treat cognitive diseases that are limited to the prefrontal cortex in a specific mode. To expose such mechanisms we analyzed the anterior cortex of the mice on a molecular level. Since we observed a very specific cognitive improvement which was limited to the function of the prefrontal cortex we decided to analyze the hippocampus as a reference region which is preceding cognitive processes upstream from the prefrontal cortex. When we analyzed these regions we discovered molecular changes which were specific to the anterior cortex and unaltered in the hippocampus of $S 1 / 2^{-/-}$ mice (Fig. 3.5). In particular p44/42 MAPK activity was increased in the anterior cortex of $S 1 / 2^{-/-}$mice, but not in the hippocampus. Previously a circadian regulation of $\mathrm{p} 44 / 42$ MAPK activity has been associated with functional hippocampal memory consolidation (Eckel-Mahan et al., 2008). Here, we show for the first time an activation of p44/42 MAPK in relation to improved memory consolidation exclusively in a defined region of the mammalian brain. Supporting the theory of functional redundancy of SHARP1 and SHARP2, we could not observe a respective deregulation in single mutant mice (Fig. 3.6). Furthermore, our data increases evidence of the mild and at the same time differential modulatory role that SHARP1 and SHARP2 might have in the regulation of downstream pathways. Although SHARP1 and SHARP2 is deleted in the prefrontal cortex as well as 
in the hippocampus, we observed a highly specific phenotype which was restricted to the prefrontal cortex.

However, the mode of function of SHARP1 and SHARP2 in the prefrontal cortex is not clear. Both transcription factors can generally act as activator as well as repressors of target genes, depending on the availability of NPAS2/CLOCK-BMAL1 co-factors (Rossner et al., 2008). Regarding the circadian expression pattern of SHARP1 and SHARPQ, the highest circadian activity seems to be located in the prefrontal cortex ( $\mathrm{Li}$ et al., 2013). Although SHARP1 and SHARP2 can modulate the amplitudes of clock gene expression, loss of both factors did not affect the expression of Per2 in the ACx (Fig. 3.9). The expression pattern of $c$-Fos, a marker of neuronal activity, was altered at the peak of neuronal activity of WT mice. Studies in human have highlighted the importance of circadian cycling of clock genes for physiological cognitive performance (Li et al., 2013). Here, in gene expression studies they identified the prefrontal cortex with highest cyclic patterns of circadian genes. Yet, this rhythmicity was lost in patients with major depressive disorder. Our data, together with the knowledge of the cyclic activity of SHARP1 and SHARP2 in the prefrontal cortex increase the evidence that SHARP1 and SHARP2 might have a very sensitive and daytime dependent role in the regulation of cortical processes.

\subsection{MAPK activity involved in cognitive processes}

Learning and memory performance involves the homeostatic regulation of neuronal activity and synaptic plasticity (Tononi and Cirelli, 2006). To understand mechanisms, underlying the cortical phenotype we analyzed a number of signaling pathways by investigating the phosphorylation status as a surrogate marker of their activity. Among all analyzed signaling molecules, only p44/42 MAPK and S6 seemed to be altered exclusively in the anterior cortex. Moreover, in the anterior cortex, the mode of activity of p44/42 MAPK correlated throughout all performed experiments with the status of remote long-term memory performance. An increase in p44/42 phosphorylation in the prefrontal cortex was associated with improved remote memory performance and vice versa. In the context of hippocampal memory, a circadian cycling of p44/42 MAPK phosphorylation in the hippocampus was previously reported to be associated with functional memory performance (Eckel-Mahan et al., 2008). Furthermore sleep deprivation-induced decrease of spatial memory was associated with a decrease in p44/42 MAPK activity (Guan et al., 2004). The loss of memory 
due to a reduction of p44/42 MAPK activity is linked to a reduction of S6 phosphorylation and synaptic plasticity (Kelleher et al., 2004). So far investigations of memory related MAPK activities have been mainly focusing on hippocampal aspects (Revest et al., 2013; Eckel-Mahan et al., 2008). Our data reveal a region specific MAPK activity status that correlates with the cognitive performance of the prefrontal cortex. The activation of MAPK that we detected in the prefrontal cortex of WT mice, was correlating with a delay with the expression pattern of Igf2 (Fig. 4.1). We could detect 2 peaks of MAPK phosphorylation, each occurring with few hours after an elevation of Igf2 RNA expression. Based on these findings and on microarray data, we further investigated the role of Igf2 signaling in the context of prefrontal cortex specific memory enhancement.

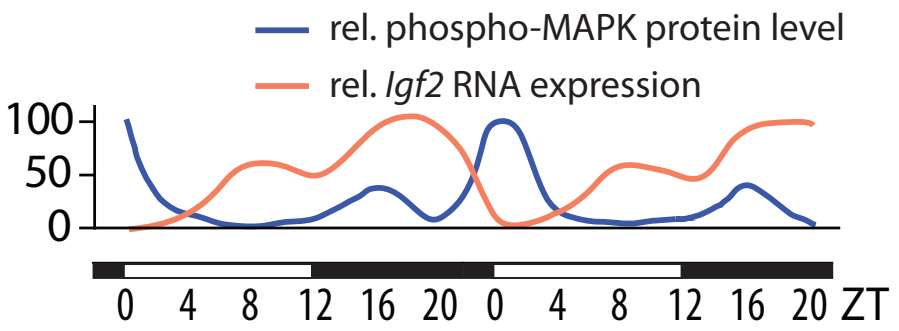

Figure 4.1: Circadian Igf2 expression and MAPK activation in the ACx of WT. Analysis of circadian MAPK activity (Fig. 3.8) and Igf2 expression (Fig. 3.10) in the ACx of WT mice. In order to analyze the cycling pattern, highest data point was set to $100 \%$, and lowest data point was set to $0 \%$.

\subsection{Role of insulin signaling in memory consolidation}

Originally insulin signaling was thought to be primarily involved in the peripheral regulation of glucose homeostasis. Increasing evidence suggest an additional role of insulin signaling in the central nerve system, beyond its function of glucose regulation. Several studies, performed in human and mice, identified factors of insulin signaling, involved in the regulation of cognitive processes (Agis-Balboa et al., 2011; Chen et al., 2011; Iwamoto and Ouchi, 2014). In parallel, studies reported an association of deregulated insulin signaling and increased risk of developing mild cognitive impairments and potentially Alzheimer's disease (Gandy, 2005; Ohara et al., 2011). However it is not understood so far which factors might be involved in insulin signaling-related aspects of memory performance. 
In the search of gene expression changes in the prefrontal cortex, we identified elevated expression of Igf2 together with decreased levels of Igfbp 5 expression. To test the categorical function of IGF2 in cognitive processes of the prefrontal cortex, we virally expressed Igf2 in neurons and glia of the anterior cingulate cortex via a CAG promoter. We could observe an enhancement of remote contextual memory, although other aspects of memory as recent contextual memory as well as recent and remote cue-related memory were not changed (Fig. 3.12). Moreover expression of Igfbp5 resulted in an inversed effect on remote context memory. So far several studies have shown a memory enhancing effect of IGF2 in the hippocampus (Agis-Balboa et al., 2011; Chen et al., 2011; Iwamoto and Ouchi, 2014).

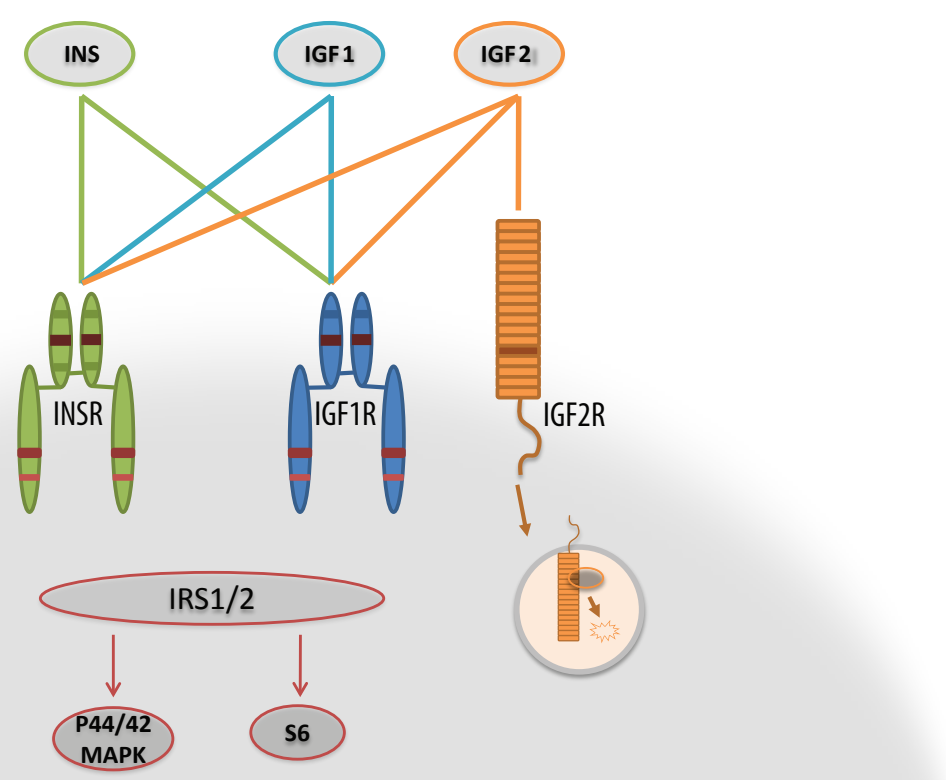

Figure 4.2: Potential receptor affinities of insulin signaling factors and downstream activation of MAPK and S6. In the brain, the receptor tyrosine kinases IGF1R and INSR can both be activated by binding of insulin, IGF1 and IGF2. In the brain, IGF2 binds with highest affinity to the InsR isoform A which is the highest expressed isoform here. Insulin and IGF1 can activate the INSR as well as the IGF1R. The IGF1R and INSR can activate MAPK and S6 signaling through IRS1 or IRS2 activation. The IGF2R mainly binds and internalizes IGF2 and leads to the endosomal degradation of IGF2. The IGF1R and INSR, both can activate downstream MAPK and S6 signaling.

Here, we demonstrate for the first time a positive effect of IGF2 on the remote memory formation in the prefrontal cortex. Interestingly the promoter of the Igf2 gene, contains 
several CACGTG E-Box binding sites that could potentially serve as binding sites for SHARP1 and SHARP2 transcription factors. However, in which extend direct binding of SHARP1 and -2 might affect changes in Igf2 expression needs to be further studied.

We analyzed which receptors might be mediating the memory enhancing effect of IGF2 in cognitive processes. In the brain, MAPK can be activated by IGF2 and insulin through the INSR as well as IGF1R (Hu et al., 2011; Roux et al., 2007; Siddle, 2011). In studies performed in the hippocampus, selective inactivation of the InsR and Igf1R does not lead to disruption of fear memory performance (Chen et al., 2011; Schubert et al., 2004). This might simply be related to the functional redundancy of both receptors, as well as the high affinity of the INSR isoform A (INSR-A) to IGF2 in the brain (Fig. 4.2) (Belfiore et al., 2009; Frasca et al., 1999). The INSR-A is highest expressed INSR isoform in the brain (Hernández-Sánchez et al., 2008).

In order to collect evidence whether IGF2 signaling generally can affect memory related pathways in the hippocampus and cortex, we tested the memory performance of neuronal Insr and Igf1r double knockout mice. These Igf1r/InsrCaMKII-cre double mutant mice, displayed a very specific contextual fear memory phenotype (Fig. 3.15). The fact that other behavioral tests did not reveal any change in cognitive performance emphasizes the highly specific neuronal role of both receptors in this particular aspect of contextual fear memory (Fig. 3.14). CaMKII-cre affected neurons in the hippocampus as well as in the prefrontal cortex. Therefore the IGF1R and INSR were disrupted in both regions. Behavior experiments revealed an impairment of hippocampal recent memory as well as cortical remote memory performance. Based on our findings, amygdala based cued fear conditioning is not affected by a manipulation of IGF2 and IGF1R/INSR signaling in the prefrontal cortex. In the context of IGF2 signaling the IGF2 receptor (IGF2R) leads to an internalization and endosomal degradation of IGF2 (Hawkes and Kar, 2004). However, so far we cannot exclude an additional effect of the IGF2R through potential G-protein coupled activation of relevant signaling factors (Hawkes et al., 2006). Yet, we showed that the neuronal IGF1R and INSR are involved in the control of cognitive processes of recent as well as remote fear memory consolidation, although an inactivation of the IGF1R and INSR receptors alone did not effect altered hippocampal memory (Chen et al., 2011; Schubert et al., 2004). Insulin injection studies revealed a rather a decline of cognitive performance than an improvement (Kopf and Baratti, 1999; Schwarzberg et al., 1989). 
Potentially the memory enhancing effect of the IGF1R and INSR is indeed limited to the function of IGF2.

Both receptors, the IGF1R and INSR can act as potential upstream activators of MAPK signaling (Siddle, 2011). Moreover based on our data we suggest a more task specific role of the MAPK activation in the cognitive processes. As we observed, the reduction in remote memory performance correlates with a decrease in p44/42 MAPK activity in the prefrontal cortex (Fig. 3.13). However, we could not observe a similar correlation between unaltered p44/42 MAPK activity in the hippocampus and decreased hippocampal recent memory performance. Therefore IGF1R and INSR-mediated activation of MAPK might be relevant cortical processes that are involved in the consolidation of remote memory.

\subsection{Potential role of astrocytes in cognitive processes}

Among genes, that were identified through micro array analyses of WT and $S 1 / 2^{-/-}$mice, surprisingly myelin and astrocyte specific genes were among the highest deregulated genes (Baier et al., manuscript in submission). In addition, the expression of myelin genes underlies a circadian pattern (Reinecke et al., manuscript in preparation). In human, a deregulation of myelin genes and myelin proteins is registered especially in the prefrontal cortex of schizophrenic patients (Flynn et al., 2003; Hakak et al., 2001; McInnes and Lauriat, 2006). However, in $S 1 / 2^{-/-}$mice, on myelin level neither myelin structure nor protein levels were affected (Reinecke et. al, manuscript in preparation). Therefore is in not clear yet, what might be the relevance of myelin mRNA deregulations. It might be possible that the highly dynamic circadian regulations of the myelin composition are involved in the adaptation of neuronal communication to the sleep or activity status.

On protein level we could observe an increase of astrocytic GFAP, exclusively in the ACx and not in the Hi of $S 1 / 2^{-/-}$mice (Fig. 3.5 and 3.11). Astrocytes are involved in the support of the energy intensive synaptic transmission (Attwell and Gibb, 2005; Rouach et al., 2008). They are crucial for function of the blood brain barrier and and can potentially regulate blood flow based on local neuronal activity (Paulson and Newman, 1987). Increasing evidence suggests the involvement of astrocytes in mechanisms of memory regulation (Bezzi and Volterra, 2011; Suzuki et al., 2011). The size, number and complexity of astrocytes is disproportionately increasing with the complexity of the brain, potentially reflecting the significance in higher cognitive functions (Oberheim et al., 2006). The implantation of 
human astrocytes in the mouse forebrain leads to increased long-term potentiation (LTP) and enhances several aspects of memory performance (Han et al., 2013).

However, it is not clear if the elevated GFAP level in the prefrontal cortex might be the cause of cognitive enhancement in related tasks. So far, we could validate that the IGF2-IGF1R/INSR path is directly mediating memory consolidation. Yet analysis of the Igf1r/InsrCaMKII-cre did not reveal levels of GFAP abundance that correlated with the Hi or ACx related cognitive performance as it did in $S 1 / 2^{-/-}$mice. Therefore it might be that the observed GFAP increase in the $\mathrm{ACx}$ of $S 1 / 2^{-/-}$mice was just a secondary effect potentially in response to altered neuronal activity. GFAP expression can be enhanced via elevated nitric oxide (NO) (Brahmachari et al., 2006). Thus oxidative stress might have led to an increase in GFAP level. Interestingly, in the $\mathrm{ACx}$ and $\mathrm{Hi}$ of aged $S 1 / 2^{-/-}$mice, we observed GFAP levels that correlated with the observed recent and remote memory performance of these mice (Fig. 3.20 and 3.22). Finally, although the expression of GFAP is potentially not the primary cause of cognitive enhancement of the $S 1 / 2^{-/}$mice, it still might be affected by mechanisms that are related to memory performance.

\subsection{Aging}

Age related sleep fragmentation is thought to be associated with the incident of Alzheimer's disease and related cognitive decline (Carskadon et al., 1982; Lim et al., 2013). Already a subtle reduction of sleep can lead to a deregulation of genes that are involved in sleep homeostasis, oxidative stress and metabolism (Möller-Levet et al., 2013). In drosophila, administration of insulin leads to a recovery of age-related sleep fragmentation (Metaxakis et al., 2014). Analyses of aged $S 1 / 2^{-/-}$mice revealed signs of early aging, and an overall decrease of contextual fear memory. Here, recent memory was impaired, yet the remote memory performance was attenuated to the level of WT mice. Again, we could observe MAPK activities directly correlating with the monitored memory performance. MAPK as well as S6, are downstream in a signaling cascade with IGF2 and associated with bipolar disorders, schizophrenia and Alzheimer's disease (Funk et al., 2012; Kalkman, 2012; Munoz and Ammit, 2010; Pei et al., 2008). All diseases which have cognitive impairments in common (Vöhringer et al., 2013). Nevertheless MAPK activity fulfills an opposed role in autism and schizophrenia (activation) as in bipolar disorder (inactivation) (Kalkman, 2012). Furthermore the development of Alzheimer's disease might be enhanced by in- 
creased S6-driven translation of tau protein that aggregates and is progressively deposited in neurons (Pei et al., 2008). Thus an increase in Igf2 signaling and following activation of MAPK and S6 potentially enhances mechanisms that are involved in memory performance, but this might occur at the price of an exhausted metabolism. Therefore, studying the long-term effect of Igf2 signaling and MAPK/S6 pathway activity in the brain is essential to understand the potential side effects that IGF2-mediated cognitive enhancement might have. 


\section{Chapter 5}

\section{Summary and conclusion}

In this study, we analyzed aspects of cognitive processing in single and double null mouse mutants of the clock modulators SHARP1 and -2 , in order to address the question how factors of sleep regulation can affect learning and memory performance. We discovered that $S 1 / 2^{-/-}$mice display enhanced performance in prefrontal cortex-dependent learning tasks. Correlating with the observed cognitive enhancement we discovered elevated Igf2 expression and activated MAPK signaling exclusively in the anterior cortex. Moreover, viral enhancement of IGF2 signaling in the anterior cingulate cortex of wild type mice improved remote fear memory performance. We conclude that in the anterior cortex, IGF2 potentially activates MAPK signaling and enhances memory consolidation in prefrontal cortex-dependent cognitive tasks in $S 1 / 2^{-/-}$mice.

MAPK signaling has been associated with circadian aspects of hippocampal memory formation, although the upstream mechanisms have not been identified so far. In parallel, IGF2 can act as a memory enhancer in the hippocampus. Our analysis reveals an additional role for IGF2/MAPK signaling in prefrontal cortex dependent cognitive processing. MAPK as well as S6 signaling are known to be involved in IGF2 signaling and insulin signaling through the insulin and IGF1 receptors. However, individual inactivation of INSR or IGF1R does not exhibit a substantial change in learning or memory abilities of mice. Postulating that this could be due to a functional redundancy among these structurally highly related receptors, we proved our hypothesis with the analysis of mice with conditional forebrain-specific Igf1r/Insr double inactivation and observed impairment of hippocampal and prefrontal cortex-associated recent and remote memory performance. However, amygdala based cue memory was not affected. A parallel reduction of MAPK activity in Igf1r/InsrCaMKII-cre, however, was restricted to the prefrontal cortex and was not detectable in the hippocampus. 
The significance of MAPK activity for the timing of memory formation in the hippocampus has been addressed already in a circadian context. Furthermore the disruption of clock genes leads to memory impairment. Since circadian and activity coupled mRNA expression of Sharp1 and - 2 is restricted to the cortex, it appears likely that in the corresponding mouse mutants cortex selective processes are affected. We could show that Igf2 expression and MAPK activation display a circadian regulation in the cortex of WT mice that appears to be uncoupled upon loss of the negative clock modulators SHARP1 and -2. Our study thus offers a way to study circadian aspects of cortex-dependent memory consolidation in more depth in the future. Moreover, our analysis supports the hypothesis that the control of sleep and memory consolidation may be regulated by similar mechanisms including IGF2-dependent signaling. IGF2 seems to be a potent memory enhancer in the hippocampus and as our data indicate also in the prefrontal cortex. IGF2 crosses the blood brain barrier and might be relevant for future therapeutic use, for example in non-invasive intra-nasal applications. In aged $S 1 / 2^{-/-}$mice, we observed a strong decline in memory performance. So far, it is not clear whether this effect is mediated by the lack of SHARP1 and -2 or continuously increased levels of Igf2 expression. Potentially IGF2 may not only provide beneficial effects as a memory enhancer. Therefore, to understand the potential long-term consequences of elevated IGF2 on the neuronal metabolism and aging-related processes is of fundamental importance. 


\section{Bibliography}

Agis-Balboa, R. C., Arcos-Diaz, D., Wittnam, J., Govindarajan, N., Blom, K., Burkhardt, S., Haladyniak, U., Agbemenyah, H. Y., Zovoilis, A., Salinas-Riester, G., Opitz, L., Sananbenesi, F. and Fischer, A. (2011). A hippocampal insulin-growth factor 2 pathway regulates the extinction of fear memories. The EMBO journal 30, 4071-4083.

Ahles, T. A. and Saykin, A. J. (2007). Candidate mechanisms for chemotherapy-induced cognitive changes. Nature Reviews Cancer 7, 192-201.

A.Kondratova, A., V.Dubrovsky, Y., Antoch, M. P. and Kondratov, R. V. (2010). Circadian clock proteins control adaptation to novel environment and memory formation. Aging (Albany NY) 2, 285-297.

Aleisa, A. M., Alzoubi, K. H. and Alkadhi, K. A. (2011). Post-learning REM sleep deprivation impairs long-term memory: Reversal by acute nicotine treatment. Neuroscience Letters 499, $28-31$.

Allen, A. J., Griss, M. E., Folley, B. S., Hawkins, K. A. and Pearlson, G. D. (2009). Endophenotypes in schizophrenia: a selective review. Schizophrenia Research 109, 24-37.

Alvarez, J. A. and Emory, E. (2006). Executive function and the frontal lobes: a meta-analytic review. Neuropsychology Review 16, 17-42.

Attwell, D. and Gibb, A. (2005). Neuroenergetics and the kinetic design of excitatory synapses. Nature Reviews Neuroscience 6, 841-849.

Avruch, J., Khokhlatchev, A., Kyriakis, J. M., Luo, Z., Tzivion, G., Vavvas, D. and Zhang, X. F. (2001). Ras activation of the Raf kinase: tyrosine kinase recruitment of the MAP kinase cascade. Recent progress in hormone research 56, 127-155.

Baier, P. C., Brzózka, M. M., Shahmoradi, A., Reinecke, L., Kroos, C., Wichert, S. P., Oster, H., Wehr, M. C., Taneja, R., Hirrlinger, J. and Rossner, M. J. (2014). Mice lacking the circadian modulators SHARP1 and SHARP2 display altered sleep and mixed state endophenotypes of psychiatric disorders. PloS One 9, e110310. 
Bekinschtein, P., Katche, C., Slipczuk, L. N., Igaz, L. M., Cammarota, M., Izquierdo, I. and Medina, J. H. (2007). mTOR signaling in the hippocampus is necessary for memory formation. Neurobiology of learning and memory $87,303-307$.

Belfiore, A., Frasca, F., Pandini, G., Sciacca, L. and Vigneri, R. (2009). Insulin Receptor Isoforms and Insulin Receptor/Insulin-Like Growth Factor Receptor Hybrids in Physiology and Disease. Endocrine Reviews 30, 586-623.

Bezzi, P. and Volterra, A. (2011). Astrocytes: Powering Memory. Cell 144, 644-645.

Birnboim, H. C. and Doly, J. (1979). A rapid alkaline extraction procedure for screening recombinant plasmid DNA. Nucleic Acids Research \%, 1513-1523.

Borbély, A. A. (1982). A two process model of sleep regulation. Human Neurobiology 1, 195-204.

Born, J. (2010). Slow-wave sleep and the consolidation of long-term memory. The World Journal of Biological Psychiatry: The Official Journal of the World Federation of Societies of Biological Psychiatry 11 Suppl 1, 16-21.

Bossers, K., Wirz, K. T. S., Meerhoff, G. F., Essing, A. H. W., van Dongen, J. W., Houba, P., Kruse, C. G., Verhaagen, J. and Swaab, D. F. (2010). Concerted changes in transcripts in the prefrontal cortex precede neuropathology in Alzheimer's disease. Brain: A Journal of Neurology 133, 3699-3723.

Botvinick, M. M., Braver, T. S., Barch, D. M., Carter, C. S. and Cohen, J. D. (2001). Conflict monitoring and cognitive control. Psychological Review 108, 624-652.

Bower, J. E. (2008). Behavioral symptoms in breast cancer patients and survivors: Fatigue, insomnia, depression, and cognitive disturbance. Journal of clinical oncology : official journal of the American Society of Clinical Oncology 26, 768-777.

Braff, D. L. and Light, G. A. (2005). The use of neurophysiological endophenotypes to understand the genetic basis of schizophrenia. Dialogues in Clinical Neuroscience $7,125-135$.

Brahmachari, S., Fung, Y. K. and Pahan, K. (2006). Induction of Glial Fibrillary Acidic Protein Expression in Astrocytes by Nitric Oxide. The Journal of Neuroscience 26, 4930-4939.

Brüning, J. C., Gautam, D., Burks, D. J., Gillette, J., Schubert, M., Orban, P. C., Klein, R., Krone, W., Müller-Wieland, D. and Kahn, C. R. (2000). Role of Brain Insulin Receptor in Control of Body Weight and Reproduction. Science 289, 2122-2125.

Brüning, J. C., Michael, M. D., Winnay, J. N., Hayashi, T., Hörsch, D., Accili, D., Goodyear, L. J. and Kahn, C. R. (1998). A muscle-specific insulin receptor knockout exhibits features of the metabolic syndrome of NIDDM without altering glucose tolerance. Molecular cell 2, 559-569. 
Brzózka, M. M., Radyushkin, K., Wichert, S. P., Ehrenreich, H. and Rossner, M. J. (2010). Cognitive and sensorimotor gating impairments in transgenic mice overexpressing the schizophrenia susceptibility gene Tcf4 in the brain. Biological Psychiatry 68, 33-40.

Butterfield, D. A. and Kanski, J. (2001). Brain protein oxidation in age-related neurodegenerative disorders that are associated with aggregated proteins. Mechanisms of Ageing and Development 122, 945-962.

Cardno, A. G., Marshall, E. J., Coid, B., Macdonald, A. M., Ribchester, T. R., Davies, N. J., Venturi, P., Jones, L. A., Lewis, S. W., Sham, P. C., Gottesman, I. I., Farmer, A. E., McGuffin, P., Reveley, A. M. and Murray, R. M. (1999). Heritability estimates for psychotic disorders: the Maudsley twin psychosis series. Archives of General Psychiatry 56, 162-168.

Carney, J. M., Starke-Reed, P. E., Oliver, C. N., Landum, R. W., Cheng, M. S., Wu, J. F. and Floyd, R. A. (1991). Reversal of age-related increase in brain protein oxidation, decrease in enzyme activity, and loss in temporal and spatial memory by chronic administration of the spintrapping compound N-tert-butyl-alpha-phenylnitrone. Proceedings of the National Academy of Sciences of the United States of America 88, 3633-3636.

Carskadon, M. A., Brown, E. D. and Dement, W. C. (1982). Sleep fragmentation in the elderly: relationship to daytime sleep tendency. Neurobiology of Aging 3, 321-327.

Chai, X. J., Whitfield-Gabrieli, S., Shinn, A. K., Gabrieli, J. D. E., Nieto Castañón, A., McCarthy, J. M., Cohen, B. M. and Öngür, D. (2011). Abnormal Medial Prefrontal Cortex Resting-State Connectivity in Bipolar Disorder and Schizophrenia. Neuropsychopharmacology 36, 2009-2017.

Chen, D. Y., Stern, S. A., Garcia-Osta, A., Saunier-Rebori, B., Pollonini, G., Bambah-Mukku, D., Blitzer, R. D. and Alberini, C. M. (2011). A critical role for IGF-II in memory consolidation and enhancement. Nature 469, 491-497.

Chen, X., Garelick, M. G., Wang, H., Li, V., Athos, J. and Storm, D. R. (2005). PI3 kinase signaling is required for retrieval and extinction of contextual memory. Nature Neuroscience 8 , 925-931.

Corfas, G., Roy, K. and Buxbaum, J. D. (2004). Neuregulin 1-erbB signaling and the molecular/cellular basis of schizophrenia. Nature Neuroscience 7, 575-580.

Davis, R. L. and Turner, D. L. (2001). Vertebrate hairy and Enhancer of split related proteins: transcriptional repressors regulating cellular differentiation and embryonic patterning. Oncogene 20, 8342-8357.

de Bruin, J. P., Sànchez-Santed, F., Heinsbroek, R. P., Donker, A. and Postmes, P. (1994). A behavioural analysis of rats with damage to the medial prefrontal cortex using the Morris water 
maze: evidence for behavioural flexibility, but not for impaired spatial navigation. Brain research 652, 323-333.

DeYoung, C. G., Hirsh, J. B., Shane, M. S., Papademetris, X., Rajeevan, N. and Gray, J. R. (2010). Testing Predictions From Personality Neuroscience: Brain Structure and the Big Five. Psychological science 21, 820-828.

Dias, R., Robbins, T. W. and Roberts, A. C. (1996). Dissociation in prefrontal cortex of affective and attentional shifts. Nature 380, 69-72.

Diekelmann, S. and Born, J. (2010). The memory function of sleep. Nature Reviews Neuroscience $11,114-126$.

Dragunow, M. and Faull, R. (1989). The use of c-fos as a metabolic marker in neuronal pathway tracing. Journal of Neuroscience Methods 29, 261-265.

Drechsel, D. A. and Patel, M. (2008). Role of reactive oxygen species in the neurotoxicity of environmental agents implicated in Parkinson's disease. Free Radical Biology \& Medicine 44 , $1873-1886$.

Ebbinghaus, H. (1885). Über das Gedächtnis. Untersuchungen zur experimentellen Psychologie. Leipzig: Duncker \& Humblot.

Eckel-Mahan, K. L., Phan, T., Han, S., Wang, H., Chan, G. C.-K., Scheiner, Z. S. and Storm, D. R. (2008). Circadian oscillation of hippocampal MAPK activity and cAMP: implications for memory persistence. Nature neuroscience 11, 1074-1082.

Eckel-Mahan, K. L. and Storm, D. R. (2009). Circadian rhythms and memory: not so simple as cogs and gears. EMBO reports 10, 584-591.

Enriquez-Barreto, L., Cuesto, G., Dominguez-Iturza, N., Gavilan, E., Ruano, D., Sandi, C., Fernandez-Ruiz, A., Martin-Vazquez, G., Herreras, O. and Morales, M. (2014). Learning improvement after PI3K activation correlates with de novo formation of functional small spines. Frontiers in Molecular Neuroscience 6.

Falvella, F. S., Colombo, F., Spinola, M., Campiglio, M., Pastorino, U. and Dragani, T. A. (2008). BHLHB3: a candidate tumor suppressor in lung cancer. Oncogene 27, 3761-3764.

Fernyhough, P., Mill, J. F., Roberts, J. L. and Ishii, D. N. (1989). Stabilization of tubulin mRNAs by insulin and insulin-like growth factor I during neurite formation. Brain Research. Molecular Brain Research 6, 109-120.

Ferré-D'Amaré, A. R., Prendergast, G. C., Ziff, E. B. and Burley, S. K. (1993). Recognition by Max of its cognate DNA through a dimeric b/HLH/Z domain. Nature 363, 38-45. 
Flynn, S. W., Lang, D. J., Mackay, A. L., Goghari, V., Vavasour, I. M., Whittall, K. P., Smith, G. N., Arango, V., Mann, J. J., Dwork, A. J., Falkai, P. and Honer, W. G. (2003). Abnormalities of myelination in schizophrenia detected in vivo with MRI, and post-mortem with analysis of oligodendrocyte proteins. Molecular Psychiatry 8, 811-820.

Forbes, C. E. and Grafman, J. (2010). The Role of the Human Prefrontal Cortex in Social Cognition and Moral Judgment*. Annual Review of Neuroscience 33, 299-324.

Forster, M. J., Dubey, A., Dawson, K. M., Stutts, W. A., Lal, H. and Sohal, R. S. (1996). Agerelated losses of cognitive function and motor skills in mice are associated with oxidative protein damage in the brain. Proceedings of the National Academy of Sciences of the United States of America 93, 4765-4769.

Fortress, A. M., Schram, S. L., Tuscher, J. J. and Frick, K. M. (2013). Canonical Wnt signaling is necessary for object recognition memory consolidation. The Journal of neuroscience: the official journal of the Society for Neuroscience 33, 12619-12626.

Franken, P., Dudley, C. A., Estill, S. J., Barakat, M., Thomason, R., O'Hara, B. F. and McKnight, S. L. (2006). NPAS2 as a transcriptional regulator of non-rapid eye movement sleep: genotype and sex interactions. Proceedings of the National Academy of Sciences of the United States of America 103, 7118-7123.

Frankland, P. W. and Bontempi, B. (2005). The organization of recent and remote memories. Nature Reviews Neuroscience 6, 119-130.

Frankland, P. W., Bontempi, B., Talton, L. E., Kaczmarek, L. and Silva, A. J. (2004). The involvement of the anterior cingulate cortex in remote contextual fear memory. Science (New York, N.Y.) 304, 881-883.

Franzek, E. and Beckmann, H. (1998). Different genetic background of schizophrenia spectrum psychoses: a twin study. The American Journal of Psychiatry 155, 76-83.

Frasca, F., Pandini, G., Scalia, P., Sciacca, L., Mineo, R., Costantino, A., Goldfine, I. D., Belfiore, A. and Vigneri, R. (1999). Insulin receptor isoform A, a newly recognized, high-affinity insulinlike growth factor II receptor in fetal and cancer cells. Molecular and cellular biology 19, $3278-3288$.

Frith, U. and Frith, C. D. (2003). Development and neurophysiology of mentalizing. Philosophical Transactions of the Royal Society of London. Series B, Biological Sciences 358, 459-473.

Fukui, K., Onodera, K., Shinkai, T., Suzuki, S. and Urano, S. (2001). Impairment of learning and memory in rats caused by oxidative stress and aging, and changes in antioxidative defense systems. Annals of the New York Academy of Sciences 928, 168-175. 
Funk, A. J., McCullumsmith, R. E., Haroutunian, V. and Meador-Woodruff, J. H. (2012). Abnormal Activity of the MAPK- and cAMP-Associated Signaling Pathways in Frontal Cortical Areas in Postmortem Brain in Schizophrenia. Neuropsychopharmacology 37, 896-905.

Gabbita, S. P., Lovell, M. A. and Markesbery, W. R. (1998). Increased nuclear DNA oxidation in the brain in Alzheimer's disease. Journal of Neurochemistry 71, 2034-2040.

Gandy, S. (2005). The role of cerebral amyloid beta accumulation in common forms of Alzheimer disease. The Journal of Clinical Investigation 115, 1121-1129.

Ganz, P. A., Kwan, L., Castellon, S. A., Oppenheim, A., Bower, J. E., Silverman, D. H. S., Cole, S. W., Irwin, M. R., Ancoli-Israel, S. and Belin, T. R. (2013). Cognitive complaints after breast cancer treatments: examining the relationship with neuropsychological test performance. Journal of the National Cancer Institute 105, 791-801.

Garcia, J. A., Zhang, D., Estill, S. J., Michnoff, C., Rutter, J., Reick, M., Scott, K., Diaz-Arrastia, R. and McKnight, S. L. (2000). Impaired cued and contextual memory in NPAS2-deficient mice. Science (New York, N.Y.) 288, 2226-2230.

Gottesman, I. I. and Shields, J. (1967). A polygenic theory of schizophrenia. Proceedings of the National Academy of Sciences of the United States of America 58, 199-205.

Graves, L. A., Heller, E. A., Pack, A. I. and Abel, T. (2003). Sleep deprivation selectively impairs memory consolidation for contextual fear conditioning. Learning \& Memory (Cold Spring Harbor, N.Y.) $10,168-176$.

Greenwood, T. A., Light, G. A., Swerdlow, N. R., Radant, A. D. and Braff, D. L. (2012). Association Analysis of 94 Candidate Genes and Schizophrenia-Related Endophenotypes. PLoS ONE 7, e29630.

Guan, Z., Peng, X. and Fang, J. (2004). Sleep deprivation impairs spatial memory and decreases extracellular signal-regulated kinase phosphorylation in the hippocampus. Brain Research 1018, $38-47$.

Gurden, H., Tassin, J. P. and Jay, T. M. (1999). Integrity of the mesocortical dopaminergic system is necessary for complete expression of in vivo hippocampal-prefrontal cortex long-term potentiation. Neuroscience 94, 1019-1027.

Guzowski, J. F., Setlow, B., Wagner, E. K. and McGaugh, J. L. (2001). Experience-Dependent Gene Expression in the Rat Hippocampus after Spatial Learning: A Comparison of the Immediate-Early GenesArc, c-fos, and zif268. The Journal of Neuroscience 21, 5089-5098. 
Hakak, Y., Walker, J. R., Li, C., Wong, W. H., Davis, K. L., Buxbaum, J. D., Haroutunian, V. and Fienberg, A. A. (2001). Genome-wide expression analysis reveals dysregulation of myelinationrelated genes in chronic schizophrenia. Proceedings of the National Academy of Sciences of the United States of America 98, 4746-4751.

Hall, C. N., Klein-Flügge, M. C., Howarth, C. and Attwell, D. (2012). Oxidative Phosphorylation, Not Glycolysis, Powers Presynaptic and Postsynaptic Mechanisms Underlying Brain Information Processing. The Journal of Neuroscience 32, 8940-8951.

Han, X., Chen, M., Wang, F., Windrem, M., Wang, S., Shanz, S., Xu, Q., Oberheim, N. A., Bekar, L., Betstadt, S., Silva, A. J., Takano, T., Goldman, S. A. and Nedergaard, M. (2013). Forebrain Engraftment by Human Glial Progenitor Cells Enhances Synaptic Plasticity and Learning in Adult Mice. Cell Stem Cell 12, 342-353.

Hawkes, C., Jhamandas, J. H., Harris, K. H., Fu, W., MacDonald, R. G. and Kar, S. (2006). Single transmembrane domain insulin-like growth factor-II/mannose-6-phosphate receptor regulates central cholinergic function by activating a G-protein-sensitive, protein kinase C-dependent pathway. The Journal of Neuroscience: The Official Journal of the Society for Neuroscience 26, $585-596$.

Hawkes, C. and Kar, S. (2004). The insulin-like growth factor-II/mannose-6-phosphate receptor: structure, distribution and function in the central nervous system. Brain Research Reviews 44 , $117-140$.

He, Y., Jones, C. R., Fujiki, N., Xu, Y., Guo, B., Holder, Jimmy L, J., Rossner, M. J., Nishino, S. and Fu, Y.-H. (2009). The transcriptional repressor DEC2 regulates sleep length in mammals. Science (New York, N.Y.) 325, 866-870.

Hernández-Sánchez, C., Mansilla, A., Pablo, F. d. and Zardoya, R. (2008). Evolution of the Insulin Receptor Family and Receptor Isoform Expression in Vertebrates. Molecular Biology and Evolution 25, 1043-1053.

Herry, C., Vouimba, R.-M. and Garcia, R. (1999). Plasticity in the mediodorsal thalamo-prefrontal cortical transmission in behaving mice. Journal of Neurophysiology 82, 2827-2832.

Honma, S., Kawamoto, T., Takagi, Y., Fujimoto, K., Sato, F., Noshiro, M., Kato, Y. and Honma, K.-i. (2002). Dec1 and Dec2 are regulators of the mammalian molecular clock. Nature 419, $841-844$.

Hosak, L. (2013). New findings in the genetics of schizophrenia. World Journal of Psychiatry 3, $57-61$. 
Hu, Q., Gao, F., Tian, W., Ruteshouser, E. C., Wang, Y., Lazar, A., Stewart, J., Strong, L. C., Behringer, R. R. and Huff, V. (2011). Wt1 ablation and Igf2 upregulation in mice result in Wilms tumors with elevated ERK1/2 phosphorylation. Journal of Clinical Investigation 121, $174-183$.

Iversen, S. D. and Mishkin, M. (1970). Perseverative interference in monkeys following selective lesions of the inferior prefrontal convexity. Experimental Brain Research 11, 376-386.

Iwamoto, T. and Ouchi, Y. (2014). Emerging evidence of insulin-like growth factor 2 as a memory enhancer: a unique animal model of cognitive dysfunction with impaired adult neurogenesis. Reviews in the neurosciences 25, 559-574.

Javanbakht, H., Halwani, R., Cen, S., Saadatmand, J., Musier-Forsyth, K., Gottlinger, H. and Kleiman, L. (2003). The interaction between HIV-1 Gag and human lysyl-tRNA synthetase during viral assembly. The Journal of Biological Chemistry 278, 27644-27651.

Junttila, T., Laato, M., Vahlberg, T., Söderström, K.-O., Visakorpi, T., Isola, J. and Elenius, K. (2003). Identification of Patients with Transitional Cell Carcinoma of the Bladder Overexpressing ErbB2, ErbB3, or Specific ErbB4 Isoforms: Real-Time Reverse Transcription-PCR Analysis in Estimation of ErbB Receptor Status from Cancer Patients. Clinical Cancer Research 9, 53465357.

Junttila, T. T., Sundvall, M., Määttä, J. A. and Elenius, K. (2000). ErbB4 and Its Isoforms: Selective Regulation of Growth Factor Responses by Naturally Occurring Receptor Variants. Trends in Cardiovascular Medicine 10, 304-310.

Kainulainen, V., Sundvall, M., Määttä, J. A., Santiestevan, E., Klagsbrun, M. and Elenius, K. (2000). A Natural ErbB4 Isoform That Does Not Activate Phosphoinositide 3-Kinase Mediates Proliferation but Not Survival or Chemotaxis. Journal of Biological Chemistry 275, 8641-8649.

Kalkman, H. O. (2012). Potential opposite roles of the extracellular signal-regulated kinase (ERK) pathway in autism spectrum and bipolar disorders. Neuroscience \& Biobehavioral Reviews 36, $2206-2213$.

Kandel, E. R. (2001). The Molecular Biology of Memory Storage: A Dialogue Between Genes and Synapses. Science 294, 1030-1038.

Kanterewicz, B. I., Knapp, L. T. and Klann, E. (1998). Stimulation of p42 and p44 MitogenActivated Protein Kinases by Reactive Oxygen Species and Nitric Oxide in Hippocampus. Journal of Neurochemistry 70, 1009-1016.

Kelleher, R. J., Govindarajan, A., Jung, H.-Y., Kang, H. and Tonegawa, S. (2004). Translational Control by MAPK Signaling in Long-Term Synaptic Plasticity and Memory. Cell 116, 467-479. 
Kim, A. H., Reimers, M., Maher, B., Williamson, V., McMichael, O., McClay, J. L., van den Oord, E. J. C. G., Riley, B. P., Kendler, K. S. and Vladimirov, V. I. (2010). MicroRNA expression profiling in the prefrontal cortex of individuals affected with schizophrenia and bipolar disorders. Schizophrenia Research 124, 183-191.

Kim, J. J. and Fanselow, M. S. (1992). Modality-specific retrograde amnesia of fear. Science (New York, N.Y.) 256, 675-677.

Kim, M. J., Chun, S. K., Kim, Y. B., Mook-Jung, I. and Jung, M. W. (2003). Long-term potentiation in visual cortical projections to the medial prefrontal cortex of the rat. Neuroscience 120 , $283-289$.

Klöting, N., Koch, L., Wunderlich, T., Kern, M., Ruschke, K., Krone, W., Brüning, J. C. and Blüher, M. (2008). Autocrine IGF-1 action in adipocytes controls systemic IGF-1 concentrations and growth. Diabetes 57, 2074-2082.

Knight, Z. A., Tan, K., Birsoy, K., Schmidt, S., Garrison, J. L., Wysocki, R. W., Emiliano, A., Ekstrand, M. I. and Friedman, J. M. (2012). Molecular profiling of activated neurons by phosphorylated ribosome capture. Cell 151, 1126-1137.

Kopf, S. R. and Baratti, C. M. (1999). Effects of Posttraining Administration of Insulin on Retention of a Habituation Response in Mice: Participation of a Central Cholinergic Mechanism. Neurobiology of Learning and Memory 71, 50-61.

Krab, L. C., Goorden, S. M. I. and Elgersma, Y. (2008). Oncogenes on my mind: ERK and MTOR signaling in cognitive diseases. Trends in Genetics 24, 498-510.

Lai, A. G., Doherty, C. J., Mueller-Roeber, B., Kay, S. A., Schippers, J. H. M. and Dijkwel, P. P. (2012). CIRCADIAN CLOCK-ASSOCIATED 1 regulates ROS homeostasis and oxidative stress responses. Proceedings of the National Academy of Sciences of the United States of America 109, 17129-17134.

Larson, E. B., Kukull, W. A. and Katzman, R. L. (1992). Cognitive impairment: dementia and Alzheimer's disease. Annual Review of Public Health 13, 431-449.

Law, A., Kleinman, J., Weinberger, D. and Weickert, C. (2007). Disease-associated intronic variants in the ErbB4 gene are related to altered ErbB4 splice-variant expression in the brain in schizophrenia. Human Molecular Genetics 16, 129-141.

Levinson, D. F., Shi, J., Wang, K., Oh, S., Riley, B., Pulver, A. E., Wildenauer, D. B., Laurent, C., Mowry, B. J., Gejman, P. V., Owen, M. J., Kendler, K. S., Nestadt, G., Schwab, S. G., Mallet, J., Nertney, D., Sanders, A. R., Williams, N. M., Wormley, B., Lasseter, V. K., Albus, M., Godard-Bauché, S., Alexander, M., Duan, J., O'Donovan, M. C., Walsh, D., O'Neill, A., 
Papadimitriou, G. N., Dikeos, D., Maier, W., Lerer, B., Campion, D., Cohen, D., Jay, M., Fanous, A., Eichhammer, P., Silverman, J. M., Norton, N., Zhang, N., Hakonarson, H., Gao, C., Citri, A., Hansen, M., Ripke, S., Schizophrenia Psychiatric GWAS Consortium, Dudbridge, F. and Holmans, P. A. (2012). Genome-wide association study of multiplex schizophrenia pedigrees. The American Journal of Psychiatry 169, 963-973.

Li, J. Z., Bunney, B. G., Meng, F., Hagenauer, M. H., Walsh, D. M., Vawter, M. P., Evans, S. J., Choudary, P. V., Cartagena, P., Barchas, J. D., Schatzberg, A. F., Jones, E. G., Myers, R. M., Watson, S. J., Akil, H. and Bunney, W. E. (2013). Circadian patterns of gene expression in the human brain and disruption in major depressive disorder. Proceedings of the National Academy of Sciences 110, 9950-9955.

Lim, A. S. P., Kowgier, M., Yu, L., Buchman, A. S. and Bennett, D. A. (2013). Sleep Fragmentation and the Risk of Incident Alzheimer's Disease and Cognitive Decline in Older Persons. SLEEP 36, 1027-1032.

Liu, Y., Wang, L., Lin, X.-Y., Wang, J., Yu, J.-H., Miao, Y. and Wang, E.-H. (2013). The transcription factor DEC1 (BHLHE40/STRA13/SHARP-2) is negatively associated with TNM stage in non-small-cell lung cancer and inhibits the proliferation through cyclin D1 in A549 and BE1 cells. Tumor Biology 34, 1641-1650.

Malenka, R. C. and Nicoll, a. R. A. (1999). Long-Term Potentiation-A Decade of Progress? Science 285, 1870-1874.

Man, H.-Y., Wang, Q., Lu, W.-Y., Ju, W., Ahmadian, G., Liu, L., D’Souza, S., Wong, T. P., Taghibiglou, C., Lu, J., Becker, L. E., Pei, L., Liu, F., Wymann, M. P., MacDonald, J. F. and Wang, Y. T. (2003). Activation of PI3-Kinase Is Required for AMPA Receptor Insertion during LTP of mEPSCs in Cultured Hippocampal Neurons. Neuron 38, 611-624.

Mander, B. A., Rao, V., Lu, B., Saletin, J. M., Lindquist, J. R., Ancoli-Israel, S., Jagust, W. and Walker, M. P. (2013). Prefrontal atrophy, disrupted NREM slow waves and impaired hippocampal-dependent memory in aging. Nature Neuroscience 16,357-364.

Manoach, D. S. (2003). Prefrontal cortex dysfunction during working memory performance in schizophrenia: reconciling discrepant findings. Schizophrenia Research 60, 285-298.

Mansour, H. A., Talkowski, M. E., Wood, J., Chowdari, K. V., McClain, L., Prasad, K., Montrose, D., Fagiolini, A., Friedman, E. S., Allen, M. H., Bowden, C. L., Calabrese, J., El-Mallakh, R. S., Escamilla, M., Faraone, S. V., Fossey, M. D., Gyulai, L., Loftis, J. M., Hauser, P., Ketter, T. A., Marangell, L. B., Miklowitz, D. J., Nierenberg, A. A., Patel, J., Sachs, G. S., Sklar, P., Smoller, J. W., Laird, N., Keshavan, M., Thase, M. E., Axelson, D., Birmaher, B., Lewis, D., Monk, T., Frank, E., Kupfer, D. J., Devlin, B. and Nimgaonkar, V. L. (2009). Association study of 
21 circadian genes with bipolar I disorder, schizoaffective disorder, and schizophrenia. Bipolar Disorders 11, 701-710.

Maroun, M. and Richter-Levin, G. (2003). Exposure to acute stress blocks the induction of longterm potentiation of the amygdala-prefrontal cortex pathway in vivo. Journal of Neuroscience 23, 4406-4409.

Marshall, L., Helgadóttir, H., Mölle, M. and Born, J. (2006). Boosting slow oscillations during sleep potentiates memory. Nature 444, 610-613.

Martin, S. J., Grimwood, P. D. and Morris, R. G. M. (2000). Synaptic Plasticity and Memory: An Evaluation of the Hypothesis. Annual Review of Neuroscience 23, 649-711.

McInnes, L. A. and Lauriat, T. L. (2006). RNA metabolism and dysmyelination in schizophrenia. Neuroscience and Biobehavioral Reviews 30, 551-561.

Mecocci, P., MacGarvey, U., Kaufman, A. E., Koontz, D., Shoffner, J. M., Wallace, D. C. and Beal, M. F. (1993). Oxidative damage to mitochondrial DNA shows marked age-dependent increases in human brain. Annals of Neurology 34, 609-616.

Meggio, F. and Pinna, L. A. (2003). One-thousand-and-one substrates of protein kinase CK2? FASEB journal: official publication of the Federation of American Societies for Experimental Biology 17, 349-368.

Mei, L. and Xiong, W.-C. (2008). Neuregulin 1 in neural development, synaptic plasticity and schizophrenia. Nature Reviews Neuroscience 9, 437-452.

Metaxakis, A., Tain, L. S., Grönke, S., Hendrich, O., Hinze, Y., Birras, U. and Partridge, L. (2014). Lowered Insulin Signalling Ameliorates Age-Related Sleep Fragmentation in Drosophila. PLoS Biol 12, e1001824.

Minichiello, L., Korte, M., Wolfer, D., Kühn, R., Unsicker, K., Cestari, V., Rossi-Arnaud, C., Lipp, H. P., Bonhoeffer, T. and Klein, R. (1999). Essential role for TrkB receptors in hippocampusmediated learning. Neuron 24, 401-414.

Mirnics, K., Middleton, F. A., Marquez, A., Lewis, D. A. and Levitt, P. (2000). Molecular characterization of schizophrenia viewed by microarray analysis of gene expression in prefrontal cortex. Neuron 28, 53-67.

Miyake, A., Friedman, N. P., Emerson, M. J., Witzki, A. H., Howerter, A. and Wager, T. D. (2000). The unity and diversity of executive functions and their contributions to complex "Frontal Lobe" tasks: a latent variable analysis. Cognitive Psychology 41, 49-100. 
Möller-Levet, C. S., Archer, S. N., Bucca, G., Laing, E. E., Slak, A., Kabiljo, R., Lo, J. C. Y., Santhi, N., von Schantz, M., Smith, C. P. and Dijk, D.-J. (2013). Effects of insufficient sleep on circadian rhythmicity and expression amplitude of the human blood transcriptome. Proceedings of the National Academy of Sciences of the United States of America 110, E1132-1141.

Montagner, M., Enzo, E., Forcato, M., Zanconato, F., Parenti, A., Rampazzo, E., Basso, G., Leo, G., Rosato, A., Bicciato, S., Cordenonsi, M. and Piccolo, S. (2012). SHARP1 suppresses breast cancer metastasis by promoting degradation of hypoxia-inducible factors. Nature $48 \%$, $380-384$.

Munoz, L. and Ammit, A. J. (2010). Targeting p38 MAPK pathway for the treatment of Alzheimer's disease. Neuropharmacology 58, 561-568.

Musiek, E. S., Lim, M. M., Yang, G., Bauer, A. Q., Qi, L., Lee, Y., Roh, J. H., Ortiz-Gonzalez, X., Dearborn, J. T., Culver, J. P., Herzog, E. D., Hogenesch, J. B., Wozniak, D. F., Dikranian, K., Giasson, B. I., Weaver, D. R., Holtzman, D. M. and FitzGerald, G. A. (2013). Circadian clock proteins regulate neuronal redox homeostasis and neurodegeneration. Journal of Clinical Investigation $123,5389-5400$.

Naylor, E., Bergmann, B. M., Krauski, K., Zee, P. C., Takahashi, J. S., Vitaterna, M. H. and Turek, F. W. (2000). The Circadian Clock Mutation Alters Sleep Homeostasis in the Mouse. The Journal of Neuroscience 20, 8138-8143.

Neddens, J. and Buonanno, A. (2010). Selective populations of hippocampal interneurons express ErbB4 and their number and distribution is altered in ErbB4 knockout mice. Hippocampus 20, $724-744$.

Nicodemus, K. K., Luna, A., Vakkalanka, R., Goldberg, T., Egan, M., Straub, R. E. and Weinberger, D. R. (2006). Further evidence for association between ErbB4 and schizophrenia and influence on cognitive intermediate phenotypes in healthy controls. Molecular Psychiatry 11, 1062-1065.

Niwa, H., Yamamura, K. and Miyazaki, J. (1991). Efficient selection for high-expression transfectants with a novel eukaryotic vector. Gene 108, 193-199.

Norton, N., Moskvina, V., Morris, D. W., Bray, N. J., Zammit, S., Williams, N. M., Williams, H. J., Preece, A. C., Dwyer, S., Wilkinson, J. C., Spurlock, G., Kirov, G., Buckland, P., Waddington, J. L., Gill, M., Corvin, A. P., Owen, M. J. and O'Donovan, M. C. (2006). Evidence that interaction between neuregulin 1 and its receptor erbB4 increases susceptibility to schizophrenia. American Journal of Medical Genetics. Part B, Neuropsychiatric Genetics: The Official Publication of the International Society of Psychiatric Genetics 141B, 96-101. 
Oberheim, N. A., Wang, X., Goldman, S. and Nedergaard, M. (2006). Astrocytic complexity distinguishes the human brain. Trends in Neurosciences 29, 547-553.

Ohara, T., Doi, Y., Ninomiya, T., Hirakawa, Y., Hata, J., Iwaki, T., Kanba, S. and Kiyohara, Y. (2011). Glucose tolerance status and risk of dementia in the community: the Hisayama study. Neurology 77, 1126-1134.

Orban, P. C., Chapman, P. F. and Brambilla, R. (1999). Is the Ras-MAPK signalling pathway necessary for long-term memory formation? Trends in Neurosciences 22, 38-44.

Otani, S., Daniel, H., Roisin, M.-P. and Crepel, F. (2003). Dopaminergic Modulation of Long-term Synaptic Plasticity in Rat Prefrontal Neurons. Cerebral Cortex 13, 1251-1256.

Pardo, J. V., Pardo, P. J., Janer, K. W. and Raichle, M. E. (1990). The anterior cingulate cortex mediates processing selection in the Stroop attentional conflict paradigm. Proceedings of the National Academy of Sciences of the United States of America 87, 256-259.

Paulson, O. B. and Newman, E. A. (1987). Does the release of potassium from astrocyte endfeet regulate cerebral blood flow? Science (New York, N.Y.) 237, 896-898.

Pei, J.-J., Björkdahl, C., Zhang, H., Zhou, X. and Winblad, B. (2008). p70 S6 Kinase and Tau in Alzheimer's Disease. Journal of Alzheimer's Disease 14, 385-392.

Perlstein, W. M., Carter, C. S., Noll, D. C. and Cohen, J. D. (2001). Relation of Prefrontal Cortex Dysfunction to Working Memory and Symptoms in Schizophrenia. American Journal of Psychiatry 158, 1105-1113.

Philips, G. T., Ye, X., Kopec, A. M. and Carew, T. J. (2013). MAPK Establishes a Molecular Context That Defines Effective Training Patterns for Long-Term Memory Formation. The Journal of Neuroscience 33, 7565-7573.

Phillips, R. G. and LeDoux, J. E. (1992). Differential contribution of amygdala and hippocampus to cued and contextual fear conditioning. Behavioral Neuroscience 106, 274-285.

Potter, W. B., O'Riordan, K. J., Barnett, D., Osting, S. M. K., Wagoner, M., Burger, C. and Roopra, A. (2010). Metabolic Regulation of Neuronal Plasticity by the Energy Sensor AMPK. PLoS ONE 5, e8996.

Rasch, B. and Born, J. (2013). About Sleep's Role in Memory. Physiological Reviews 93, 681-766.

Reick, M., Garcia, J. A., Dudley, C. and McKnight, S. L. (2001). NPAS2: an analog of clock operative in the mammalian forebrain. Science (New York, N.Y.) 293, 506-509.

Reppert, S. M. and Weaver, D. R. (2001). Molecular analysis of mammalian circadian rhythms. Annual Review of Physiology 63, 647-676. 
Revest, J.-M., Le Roux, A., Roullot-Lacarrière, V., Kaouane, N., Vallée, M., Kasanetz, F., RougéPont, F., Tronche, F., Desmedt, A. and Piazza, P. V. (2013). BDNF-TrkB signaling through Erk1/2MAPK phosphorylation mediates the enhancement of fear memory induced by glucocorticoids. Molecular Psychiatry 1-9.

Ribbe, K., Friedrichs, H., Begemann, M., Grube, S., Papiol, S., Kästner, A., Gerchen, M. F., Ackermann, V., Tarami, A., Treitz, A., Flögel, M., Adler, L., Aldenhoff, J. B., Becker-Emner, M., Becker, T., Czernik, A., Dose, M., Folkerts, H., Freese, R., Günther, R., Herpertz, S., Hesse, D., Kruse, G., Kunze, H., Franz, M., Löhrer, F., Maier, W., Mielke, A., Müller-Isberner, R., Oestereich, C., Pajonk, F.-G., Pollmächer, T., Schneider, U., Schwarz, H.-J., Kröner-Herwig, B., Havemann-Reinecke, U., Frahm, J., Stühmer, W., Falkai, P., Brose, N., Nave, K.-A. and Ehrenreich, H. (2010). The cross-sectional GRAS sample: a comprehensive phenotypical data collection of schizophrenic patients. BMC psychiatry 10, 91.

Rolls, E. T. (2000). The orbitofrontal cortex and reward. Cerebral Cortex (New York, N.Y.: 1991) 10, 284-294.

Rolls, E. T. (2004). The functions of the orbitofrontal cortex. Brain and Cognition 55, 11-29.

Rossner, M. J., Dörr, J., Gass, P., Schwab, M. H. and Nave, K. A. (1997). SHARPs: mammalian enhancer-of-split- and hairy-related proteins coupled to neuronal stimulation. Molecular and cellular neurosciences $10,460-475$.

Rossner, M. J., Oster, H., Wichert, S. P., Reinecke, L., Wehr, M. C., Reinecke, J., Eichele, G., Taneja, R. and Nave, K.-A. (2008). Disturbed Clockwork Resetting in Sharp-1 and Sharp-2 Single and Double Mutant Mice. PLoS ONE 3, e2762.

Rouach, N., Koulakoff, A., Abudara, V., Willecke, K. and Giaume, C. (2008). Astroglial Metabolic Networks Sustain Hippocampal Synaptic Transmission. Science 322, 1551-1555.

Roux, P. P., Shahbazian, D., Vu, H., Holz, M. K., Cohen, M. S., Taunton, J., Sonenberg, N. and Blenis, J. (2007). RAS/ERK signaling promotes site-specific ribosomal protein S6 phosphorylation via RSK and stimulates cap-dependent translation. The Journal of biological chemistry 282, 14056-14064.

Ruzzene, M. and Pinna, L. A. (2010). Addiction to protein kinase CK2: a common denominator of diverse cancer cells? Biochimica Et Biophysica Acta 1804, 499-504.

Sakai, T., Tamura, T., Kitamoto, T. and Kidokoro, Y. (2004). A clock gene, period, plays a key role in long-term memory formation in Drosophila. Proceedings of the National Academy of Sciences of the United States of America 101, 16058-16063.

Sambrook, J. and Russel, D. W. (2001). Molecular cloning : a laboratory manual. Cold Spring Harbor Laboratory Press, New York. 
Sato, F., Kawamoto, T., Fujimoto, K., Noshiro, M., Honda, K. K., Honma, S., Honma, K.-i. and Kato, Y. (2004). Functional analysis of the basic helix-loop-helix transcription factor DEC1 in circadian regulation. Interaction with BMAL1. European Journal of Biochemistry / FEBS 271, 4409-4419.

Schoenbaum, G., Roesch, M. R., Stalnaker, T. A. and Takahashi, Y. K. (2009). A new perspective on the role of the orbitofrontal cortex in adaptive behaviour. Nature Reviews. Neuroscience 10 , 885-892.

Schubert, M., Gautam, D., Surjo, D., Ueki, K., Baudler, S., Schubert, D., Kondo, T., Alber, J., Galldiks, N., Kustermann, E., Arndt, S., Jacobs, A. H., Krone, W., Kahn, C. R. and Bruning, J. C. (2004). Role for neuronal insulin resistance in neurodegenerative diseases. Proceedings of the National Academy of Sciences of the United States of America 101, 3100-3105.

Schwarzberg, H., Bernstein, H. G., Reiser, M. and Günther, O. (1989). Intracerebroventricular administration of insulin attenuates retrieval of a passive avoidance response in rats. Neuropeptides 13, 79-81.

Seger, R., Biener, Y., Feinstein, R., Hanoch, T., Gazit, A. and Zick, Y. (1995). Differential Activation of Mitogen-activated Protein Kinase and S6 Kinase Signaling Pathways by 12-OTetradecanoylphorbol-13-acetate (TPA) and Insulin EVIDENCE FOR INVOLVEMENT OF A TPA-STIMULATED PROTEIN-TYROSINE KINASE. Journal of Biological Chemistry 270, $28325-28330$.

Shahmoradi, A., Radyushkin, K. and Rossner, M. J. (2015). Enhanced memory consolidation in mice lacking the circadian modulators Sharp1 and -2 caused by elevated Igf2 signaling in the cortex. Proceedings of the National Academy of Sciences , 201423989.

Shetty, P. K., Huang, F. L. and Huang, K.-P. (2008). Ischemia-elicited oxidative modulation of Ca2+/calmodulin-dependent protein kinase II. The Journal of Biological Chemistry 283, $5389-5401$.

Shi, J., Wittke-Thompson, J. K., Badner, J. A., Hattori, E., Potash, J. B., Willour, V. L., McMahon, F. J., Gershon, E. S. and Liu, C. (2008). Clock genes may influence bipolar disorder susceptibility and dysfunctional circadian rhythm. American journal of medical genetics. Part B, Neuropsychiatric genetics: the official publication of the International Society of Psychiatric Genetics 147B, 1047-1055.

Siddle, K. (2011). Signalling by insulin and IGF receptors: supporting acts and new players. Journal of Molecular Endocrinology 47, R1-R10.

Silberberg, G., Darvasi, A., Pinkas-Kramarski, R. and Navon, R. (2006). The involvement of ErbB4 with schizophrenia: association and expression studies. American Journal of Medical Genetics. 
Part B, Neuropsychiatric Genetics: The Official Publication of the International Society of Psychiatric Genetics 141B, 142-148.

Steidl, C., Leimeister, C., Klamt, B., Maier, M., Nanda, I., Dixon, M., Clarke, R., Schmid, M. and Gessler, M. (2000). Characterization of the human and mouse HEY1, HEY2, and HEYL genes: cloning, mapping, and mutation screening of a new bHLH gene family. Genomics 66, 195-203.

Sun, H., Lu, B., Li, R. Q., Flavell, R. A. and Taneja, R. (2001). Defective T cell activation and autoimmune disorder in Stra13-deficient mice. Nature Immunology 2, 1040-1047.

Suzuki, A., Stern, S. A., Bozdagi, O., Huntley, G. W., Walker, R. H., Magistretti, P. J. and Alberini, C. M. (2011). Astrocyte-Neuron Lactate Transport Is Required for Long-Term Memory Formation. Cell 144, 810-823.

Tononi, G. and Cirelli, C. (2006). Sleep function and synaptic homeostasis. Sleep Medicine Reviews $10,49-62$.

Tononi, G. and Cirelli, C. (2014). Sleep and the Price of Plasticity: From Synaptic and Cellular Homeostasis to Memory Consolidation and Integration. Neuron 81, 12-34.

Turek, F. W., Joshu, C., Kohsaka, A., Lin, E., Ivanova, G., McDearmon, E., Laposky, A., LoseeOlson, S., Easton, A., Jensen, D. R., Eckel, R. H., Takahashi, J. S. and Bass, J. (2005). Obesity and metabolic syndrome in circadian Clock mutant mice. Science (New York, N.Y.) 308, 1043-1045.

Um, S. H., D'Alessio, D. and Thomas, G. (2006). Nutrient overload, insulin resistance, and ribosomal protein S6 kinase 1, S6K1. Cell Metabolism 3, 393-402.

Vallortigara, J., Rangarajan, S., Whitfield, D., Alghamdi, A., Howlett, D., Hortobágyi, T., Johnson, M., Attems, J., Ballard, C., Thomas, A., O’Brien, J., Aarsland, D. and Francis, P. (2014). Dynamin1 concentration in the prefrontal cortex is associated with cognitive impairment in Lewy body dementia. F1000Research 3, 108.

van Omer, E. (1933). Sleep and retention. Psychological Bulletin 30, 415-439.

Vardy, J. and Tannock, I. (2007). Cognitive function after chemotherapy in adults with solid tumours. Critical Reviews in Oncology/Hematology 63, 183-202.

Vawter, M. P., Crook, J. M., Hyde, T. M., Kleinman, J. E., Weinberger, D. R., Becker, K. G. and Freed, W. J. (2002). Microarray analysis of gene expression in the prefrontal cortex in schizophrenia: a preliminary study. Schizophrenia Research 58, 11-20.

Vöhringer, P. A. M. S., Barroilhet, S. P. D., Amerio, A., Reale, M. L., Vergne, D., Alvear, K. P. D. and Ghaemi, S. N. M. P. H. (2013). Cognitive impairment in bipolar disorder and schizophrenia: a systematic review. Schizophrenia 4,87 . 
Wardlaw, S. M., Phan, T. H., Saraf, A., Chen, X. and Storm, D. R. (2014). Genetic disruption of the core circadian clock impairs hippocampus-dependent memory. Learning \& Memory 21, $417-423$.

Wefel, J. S., Kayl, A. E. and Meyers, C. A. (2004). Neuropsychological dysfunction associated with cancer and cancer therapies: a conceptual review of an emerging target. British Journal of Cancer 90, 1691-1696.

Wong, S., Flanagan, E., Savage, G., Hodges, J. R. and Hornberger, M. (2014). Contrasting Prefrontal Cortex Contributions to Episodic Memory Dysfunction in Behavioural Variant Frontotemporal Dementia and Alzheimer's Disease. PLoS ONE 9, e87778.

Xu, Z.-Q., Gao, C.-Y., Fang, C.-Q., Zhou, H.-D. and Jiang, X.-J. (2010). The mechanism and characterization of learning and memory impairment in sleep-deprived mice. Cell Biochemistry and Biophysics 58, 137-140.

Zhu, B., Dong, Y., Xu, Z., Gompf, H. S., Ward, S. A., Xue, Z., Miao, C., Zhang, Y., Chamberlin, N. L. and Xie, Z. (2012). Sleep disturbance induces neuroinflammation and impairment of learning and memory. Neurobiology of Disease 48, 348-355.

Zola-Morgan, S. M. and Squire, L. R. (1990). The primate hippocampal formation: evidence for a time-limited role in memory storage. Science (New York, N.Y.) 250, 288-290. 


\section{Related publications}

Brid Bode, Ali Shahmoradi, Reeshma Taneja, Moritz J. Rossner, Henrik Oster (2011) Genetic interaction of Per1 and Dec1/2 in the regulation of circadian locomotor activity. Journal of Biological Rhythms 26:530-540

Christian Schnell, Ali Shahmoradi, Sven P. Wichert, Steffen Mayerl, Yohannes Hagos, Heike Heuer, Moritz J. Rossner \& Swen Hülsmann (2013) The multispecific thyroid hormone transporter OATP1C1 mediates cell-specific sulforhodamine 101-labeling of hippocampal astrocytes. Brain Structure and Function

Paul C. Baier, Magdalena M. Brzózka, Shahmoradi A, Lisa Reinecke, Christina Kroos, Sven P. Wichert, Henrik Oster, Michael C. Wehr, Reshma Taneja, Johannes Hirrlinger \& Moritz J. Rossner (2014) Mice lacking the circadian modulators SHARP1 and SHARP2 display endophenotypes of psychiatric disorders. (PLoS ONE)

Ali Shahmoradi, Konstantin Radyushkin \& Moritz J. Rossner (2015) Enhanced memory consolidation in mice lacking the circadian modulators Sharp1 and -2 caused by elevated Igf2 signaling in the cortex. (Proceedings of the National Academy of Sciences) 